\title{
The NCSBN 2022 Environmental Scan: Resiliency, Achievement, and Public Protection
}

National Council of State Boards of Nursing 


\section{CONTENTS}

JanUARY 2022 VOLUme I 2 - SuPPlement

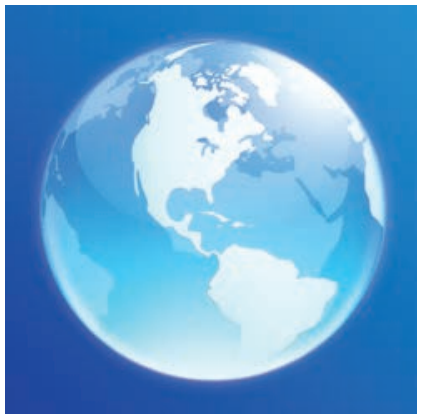

Advancing nursing excellence for public protection
The U.S. Nursing Workforce . . . . . . . . . . . . . . . . . . S3

National and State Data . . . . . . . . . . . . . . . . . . . S3

The RN and LPN/LVN Workforce. . . . . . . . . . . . . . . . . . . . . S3

The APRN Workforce . . . . . . . . . . . . . . . . . . . . . . S5

The 2020 National Nursing Workforce Survey. . . . . . . . . . . . . . . . . . . . . . S6

Health Resources and Services Administration Projections of Supply and Demand

for Women's Health Service Providers . . . . . . . . . . . . . . . . . . . s8

The National Academies of Sciences, Engineering, and Medicine's Future of Nursing Report . . . . . . S8

International and U.S. Nurse Workforce Supply and Retention . . . . . . . . . . . . . . . S8

Vaccine Mandates and the Nursing Workforce . . . . . . . . . . . . . . . . S9

Post-Pandemic Workforce Dynamics . . . . . . . . . . . . . . . . . . . . . . s9

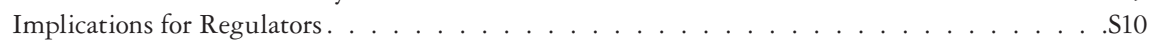

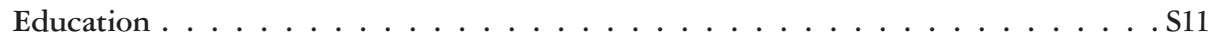

COVID-19 Impact on Nursing Education . . . . . . . . . . . . . . S11

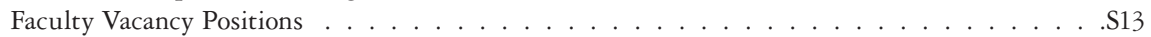

Simulation in Prelicensure Nursing Programs . . . . . . . . . . . . . . S14

Practice-Academic Partnerships. . . . . . . . . . . . . . . . . . . . . . . . . . . . . . . . . . . . . . . .

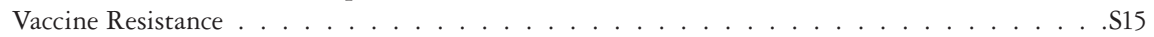

Trends and Analyses of Nursing Education Programs. . . . . . . . . . . . . . . . . . . . . . . . . . .

Graduate Nursing Education Trends in the United States . . . . . . . . . . . . . . . . . . S17

Nurse Practitioner Program . . . . . . . . . . . . . . . . . . . . . . . . . . . . . . . . . . . . . .

PhD Nursing Education Programs in the United States . . . . . . . . . . . . . . . . . S20

Measuring Outcomes: National Nursing Education Core Database . . . . . . . . . . . . . . S21

The Essentials: Core Competencies for Professional Nursing Education . . . . . . . . . . . . . S21

Diversity, Equity, and Inclusion $\ldots \ldots \ldots \ldots$. . . . . . . . . . . . S21

Consistency in Global Standards and Strategies . . . . . . . . . . . . . . . . S22

Current and Future Nursing Students . . . . . . . . . . . . . . . . . . . . . S23

Implications for Regulators . . . . . . . . . . . . . . . . . . . . . . . . . . . . . . . . . . . . . . . . . . . . . . . . . . . . . . .

Healthcare Delivery . . . . . . . . . . . . . . . . . S24

Quality of Care and Patient Safety . . . . . . . . . . . . . . . . . . S24

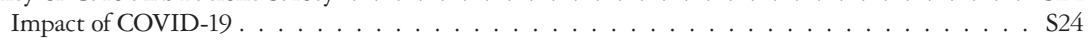

Healthcare Equity . . . . . . . . . . . . . . . . . . . . . . . S25

Patient Safety . . . . . . . . . . . . . . . . . . . . . . . . . . . . . . . .

Implications for Regulators $\ldots \ldots \ldots \ldots \ldots \ldots \ldots$ S26

Global Technology . . . . . . . . . . . . . . . . . . . . . . . . 528

Healthcare Robots . . . . . . . . . . . . . . . . . . . . . . . . . . . . . . S28

Artificial Intelligence . . . . . . . . . . . . . . . . . . . . . . 28

Cybersecurity . . . . . . . . . . . . . . . . . . . . . . . . . . . . S29

Telehealth. . . . . . . . . . . . . . . . . . . . . . . . . . . . . S29

Implications for Regulators . . . . . . . . . . . . . . . . . . . . . . . . . S32

Legislation and Policy Issues. . . . . . . . . . . . . . . . . . . . . . . . . . . . . . . . . . . . . . . .

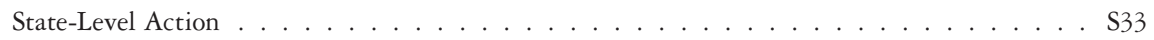

COVID-19 Response Bills . . . . . . . . . . . . . . . . . . . . . . S33

Licensure Compacts. . . . . . . . . . . . . . . . . . . . . . . . . . . . . . . . . . . . . . .

Military Licensure . . . . . . . . . . . . . . . . . . . . . . . . S35

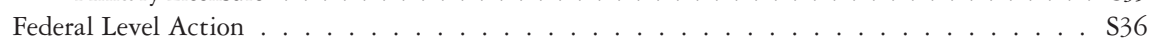

APRNs, Emergency Waivers, and Provisions. . . . . . . . . . . . . . . . . S36

APRN Consensus Model . . . . . . . . . . . . . . . . . . . . . . . . . . S37

COVID-19 and Opioid Morbidity and Mortality . . . . . . . . . . . . . . . . . . . . . . . . . . . .

Reasons for the Increase . . . . . . . . . . . . . . . . . . . . . . . S40

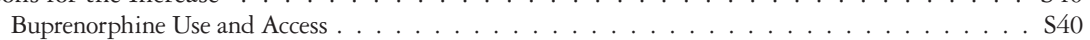

Reexamining Regulatory Requirements . . . . . . . . . . . . . . . . . . . S41

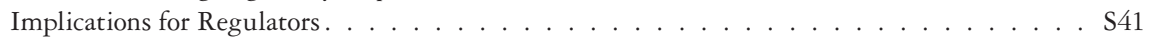

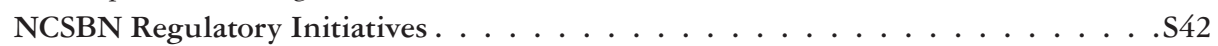

International Center for Regulatory Scholarship . . . . . . . . . . . . . . . . . . . . S42

Nurse Licensure Guidance Tool. . . . . . . . . . . . . . . . . . . . . . . . . S42

Pioneering Research . . . . . . . . . . . . . . . . . . . . . . . . . . . . S42

NURSE ID: Unique Nurse Identifiers . . . . . . . . . . . . . . . . . . . . . . . . . . . . . . . . . . . . . .

Summary: What Regulators Can Expect in 2022 and Beyond . . . . . . . . . . . . .S44

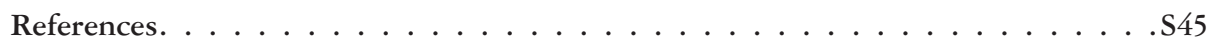

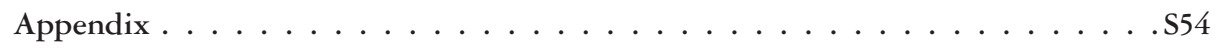




\section{The NCSBN 2022 Environmental Scan: Resiliency, Achievement, and Public Protection}

$\mathrm{L}$ ast year's Environmental Scan described the profound impact of COVID-19 on nursing and regulation. Although 2022 was armored with the arrival of three vaccines for adults in the US, many people around the country, tragically, continued to suffer die from COVID-19. Vaccine hesitancy and a particularly virulent variant of the virus, the Delta variant, reminded the nation that the pandemic was far from over. There was an opportunity for optimism, however. Millions of adults across the United States received a COVID-19 vaccine, and this allowed a return to many aspects of pre-pandemic life.

This report is a comprehensive examination of the current state of nursing, healthcare, and regulation in the year 2022, including the continuing impact of COVID-19 on the nursing workforce, nursing education, healthcare delivery, and legislative and policy issues. It is also a look ahead and is intended to assist nursing regulatory bodies, policymakers, and others in strategic planning and preparing for the future. It is based on the most recent statistics, literature, and research related to healthcare and public protection.

The 2022 Environmental Scan, however, is more than a depiction of recent trends and events; it is a story of resiliency. Despite the continued hardships and challenges of the pandemic, the nursing workforce continues to provide high quality care to patients, nursing education programs are using innovative and collaborative methods to educate students, and nursing regulators are behind the scenes providing support and, of course, protecting the public.

\section{The U.S. Nursing Workforce}

While it remains to be seen what lasting impacts the COVID-19 pandemic will have on the nursing and regulatory landscapes, one of the most carefully watched is the impact of the pandemic on the nursing workforce. The existing nursing shortages, the aging of the nursing workforce, and the growing "COVID-19 effect" of nurses leaving the profession due to burnout, fear of infection, or vaccine refusal means that millions of additional nurses will be needed by 2030 to fill the global nurse shortage. While the latest available data suggest a subtly changing workforce, the pandemic may have set in motion a tectonic shift in workforce demographics and postpandemic dynamics that will reverberate over the next several years.

\section{National and State Data}

The latest registered nurse (RN), licensed practical nurse (LPN)/licensed vocational nurse (LVN), and advance practice registered nurse (APRN) workforce data show steady RN employment, declining LPN/LVN employment, and growing APRN employment in 2020. The workforce in 2020 was more demographically diverse and representative of the country's population than in any other year studied.

The National Academies of Sciences, Engineering, and Medicine's (2021) The Future of Nursing 2020-2030: Charting a Path to Achieve Health Equity estimates that around 1 million of the U.S.'s oldest nurses could leave the profession within 10 years.

\section{The RN and LPN/LVN Workforce}

The National Council of State Boards of Nursing's (NCSBN's) National Nursing Database tracks the number of U.S. licensed nurses from 57 boards of nursing (BONs) and is updated daily (excluding Michigan). There were 4,317,277 RNs and 918,919 LPNs/LVNs in the United States as of September 30, 2021 (NCSBN, 2021a). The most recent Occupational Employment Statistics data from May 2020 indicate that 2,986,510 RNs and 676,460 LPN/LVNs were employed in the United States (U.S. Bureau of Labor Statistics [BLS], 2021a). Figures 1 and 2 illustrate steady RN employment and declining LPN/LVN employment. 


\section{FIGURE 1}

\section{Number of Employed Registered Nurses in the United States, 2008-2020}

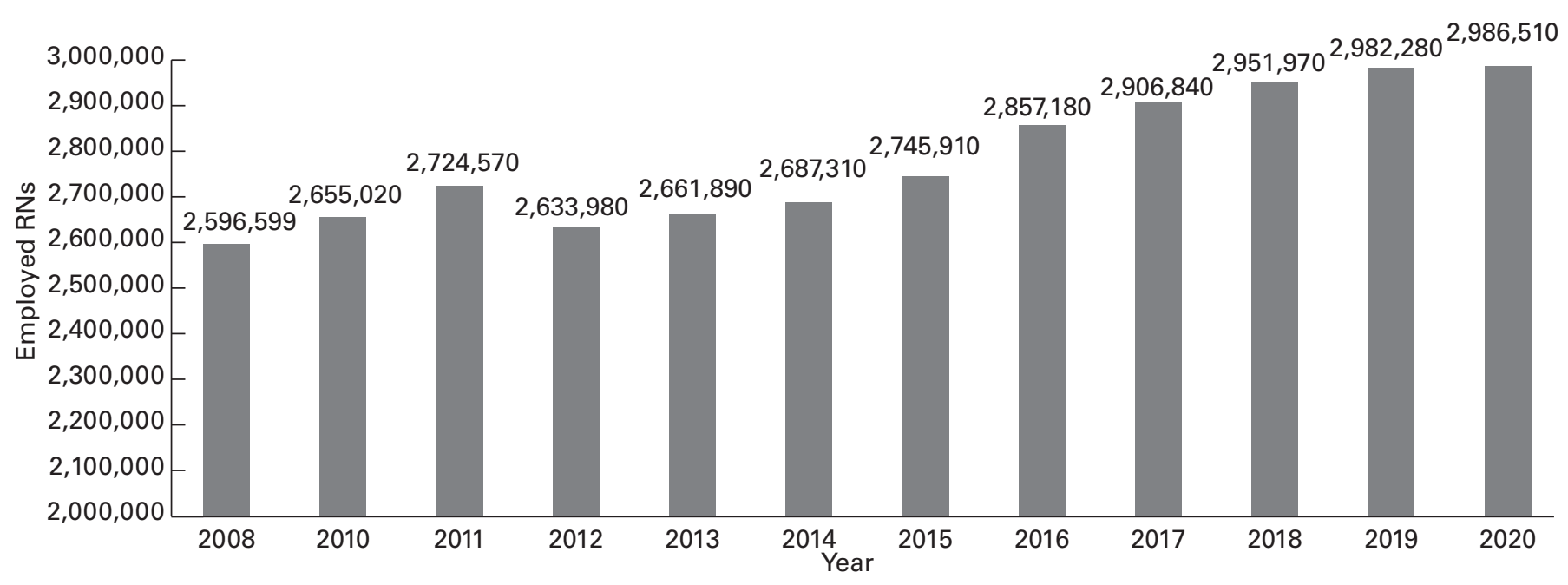

Note. The 2010-2020 data were taken from the semi-annual Occupational Employment Statistics survey published by the U.S. Bureau of Labor Statistics (2021a). The 2008 data were taken from the U.S. Department of Health and Human Services Health Resources and Services Administration National Sample Survey of Registered Nurses (2010).

\section{FIGURE 2}

\section{Number of Licensed Practical Nurses/Licensed Vocational Nurses in the United States, 2012- 2020}

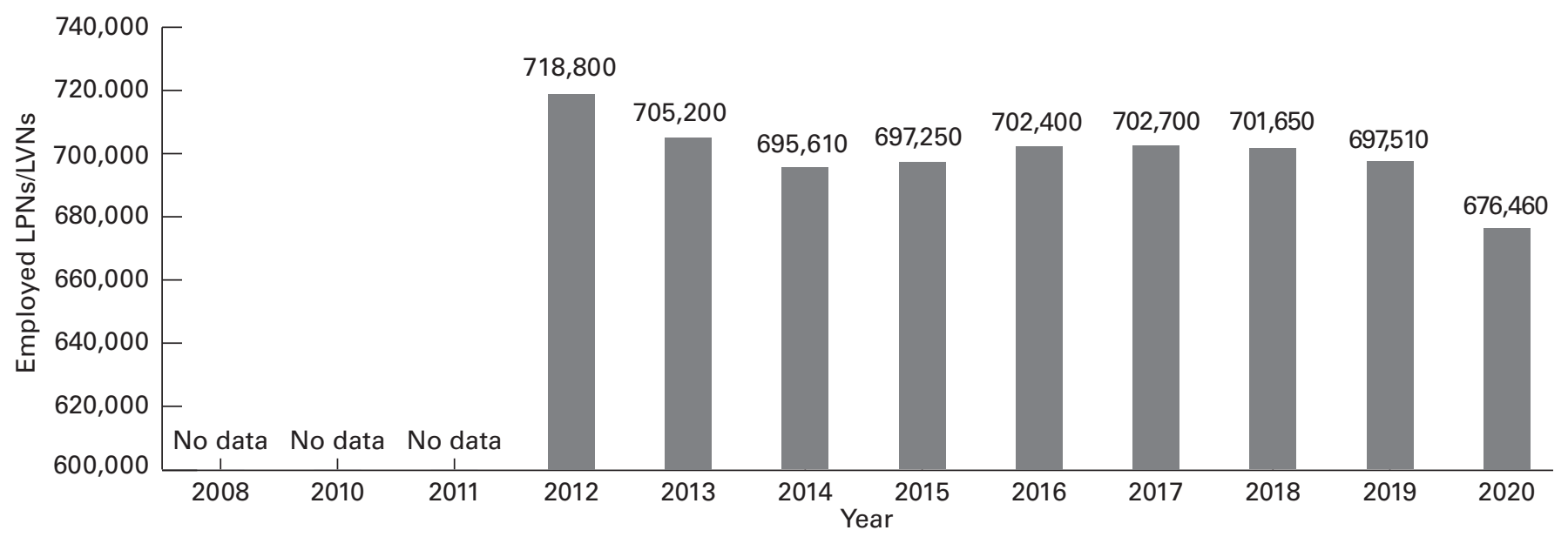

Note. Data were taken from the semiannual Occupational Employment Statistics survey published by the U.S. Bureau of Labor Statistics (2021a).

The number of employed RNs per population in each state varies widely across the country, from fewer than 700 nurses per 100,000 people in Georgia to nearly 1,550 nurses per 100,000 in the District of Columbia (Figure 3) (BLS, 2021a; U.S. Census Bureau, 2021). Utah also has approximately 700 RNs per 100,000 people. Conversely, states in the upper Midwest-South Dakota (1,481 per 100,000), North Dakota (1,280 per 100,000), and Minnesota (1,241 per 100,000)_have the highest ratios of employed RNs per population. The ratio of employed LPN/LVNs is between 45 and 65 per 100,000 people in Alaska, Utah, and Hawaii and nearly 400 per 100,000 in Louisiana (Figure 4). 


\section{FIGURE 3}

\section{Number of Employed Registered Nurses per 100,000 People*}

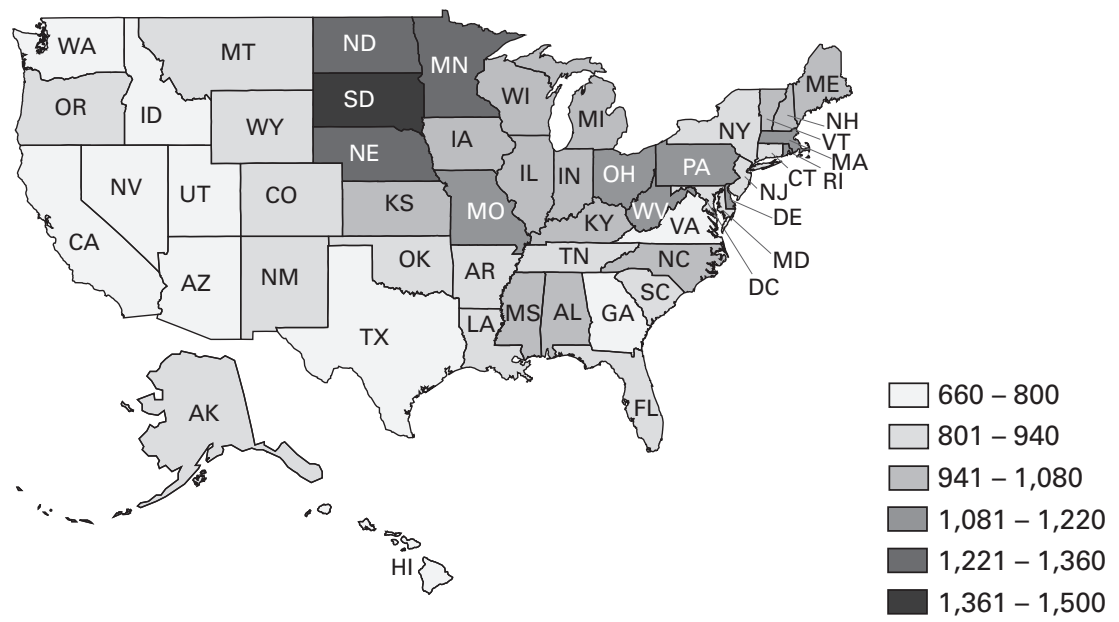

Note. Employed registered nurses per 100,000 people by state as of May 2020.

Sources: U.S. Bureau of Labor Statistics, 2021a; U.S. Census Bureau, 2021.

\section{FIGURE 4}

\section{Number of Employed Licensed Practical Nurses/Licensed Vocational Nurses per 100,000 People}

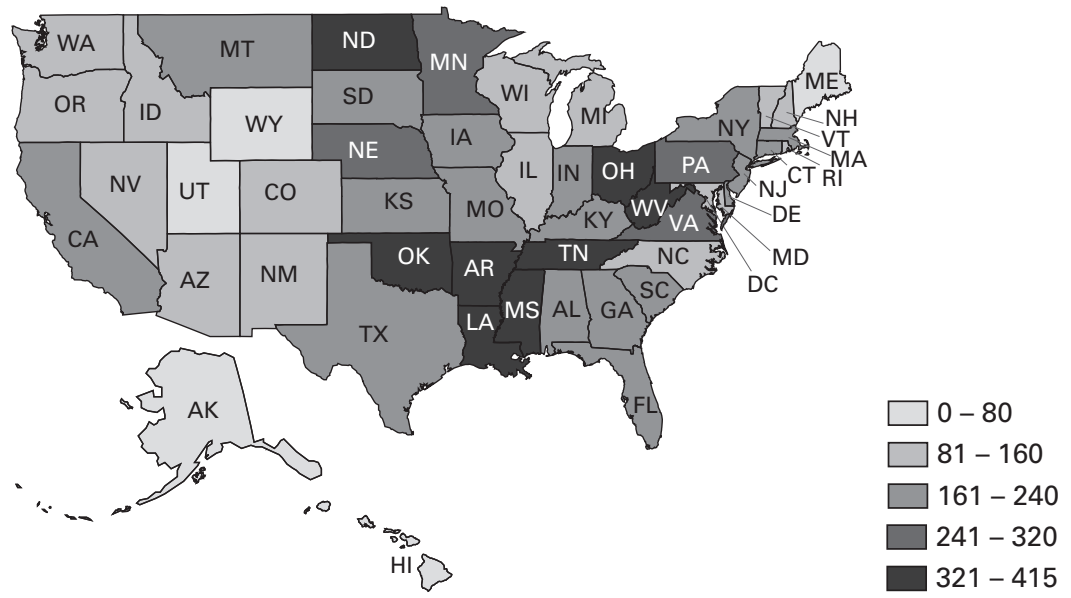

Note. Employed licensed practical nurses/licensed vocational nurses per 100,000 people by state as of May 2020.

Sources: U.S. Bureau of Labor Statistics, 2021a; U.S. Census Bureau, 2021.

The maps in Figures 3 and 4 give a quick state-level snapshot of the supply of employed nurses, noting that there are regional differences within each state that could be different from the overall state-level view. These regional differences within states are often the main concern for individuals involved in studying and monitoring the nursing workforce. For instance, California has one of the lowest employed nurse-to-population ratios; however, within the state, city centers like San Francisco may have very high nurse-topopulation ratios, whereas rural areas of the state may have very low nurse-to-population ratios. Within-state regional nurse employment numbers are available from the BLS (2021a).

\section{The APRN Workforce}

There are four nursing roles that make up the APRN title: (a) certified nurse practitioners (CNPs), (b) certified nurse midwives (CNMs), (c) clinical nurse specialists (CNSs), and (d) certified registered nurse anesthetists (CRNAs). The APRN workforce is difficult to accurately measure due to variations in state statutes regarding how APRNs are classified; however, the profession continues to grow. 
The BLS tracks employment data for the CNP, CNM, and CRNA roles. Currently, the BLS does not independently track employment data for the CNS role. According to the most recent estimates (May 2020), the total number of APRNs employed in the three tracked roles is 271,900 (BLS, 2021c). The BLS expects the role to continue to grow by $45 \%$ through the year 2030 , adding an estimated 120,000 individuals by that time (BLS, 2021c).

CNPs still make up the most populous APRN role, with 211,280 CNPs employed in the United States according to the most recent data (Figure 5). The role has now doubled in size since the BLS began tracking CNPs a decade ago (BLS, 2021d).

\section{FIGURE 5}

\section{Number of Certified Nurse Practitioners in the United States, 2012-2020}

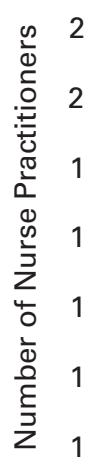

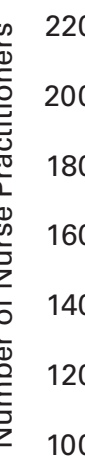

220,000
200,000
180,000
160,000
140,000
120,000
100,000

\section{T}
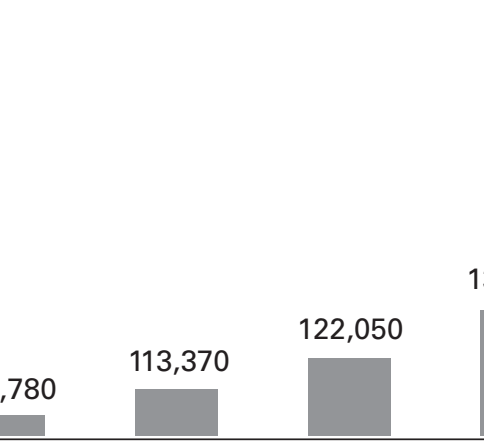

Source: U.S. Bureau of Labor Statistics (2020a).

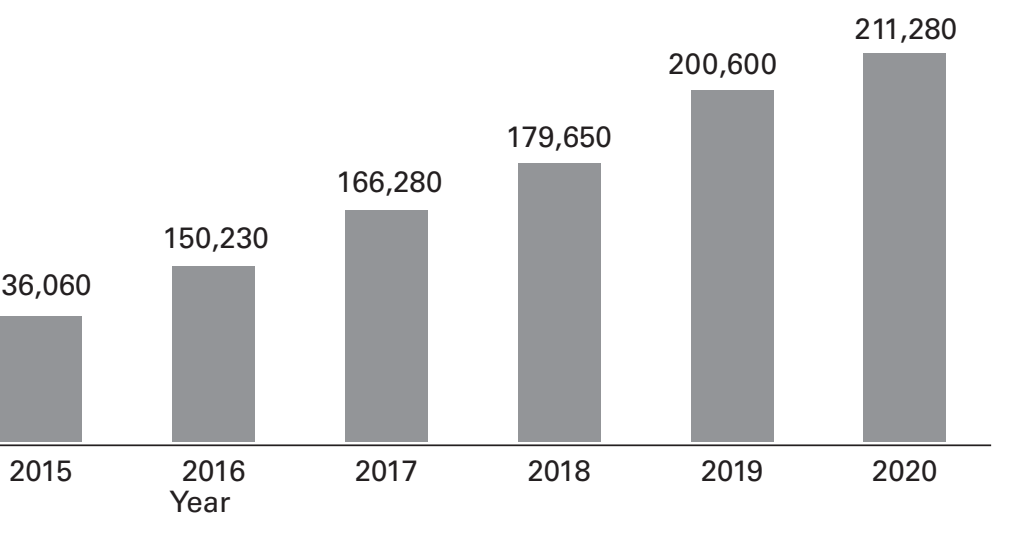

The number of employed CNMs has increased at a smaller rate, according to the latest data. The BLS estimates the role contains 7,120 individuals as of May 2020, an increase of less than 3\% from the previous year (BLS, 2021e).

In contrast to the recent trend, the number of employed CRNAs has decreased according to the most recent data. A total of 41,960 CRNAs were employed in May 2020, representing a decrease of nearly 4\% from the previous year (BLS, 2021f). This decrease may be due to the timing of the most recently available BLS data, which show employment numbers from within the first few months of the COVID-19 pandemic. At that time, many health systems had suspended elective surgeries, leading to a furlough of anesthesiology staff, though some were redeployed to intensive and critical care to assist with COVID-19 patients (Relias Media, 2021). As more recent BLS data become available, the CRNA employment trend will bear watching.

\section{The 2020 National Nursing Workforce Survey}

Since 2013, NCSBN and the National Forum of State Nursing Workforce Centers have partnered every 2 years to conduct a national sample survey using the Forum's Nurse Supply Minimum Data Set, a standardized survey tool designed to collect workforce data. The results from the 2020 survey were released in 2021 (Smiley et al., 2021).

\section{Demographics}

The workforce in 2020 was more demographically diverse and representative of the country's population than in any other year in which this study was previously conducted. Overall, the $\mathrm{RN}$ workforce is $81 \%$ White/Caucasian. In contrast, $72 \%$ of the U.S. population identifies as Caucasian (U.S. Census Bureau, 2020). Although these data indicate that persons of color are not adequately represented in the $\mathrm{RN}$ workforce, as younger nurses have entered the workforce, they have introduced greater racial diversity by identifying as an underrepresented minority. Nurses between 19 and 49 years of age comprise $47 \%$ of all RNs but account for $49 \%$ of RNs who identify as Black/African American and more than $60 \%$ of RNs who identify as multiracial, Asian, or Native Hawaiian or other Pacific Islander.

In a pattern similar to that of RNs, younger LPNs/LVNs have introduced more racial diversity to the workforce. However, the racial distribution of the LPN/LVN workforce much more closely matches the racial distribution of the U.S. population than does that of the RN workforce. LPN/LVN licensure requires the lowest level of nursing education and yields a median annual salary that is more than 35\% lower than the median income of RNs. Thus, as the workforce ages and the less racially diverse generation of nurses begins to retire, it will be important to monitor whether persons of color begin to account for more of the LPN/LVN workforce than would be representative of the country's population, as this could indicate barriers in more advanced nursing education that require further exploration.

An additional area that warrants monitoring is the proportion of nurses in the workforce who are working past typical retirement age. Nurses aged 65 years or older account for nearly 20\% of each of the RN and LPN/LVN workforces in 2020 (Smiley et al., 2021). 
In 2017, this same age cohort accounted for 15\% of RNs and 13\% of LPNs/LVNs (Smiley et al., 2017). During the COVID-19 pandemic, which has resulted in a high rate of complications and mortality for patients older than 65 years, many nurses are reconsidering how long they plan to remain in the workforce (as the 2020 National Nursing Workforce Survey was conducted in the first months of the pandemic, any demographic shifts of this nature would not have been fully captured).

Although women continue to account for the majority of nurses, the proportion of men licensed as RNs or LPNs/LVNs in the country is increasing. Currently, men account for just under 10\% of the RN workforce, which is up from $7 \%$ in 2013 . The same pattern, though less pronounced, holds true for the proportion of men in the LPN/LVN workforce (8.1\%, up from 7.5\% in 2015). The increase in the number of men in the overall nursing workforce reflects the improved representation of men among nurses younger than 50 years. Men account for a higher proportion of nurses within every age cohort between 19 and 49 years of age than they account for in the workforce as a whole.

\section{Employment}

Data suggest that an average of $83 \%$ of all nurses who maintain licensure are employed in nursing; of those, roughly two thirds work full time, $10 \%$ work part time, and about $7 \%$ work per diem shifts. During the past four reporting periods, there has been a consistent number of RNs and LPNs/LVNs who maintain a nursing license and report working in fields other than nursing. Using weighted sample values, this translates to approximately 200,000 licensees. Additionally, there are approximately 175,000 projected licensees who report being unemployed but are not seeking work as nurses. Still another approximately $15 \%$ of unemployed nurses who are seeking nursing employment reported difficulty in finding a nursing position. For nurses who report being unemployed, about half of RNs and roughly $43.3 \%$ of LPNs/LVNs cite taking care of their home and family as their reason for not working.

The proportion of nurses reporting a retired nursing employment status is on the rise. In a new survey question for 2020, respondents were asked if they plan to retire in the next 5 years. More than one fifth of all nurses replied positively to the question. The authors note this may be more critical as we face COVID-19 pandemic responses, which may more quickly accelerate the retirement rate due to the increased health risks that COVID-19 places on persons older than 60 years.

Nearly $84 \%$ of RNs work only one position in nursing; however, $13.7 \%$ reported that they work two positions and $2.4 \%$ reported working three positions or more. Nearly $60 \%$ of nurses work 32 to 40 hours per week and more than one fifth of nurses work more than 40 hours per week. Similar to RNs, $82.4 \%$ of LPNs/LVNs reported being currently employed in only one position, and those who reported working two positions increased from 2017 to 2020. One fifth of LPNs/LVNs reported working 41 to 50 hours in their typical week and roughly $60 \%$ reported working 32 to 40 hours.

Hospitals continue to be the primary practice setting for RNs, followed by the ambulatory care setting, home health, and nursing homes. The number of LPNs/LVNs who are working in hospitals has increased since 2017, which corresponds with the decrease of those who reported working in nursing homes or extended care settings. In the recent 2021 NCSBN LPN/LVN Practice Analysis, $48.3 \%$ of LPNs/LVNs reported working in long-term facilities, compared to $49.4 \%$ in 2018 . Similarly, $14.7 \%$ of LPNs/LVNs reported working in hospitals in 2021, compared to $13.5 \%$ in 2018 (NCSBN, in press; NCSBN, 2019).

Of those nurses who provide direct patient care, more than $90 \%$ of the respondents hold the title of staff nurse. Not surprisingly, the title with the least amount of direct patient care is nurse executive. In the specialty area of anesthesia, $94.7 \%$ of respondents provide direct patient care; for nurses who report neonatal as their specialty, $91.2 \%$ provide direct patient care. Of those nurses reporting geriatric/ gerontology as their specialty area, $45.1 \%$ provide direct patient care. Nurses who reported public health $(31.0 \%)$ and community $(26.7 \%)$ as specialty areas are provide direct patient care at a proportion lower than that of all other specialties.

\section{Education}

In the 2020 survey, the proportion of RNs holding a baccalaureate degree increased for those reporting their highest level of nursing education, but it remained steady for those reporting the degree held when obtaining their first nursing license. The proportion of RNs holding an associate degree when first licensed increased slightly in 2020. This trend had been declining in recent years. When considering only the highest nursing degree earned, the proportion of RNs earning a baccalaureate degree or higher continues to increase, with $65 \%$ of nurses currently holding a BSN or higher, although the proportion falls short of the National Academy of Medicine (formerly the Institute of Medicine) 2020 goal of $80 \%$ of RNs holding a baccalaureate degree or higher (Institute of Medicine, 2011). The proportion of LPNs/LVNs earning an associate or baccalaureate degree also increased slightly this year, while the proportion of those with a practical/vocational certificate or nursing diploma declined.

There is also evidence that RNs and LPNs/LVNs are continuing their nursing education after obtaining their initial nursing license. Comparing the highest level of nursing education to the educational attainment when first licensed shows that proportionally more RNs hold a baccalaureate or graduate degree than they did at initial licensure. Additionally, proportionally more LPNs/LVNs hold an associate or baccalaureate degree as their highest level of nursing education than at initial licensure. 
According to survey respondents, both RNs and LPNs/LVNs are more experienced now than in previous years. The proportion of nurses practicing for 10 years or less has declined, while the proportion of those practicing between 11 and 30 years grew in 2020. As in previous years, most RNs (95\%) and LPNs/LVNs (99\%) obtained their initial nursing license in the United States.

\section{Salary}

The Occupational Outlook Handbook (BLS, 2021b) reported that the median pay for RNs in 2020 was $\$ 75,330$. The median pay for LPNs /LVNs in 2020 was reported to be $\$ 48,820$.

Nursing incomes overall have at best remained essentially flat over time, with increases that just barely beat out inflation. Regional income increases in specific states as described in the report may be a good indicator for where employment demand for nurses is high in the country. Of concern are greater-than-average drops in reported median income in specialties related to women and maternal-child health. However, this finding may simply be an indicator that there is less demand in these areas as our population ages.

While telehealth has become a major focus of pandemic healthcare delivery, at the time of this survey, it does not seem that there have been major changes to how nurses use telehealth. It is anticipated that this will change a great deal in the future as our care delivery systems learn how best to utilize nursing services in this new normal.

\section{Health Resources and Services Administration Projections of Supply and Demand for Women's Health Service Providers}

In March 2021, the National Center for Health Workforce Analysis's report Projections of Supply and Demand for Women's Health Service Providers: 2018-2030 was released. The key findings of the study are that demand for obstetricians/gynecologists (OB-GYNs) will exceed the national supply, although other women's health providers are expected to grow at rates that exceed demand. Specifically, based on current utilization patterns, demand for OB-GYNs is projected to exceed supply by 5,170 full-time equivalents (FTEs) by 2030, with supply decreasing from 50,850 to 47,490 (7\%).

In contrast, if current usage patterns and new entrant levels remain unchanged, other providers may compensate for this shortage by 2030. Certified nurse midwife (CNM) supply is expected to grow by $32 \%$ (from 9,830 to 12,950 FTEs) and women's health nurse practitioner (NP) supply is projected to grow by $89 \%$ (from 10,610 to 20,020 FTEs) while demand is projected to grow by $4 \%$ (from 10,610 to 11,050 FTEs) (National Center for Health Workforce Analysis, 2021).

\section{The National Academies of Sciences, Engineering, and Medicine's Future of Nursing Report}

In 2021, The National Academies of Sciences, Engineering, and Medicine released their newest report, The Future of Nursing 2020-2030: Charting a Path to Achieve Health Equity. The report estimates that up to 1 million of the U.S. workforce's oldest nurses could leave the profession within the next 10 years. This loss will be mitigated by more than 1 million nurses anticipated to join the workforce in that same time frame, as well as the continued immigration of internationally educated nurses, which the report estimates may ultimately comprise between $8 \%$ to $15 \%$ of the workforce. Although this supply is predicted to be sufficient to cover the losses caused by retirements, the report acknowledges that this supply will not be evenly distributed across all regions of the country.

\section{International and U.S. Nurse Workforce Supply and Retention}

A survey of national nursing associations by the International Council of Nurses revealed that $90 \%$ of these associations are somewhat or extremely concerned that heavy workloads, insufficient resourcing, and burnout and stress related to the pandemic response are the key drivers resulting in increased numbers of nurses who have left the profession and increased reported rates of intention to leave this year and when the pandemic is over (International Council of Nurses, 2021). Twenty percent of national nursing associations reported an increased rate of nurses leaving the profession in 2020, and studies from associations around the world have consistently highlighted increased intention-to-leave rates.

Due to existing nursing shortages, the aging of the nursing workforce, and the growing COVID-19 effect, the International Council of Nurses now estimates that 10.6 million nurses will need to be added to the global workforce by 2030 to fill the global nurse shortage gap.

Despite reports of professional burnout and stress on the workforce, a recent study demonstrated the resiliency of the U.S. workforce. In a study of 904 nurses from Japan, Republic of Korea, Republic of Turkey, and the United States, resiliency was associated with nurses receiving organizational support, nurses being involved in the development of policies, and nurses' country of practice. Mean resilience was greater for U.S. nurses than those of other countries participating in the study (Jo, 2021). Another study examined the factors that increased resilience among healthcare providers during COVID-19. A survey conducted by Munn et al. $(2021)(n=2,459)$ indicated that greater resilience is associated with positive perceptions of leadership support, the organization's understanding of the emotional support needed by staff, deployment policy, availability of educational resources, and psychological safety. 
While the long-term effects of COVID-19 on the U.S. nursing workforce remain to be seen, many regions are beginning to attribute a decline in workforce supply to burnout from the sustained pandemic response, and nurse leaders are raising alarms about the forthcoming consequences. On September 1, 2021, the president of the American Nurses Association (ANA) sent a letter to the secretary of the U. S. Department of Health and Human Services (HHS) expressing deep concern that "this severe shortage of nurses, especially in areas experiencing high numbers of COVID-19 cases, will have long-term repercussions for the profession, the entire health care delivery system, and ultimately, on the health of the nation" (ANA, 2021, p.1). The letter cited the following examples of shortages of nursing staff being reported across the country:

- Mississippi has reported that it has seen a decrease of 2,000 nurses since the beginning of 2021.

- Tennessee hospitals are operating with 1,000 fewer staff than at the beginning of the pandemic, prompting them to call on their National Guard for reinforcements.

- Texas is recruiting 2,500 nurses from outside the state, a number that still will fall short of expected demand.

\section{Vaccine Mandates and the Nursing Workforce}

On August 23, 2021, the U.S. Food and Drug Administration (FDA) fully approved the Pfizer-BioNtech COVID-19 vaccine for use in adults aged 16 or older (FDA, 2021). Subsequently, the Biden administration announced a rule, finalized in November 2021, requiring all healthcare workers at facilities that participate in Medicare and Medicaid to be vaccinated (Reed, 2021a). Even prior to the vaccine approval, many private employers made the decision to require COVID-19 vaccination as a condition of employment. At the time of FDA approval, the American Hospital Association estimated that 35\% of hospitals already mandated the COVID-19 vaccine for their staff (Reed, 2021b), and that percentage continued to climb as the Federal mandate was drafted and finalized (Reed, 2021b; Hughes, 2021).

Some U.S. regulatory bodies took additional steps to ensure public protection. The District of Columbia Health Regulation and Licensing Administration made vaccination a requirement of licensure, requiring licensees in all licensed healthcare professions to attest by September 30, 2021, that they had received at least one dose of the COVID-19 vaccine, or they would face disciplinary action, which could include license suspension, revocation, or non-renewal (DC Health, 2021). Similarly, in Oregon, Governor Kate Brown rescinded the option for healthcare workers to be regularly tested for COVID-19 in lieu of receiving the vaccine, requiring all healthcare workers to be fully vaccinated by October 18, 2021 (State of Oregon Newsroom, 2021). In response, the Oregon BON issued a temporary rule that failure to comply with Oregon Health Authority COVID-19 vaccine rules would be added to the list of actions considered conduct unbecoming a licensee in the state's nurse practice act (NPA). Any nurse reported to be not in compliance would be subject to a due-process investigation and possible discipline. The Oregon BON addressed licensee concerns about the impact on the profession by stating that "the Board does not have jurisdictional authority to favor the profession over its role as a state agency and protection of the public" (Oregon Board of Nursing, 2021, p.2). The temporary rule will be made permanent if the Oregon Health Authority's rules regarding vaccination are also made permanent.

In the face of vaccine mandates, concerns were raised about the potential losses to the healthcare workforce if practitioners chose to leave their positions rather than receive the vaccine. As of November 2021, these losses appear to represent a small percentage of the workforce. According to a compiled list of self-reports by health systems as individual vaccine mandates come into effect, the majority of health systems lost approximately $1 \%$ or less of their workforce through resignations or terminations related to the mandate (Muoio, 2021).

Officials acknowledge, however, that even a $1 \%$ reduction in workforce is problematic at a time when many health systems already find their workforces strained. As New Mexico Health Department Acting Head Dave Scrase pointed out, unvaccinated staff requiring extended leave due to infection and illness would also place a strain on the system (Kornfield \& Timsit, 2021). In some instances, the losses have been sufficient to temporarily suspend or consolidate certain services normally offered by the health system, such as imaging or maternal health (Muoio, 2021; Kornfield \& Timsit, 2021). It should be noted that a given health system's mandate compliance rate is not representative of its vaccination rate, as the granting of religious or medical exemptions is not uniform and varies from system to system. In some cases in which larger percentages of employees left their positions, it may have been the case that the criteria for exemption were less lenient (Kornfield \& Timsit, 2021).

\section{Post-Pandemic Workforce Dynamics}

While workforce dynamics prior to the pandemic were disrupted by globalization and emerging technologies, the disrupting factor for the future will be location of the worksite.

A McKinsey Global Institute report (Lund et al., 2021) makes three major predictions about the state of the post-COVID-19 workforce. First, remote work will likely continue after the pandemic. In advanced economies, this could be at a rate 4 to 5 times 
higher than pre-pandemic levels. Such an increase in remote work could have an impact on the greater geography of the workforce as fewer workers commuting may mean fewer services are required to take place in major metropolitan centers. Second, workplaces with high physical proximity_-such as medical care—will continue to innovate ways to reduce physical exposure via automation and machine learning. Third, there will likely be a shift in demand, away from low-wage jobs and toward high-wage jobs, which will require low-wage workers to develop new skills. According to the report's analysis of the workforce in eight countries, as many as 1 in 16 workers may have to transition to new occupations by the year 2030 to account for changing demand. These changes are expected to disparately impact women and minorities in many of the countries analyzed (Lund et al., 2021).

The report specifies that demand for healthcare workers will likely continue to remain high (Lund et al., 2021), which is in line with many workforce projections in the United States. Taken together with the National Academies of Sciences, Engineering, and Medicine's (2021) charge to increase health equity, an opportunity comes into focus for nurse educators, employers, and regulators to take steps now to facilitate the entry of these displaced workers into the nursing profession.

\section{Implications for Regulators}

It is important to note that even the most current workforce data, from any source, comprise just a snapshot of a moment that is already past; therefore, the fallout of a sustained public health emergency on the nursing workforce remains to be seen. Regulators should prepare for the possibility that the pandemic will lead to a wave of retirements. There is a future opportunity to use the data most healthcare regulatory bodies already collect on their licensees to project workforce needs at the state and regional level and to enact steps to mitigate shortages before they begin. This possibility was noted in NCSBN's global research agenda (Alexander et al., 2021), which calls upon researchers to explore the practical applications of these existing resources. 


\section{Education}

Nursing education in 2021 continued to be challenged by the COVID-19 pandemic, though the context was different from that in 2020. While many of the alternative strategies used in 2020 continued, there was a steady movement toward normality in 2021. Similarly, there was more comfort in using novel technologies and a recognition that many of the successful innovations could continue.

\section{COVID-19 Impact on Nursing Education}

In 2020, faculty and students had to quickly pivot to mostly online didactic education and adapt clinical experiences to compensate for loss of access to clinical sites, either through increased in-person simulation, virtual simulation, or other innovative strategies. By 2021, although COVID-19 and the more contagious Delta variant were still considerations, nursing programs began to normalize to what they were pre-pandemic. An informal survey of BONs in October 2021 found that the majority of nursing students in the 33 responding states had returned to clinical facilities, although percentages varied by region. Nearly half of respondents (45\%) reported that the percentage of online didactic education was about the same as in pre-pandemic times; $39 \%$ reported that the percentage of online education was less than in 2020, though it was still significant; $16 \%$ reported that the percentage of online didactic education was about the same as seen during the pandemic in 2020 (NCSBN, unpublished findings).

The effects of the pandemic on nursing education are wide-ranging. In a systematic review conducted in Spain (Goni-Fuste et al., 2021), researchers evaluated 48 articles regarding the experiences of nursing students during global pandemics, from 2003 to 2020, and identified the following themes:

- Education, including knowledge of the pandemic and the need for flexibility and finding creative ways for students to complete their education

- Concern about risk and preventive behavior

- Willingness to work during an outbreak

- Emotional impact on the students

- Ethical dilemmas.

These themes are similar to those found in U.S. studies during the COVID-19 pandemic (Emory et al., 2021; Feeg et al., 2021a; Michel et al., 2021).

Additionally, U.S. studies on the impact of COVID-19 on nursing education revealed concerns by students that that pandemicbased changes in nursing education delivery have left them unprepared for practice. In a qualitative survey of 993 students on the impact of the pandemic, Feeg et al. (2021a) uncovered worries about passing the NCLEX because of the changes incurred due to the pandemic. Likewise, in a national survey of 620 nursing students by Emory et al. (2021), 58\% of the students reported their fear that the changes in learning experiences will affect their success on licensure examinations. Additionally, more than $53 \%$ of the students surveyed in Emory et al.'s (2021) study expressed concern that the quality of their care would be affected because of the alternative teaching strategies, which is a significant concern to regulation, education, and practice.

Nursing students in the United States also expressed concerns about lacking in-person clinical experiences and their difficult adjustment to online learning. These concerns were emerging themes in Michel et al.'s (2021) study of the impact of the COVID-19 pandemic on undergraduate students ( $n=772$ for the quantitative questions and $n=540$ for the qualitative questions). For example, one student stated that book learning cannot replace hands-on experience. Another worried that the lack of clinical experiences would create barriers to finding a job. Similarly, in their qualitative findings, Emory et al. (2021) reported a theme that online schooling was not effective. Michel et al. (2021) suggested that schools of nursing, practice partners, and regulators should collaborate to facilitate clinical experiences during times of crisis. Interestingly, while U.S. students clearly preferred direct patient care over simulation (Michel et al., 2021), in other parts of the world there was a concern that simulation programs were not yet widely available for nursing schools (Sümen \& Adibelli, 2021).

Given nursing students' fears about alternative teaching strategies affecting their passage of the NCLEX, national pass rates (NCSBN, 2021b) for 2020 and 2021 (through July 30), along with the 2 years prior to that, are compared in Table 1. 
TABLE 1

\section{NCLEX Pass Rates Before and During the COVID-19 Pandemic}

\begin{tabular}{|c|c|c|c|c|}
\hline \multirow[t]{2}{*}{ Examination } & \multicolumn{2}{|c|}{ Pre-Pandemic } & \multicolumn{2}{|c|}{ During Pandemic } \\
\hline & 2018 & 2019 & 2020 & 2021 \\
\hline NCLEX-RN & $\begin{array}{c}88.29 \% \\
N=163,238\end{array}$ & $\begin{array}{c}88.18 \% \\
N=171,387\end{array}$ & $\begin{array}{c}86.57 \% \\
N=177,407\end{array}$ & $\begin{array}{c}83.75 \% \\
N=104,298\end{array}$ \\
\hline NCLEX-PN & $\begin{array}{c}85.91 \% \\
N=47,031\end{array}$ & $\begin{array}{c}85.63 \% \\
N=48,234\end{array}$ & $\begin{array}{c}83.08 \% \\
N=45,661\end{array}$ & $\begin{array}{c}80.01 \% \\
N=21,808\end{array}$ \\
\hline
\end{tabular}

There was a slight decline in pass rates in 2020 and 2021 (through July 30). Although further study would be required to determine the causes of this slight decline, it is possible that the alternative education strategies used by nursing programs during the pandemic were contributory.

The Future of Nursing 2020-2030 asserted that the COVID-19 pandemic highlighted the deficiencies in the nursing workforce's preparedness to respond to public health and other disasters and identified nursing education as one avenue toward addressing this gap (National Academies of Science, Engineering and Medicine, 2021). This deficiency exists not only in the nursing curriculum, but also in the infrastructure of programs themselves. Michel et al. (2021) noted the lack of emergency preparedness of nursing programs as evidenced by the haphazard movement to remote teaching and the abrupt removal of students from clinical facilities. They suggest that future planning should address how disasters may affect students, their clinical experiences, collaborative agreements, and regulatory requirements. Planning should address delivery of the courses while considering the comfort of both the students and the faculty. Additionally, students need to receive safety training about the disaster, including how to don and doff personal protective equipment. Emory et al. (2021) found that $30.8 \%$ of their student respondents reported not having any safety training related to caring for patients with COVID-19. This lack of readiness to care during a disaster was also found globally. For example, in a study of nursing student readiness to care for COVID-19 patients in Turkey, nearly three quarters of the students $(n=967)$ did not consider the curriculum to be sufficient in terms of readiness for a global crisis.

One important question is how the COVID-19 pandemic affected new graduate nurse employment in 2020. The National Student Nurses' Association surveys their members annually about student nurse post-graduation employment, and their 2020 survey reports that overall employment of new graduates was 85\% in 2020, down from 87\% in 2019 and $89 \%$ in 2018 (Feeg et al., 2021b). See figures 3 and 4 for employment trends across the country. Employment trends for new graduates in 2020 were down in all regions but the South. The lowest employment was in the West $(77 \%)$ and Northeast (79\%), which reflected the areas most affected by the pandemic during that time. The 2021 data were not available, but it will be interesting to see if this downward trend in new graduate employment continues.

New graduate nurses who found employment during the pandemic reported unique challenges in their transition into nursing practice. In a mixed methods descriptive study of 295 new graduates who began employment in July 2020, researchers at one academic medical center studied the impact of COVID-19 on new graduate preparedness for professional practice (Smith et al., 2021). The sample represented graduates from 136 nursing programs across 38 states. Interestingly, of the 295 participants, only 8 indicated they had completed their full clinical experience requirements. The new graduates reported that up to 240 clinical hours were replaced by either virtual simulation or another experience. Because of this, many new graduates lost in-person clinical hours with one or more clinical specialties, including those with medical-surgical, maternity, psychiatric, or community health patients. Many reported that there were large gaps in time (e.g., several months) since they had hands-on direct patient care. One student had not been in the clinical setting since the fall of 2019. The new graduates overall feared being overwhelmed or unsafe in their practice. Smith et al. (2021) recommend further research on the impact of COVID-19 on new graduates related to their competency, confidence, resiliency, and retention. Additionally, there is a need for more intense transitioning of these graduates, with leadership that supports new graduates in a residency program with trained preceptors.

While the COVID-19 pandemic certainly was challenging for nursing students, it is heartening to note that there has been an increased interest in nursing as a career. The American Association of Colleges of Nursing (AACN) reported that in 2020, there was a $5.6 \%$ increase in enrollment in baccalaureate nursing programs (AACN, 2021a). A continuing concern, however, is the faculty shortage that is limiting the number of qualified students who can be admitted to nursing programs. 


\section{Faculty Vacancy Positions}

The AACN's Special Survey on Vacant Faculty Positions for Academic Year 2021-2022 (McFadden et al., 2021) reports the issues and trends related to nursing faculty in baccalaureate or higher nursing education. According to their research, the total number of budgeted faculty positions has continued to increase since 2009, with a larger spike in 2021 than in previous years (Table 2). The 2021 survey data also shows a larger growth in the faculty vacancy rate $(8 \%)$ compared to the 2020 data.

There are more schools overall with faculty vacancies $(n=576)$ than in 2020 and the previous eleven years. Regional data reveals that the Midwest is experiencing the lowest vacancy (7\%) compared to the South (8.1\%), North Atlantic (8.3\%) and West (9\%) regions (Figure 6).

\section{TABLE 2}

\section{Nursing Program Full-time Faculty Positions and Needs, 2009-2021}

\begin{tabular}{|c|c|c|c|c|c|c|c|}
\hline Faculty Positions and Needs & 2015 & 2016 & 2017 & 2018 & 2019 & 2020 & 2021 \\
\hline No. of budgeted faculty positions & 18,511 & 19,830 & 21,533 & 21,685 & 22,649 & 22,838 & 24,539 \\
\hline No. of faculty vacancies (vacancy rate) & $\begin{array}{l}1,328 \\
(7.1 \%)\end{array}$ & $\begin{array}{l}1,567 \\
(7.9 \%)\end{array}$ & $\begin{array}{l}1,565 \\
(7.3 \%)\end{array}$ & $\begin{array}{l}1,715 \\
(7.9 \%)\end{array}$ & $\begin{array}{l}1,637 \\
(7.2 \%)\end{array}$ & $\begin{array}{c}1,492 \\
(6.5 \%)\end{array}$ & $\begin{array}{l}1,965 \\
(8 \%)\end{array}$ \\
\hline No. of filled faculty positions (filled rate) & $\begin{array}{c}17,183 \\
(92.9 \%)\end{array}$ & $\begin{array}{c}18,263 \\
(92.1 \%)\end{array}$ & $\begin{array}{c}19,968 \\
(92.7 \%)\end{array}$ & $\begin{array}{c}19,970 \\
(92.1 \%)\end{array}$ & $\begin{array}{c}21,012 \\
(92.8 \%)\end{array}$ & $\begin{array}{c}21,346 \\
(93.5 \%)\end{array}$ & $\begin{array}{l}22,574 \\
(92 \%)\end{array}$ \\
\hline No. of schools with faculty vacancies & 429 & 461 & 480 & 488 & 475 & 461 & 576 \\
\hline $\begin{array}{l}\text { No. of schools with no faculty vacancies, } \\
\text { need additional faculty }\end{array}$ & 130 & 133 & 128 & 138 & 134 & 136 & 118 \\
\hline $\begin{array}{l}\text { Number of schools with no faculty } \\
\text { vacancies, do not need additional faculty }\end{array}$ & 182 & 220 & 224 & 245 & 284 & 287 & 241 \\
\hline
\end{tabular}

\section{FIGURE 6}

\section{Full-time Faculty Vacancy Rates by Region, 2021-2022 Academic Year}

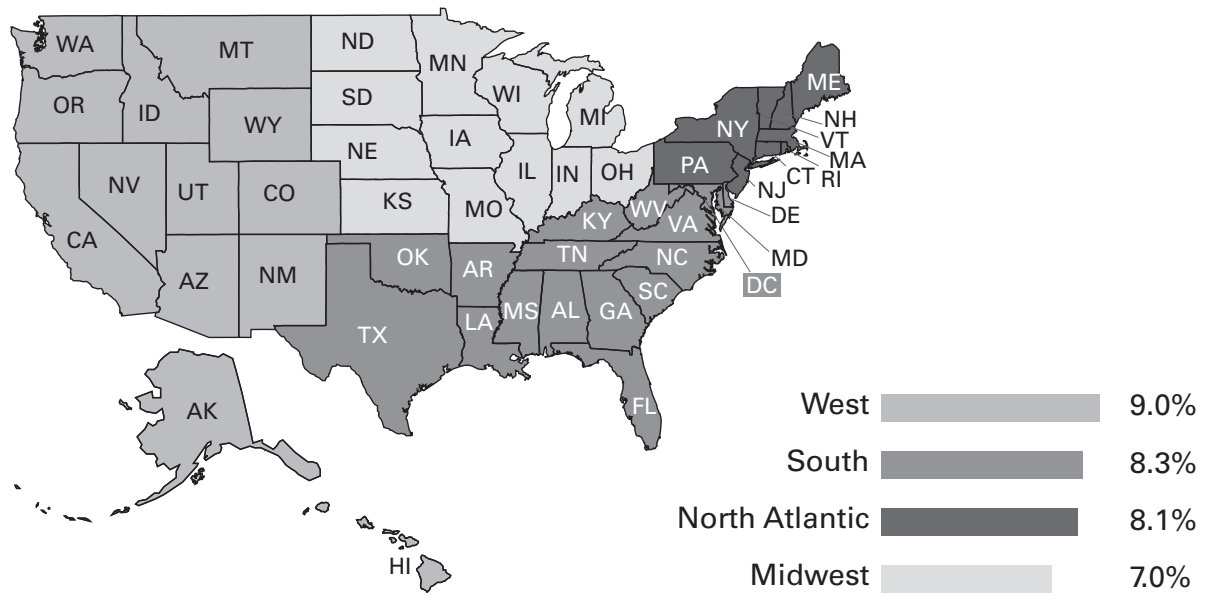

Source: American Association of Colleges of Nursing (McFadden et al., 2021).

According to the AACN's faculty vacancy survey (McFadden et al., 2021), the largest barriers to nursing education programs hiring new faculty members are in line with previous years' data and are identical to the top four barriers identified in 2020 :

- Nursing programs have inadequate funds to hire additional faculty

- The administration is unwilling to commit to more full-time positions

- Competition for jobs in other marketplaces causes an inability to recruit qualified faculty

- Qualified applicants for faculty positions are unavailable in the geographic area needed.

Furthermore, nursing programs continue to report the same critical issues related to faculty recruitment (McFadden et al., 2021): 
- Noncompetitive salaries

- Finding faculty with the right specialty mix

- A limited pool of doctorally prepared faculty

- Finding faculty willing and able to teach clinical courses

- Finding faculty willing and able to conduct research

- High faculty workload.

Other notable critical issues concerning faculty recruitment that schools are reporting remain consistent with data from 2020

(McFadden et al., 2021):

- Challenging location (rural areas or those areas with a high cost of living)

- Institutional budget cuts or restrictions

- Finding faculty who fit well with the school culture

- Recruitment from historically underrepresented populations.

The overall number of schools experiencing faculty vacancies continues to increase across the United States. These data trends suggest these numbers will continue to rise.

\section{Simulation in Prelicensure Nursing Programs}

Educators have been left with many questions in the wake of clinical site closures during the pandemic. What ratio of clinical hours to simulation hours can be used to substitute for clinical experiences (Haerling [Adamson] \& Prion, 2021)? What are the outcomes of traditional supervised clinical experiences (Leighton et al., 2021)? Can virtual simulation substitute for clinical simulation (Badowski et al., 2021)? These are all critical questions that need more research.

Hayden et al.'s (2014) landmark study on simulation, which provided evidence that simulation can be substituted for up to $50 \%$ of traditional clinical experiences with no significant difference in outcome, used a 1:1 ratio of clinical experience hours to simulation hours. While a couple of studies (Curl et al., 2016; Sullivan et al., 2019) have investigated using a 2:1 ratio, with promising results, these studies only included a small number of nursing programs and students. Additional and more robust studies are needed to guide future policy.

Other researchers studied virtual simulation, which they defined as screen-based simulation, for meeting students' needs. In a retrospective, multisite, exploratory descriptive study with 97 prelicensure nursing students from three universities, investigators compared student perceptions of virtual simulation in meeting student learning needs to traditional clinical experiences and manikinbased simulation environments using the Clinical Learning Environment Comparison Survey (CLECS) 2.0 (Badowski et al., 2021). The researchers found that traditional clinical experiences met students' perceived needs on all six subscale items, manikin-based simulation met the perceived needs in two areas, and virtual simulation met the perceived needs in four areas. These findings suggest that virtual simulation can be used to supplement traditional clinical experiences; however, more robust studies on virtual simulation are needed before it can replace traditional clinical experiences. In a systematic review of virtual simulation in nursing education studies from 1996 to 2018, Foronda et al. (2020) found virtual simulation to be a promising strategy, citing the high number of exploratory and other descriptive designs as well as the variability of objectives, conditions, equipment, and samples in the studies included. They recommended randomized controlled trials to elevate the science of virtual simulation.

Much of the current data on the impact of the COVID-19 pandemic, when clinical experiences are limited, suggest the importance of in-person clinical experiences. Yet, Leighton et al. (2021) uncovered evidence that the outcomes of traditional clinical experiences have not been rigorously studied. They attempted to conduct a systematic review on learning outcomes of traditional clinical experiences in nursing education but came up empty systematic — that is, no studies met their criteria. They suggest that we need sound scientific inquiry on the how to rigorously evaluate nursing education outcomes. Likewise, although one large mixed-methods study (Spector et al., 2020) suggested that clinical experiences with patients are critical to nursing education, it is unclear what specifically constitutes quality clinical experiences.

\section{Practice-Academic Partnerships}

A primary challenge for many nursing students throughout the pandemic was as visitors to clinical sites, they were barred from entering their clinical training sites during the pandemic (National Academies of Sciences, Engineering, and Medicine, 2021). However, one positive outcome of the COVID-19 pandemic is an increased interest in practice facilities and education programs collaborating to form practice-academic partnerships (Gilliss et al., 2021; Honig et al., 2021; National Academies of Sciences, Engineering, and Medicine, 2021; Robertson et al., 2021; Spector et al., 2021; Zerwic et al., 2021). Under this model, education programs partner formally with institutions to provide hands-on clinical experiences to nursing students while allowing them to simultaneously earn academic credit 
for their experiences. In a practice-academic partnership, students are classified as essential workers rather than as visitors to a clinical site, allowing access to clinical experiences during public health emergencies such as the COVID-19 pandemic.

Nursing education programs used a variety of models for these partnerships. In some cases, students were able to work as paid nurse technicians in partnering medical centers (Honig et al., 2021); in others, students were unpaid, but the partnership enabled clinical experiences to continue (Zerwic et al., 2021). Some partnerships utilized unique care settings, such as community-based integrated primary care (Mixer et al., 2021) or, in one case, a partnership between a nursing education program, a health system, and a YMCA (Cooper, 2021). These valuable models provide essential primary and preventive care experiences to students while also giving them experience caring for diverse or underserved populations. Regardless of the model, the status of these partnerships was solidified when national nursing leaders released a policy brief in support of them on March 27, 2020 (NCSBN, 2020).

While guiding principles and best practices from these partnerships are beginning to appear in the literature (Zerwic et al., 2021; Gilliss et al., 2021), some notable recommendations for future practice-academic partnerships are the inclusion of nurse regulators in the partnership model (Spector et al., 2021) and the development of valid and reliable outcome measures to effectively evaluate partnerships once they are in place (Robertson et al., 2021).

\section{Vaccine Resistance}

As COVID-19 vaccines became widely available in early 2021, several BONs reported the emergence of a new challenge to the completion of clinical experiences. Although data suggest that the vast majority $(86 \%)$ of students were vaccinated or planned to be as of August 2021 (National Student Nurses' Association, 2021), as clinical facilities began to require all staff to be vaccinated, students who were not vaccinated were unable to complete the clinical requirements of their nursing programs at these facilities. Both educators and regulators expressed uncertainty about how to proceed; therefore, NCSBN convened a group of leaders from BONs and key nursing organizations to discuss the matter and develop a policy brief. The policy brief (NCSBN, 2021c) included the following recommendations:

- Students should be vaccinated so that they can participate in clinical experiences.

- Nursing programs should educate vaccine-hesitant students and address the myths and misleading information about the vaccines.

- Course descriptions should state that clinical experiences are required.

- Programs are mandated by accreditors and BONs to provide clinical experiences, but they are not obligated to provide students with alternative experiences if the students cannot participate in the experiences provided.

- Other vaccines are often required by clinical facilities; the COVID-19 vaccine is not different.

- BONs have no obligation to waive students' clinical experience requirements.

- Accommodations for medical or sincerely held religious beliefs should be decided on a case-by-case basis.

\section{Trends and Analyses of Nursing Education Programs}

NCSBN has been analyzing trends of new U.S. RN and LPN/LVN education programs since 2003 and using these data as a proxy for predicting future workforce numbers. The percentage of growth since 2003 for RN programs is $69 \%$ and for LPN programs is $23 \%$. RN program growth continues to steadily increase over the years. LPN/LVN program growth decreased from 2013-2018, but growth increased in 2019 and 2020 (NCSBN, 2021d) (Figure 7).

\section{FIGURE 7}

\section{Number of Approved Nursing Programs in the United States, 2003-2020}

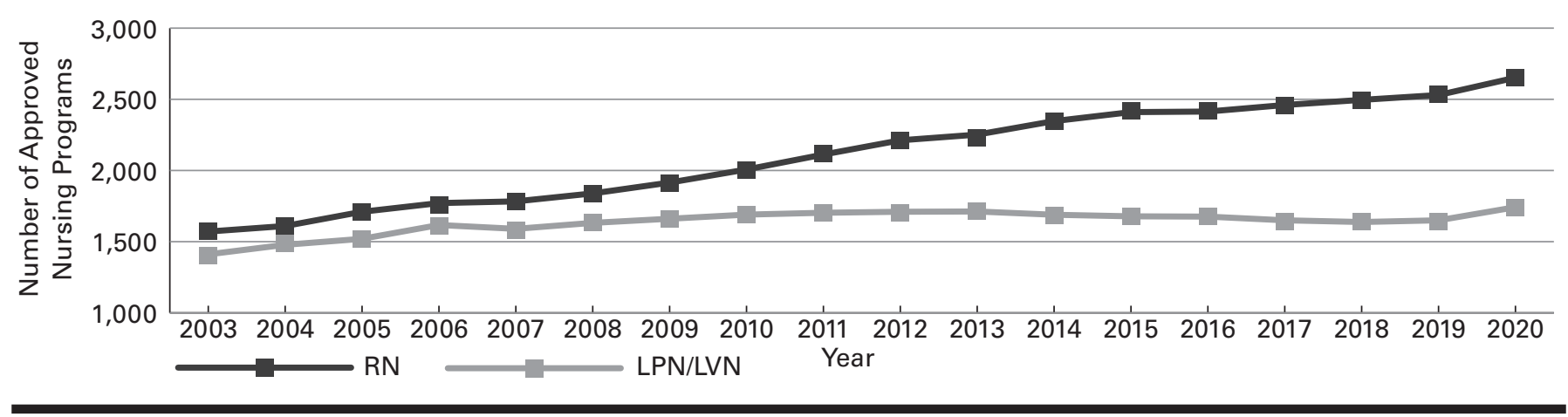


TABLE 3

Number of Approved Nursing Programs in the United States, 2003-2020

\begin{tabular}{|c|c|c|c|c|c|c|c|c|c|c|c|c|c|c|c|c|c|c|}
\hline Year & 2003 & 2004 & 2005 & 2006 & 2007 & 2008 & 2009 & 2010 & 2011 & 2012 & 2013 & 2014 & 2015 & 2016 & 2017 & 2018 & 2019 & 2020 \\
\hline LPN & 1,411 & 1,478 & 1,520 & 1,617 & 1,590 & 1,632 & 1,661 & 1,690 & 1,703 & 1,710 & 1,712 & 1,689 & 1,678 & 1,676 & 1,650 & 1,638 & 1,650 & 1,742 \\
\hline $\mathrm{RN}$ & 1,571 & 1,610 & 1,710 & 1,771 & 1,783 & 1,839 & 1,915 & 2,007 & 2,112 & 2,212 & 2,252 & 2,347 & 2,410 & 2,414 & 2,460 & 2,496 & 2,530 & 2,652 \\
\hline
\end{tabular}

In addition to collecting annual approved nursing program data, NCSBN evaluates trends for the numbers of first-time NCLEX test takers to predict the future nursing workforce. Upon examining the 10-year trend of first-time NCLEX takers in the United States (2011-2020), the number of RN first-time NCLEX takers plateaued between 2014-2017; however, since 2018, there has been a growing increase (NCSBN, 2021b). There was a gradual decline in first-time NCLEX-PN takers from 2012-2016, with a small rise occurring from 2017 to 2019, but in 2020, the number of NCLEX-PN test takers decreased to its lowest number in 10 years (Figure 8).

\section{FIGURE 8}

\section{Ten-Year Trend of U.S. RN and LPN/LVN First-time NCLEX Takers, 2011-2020}

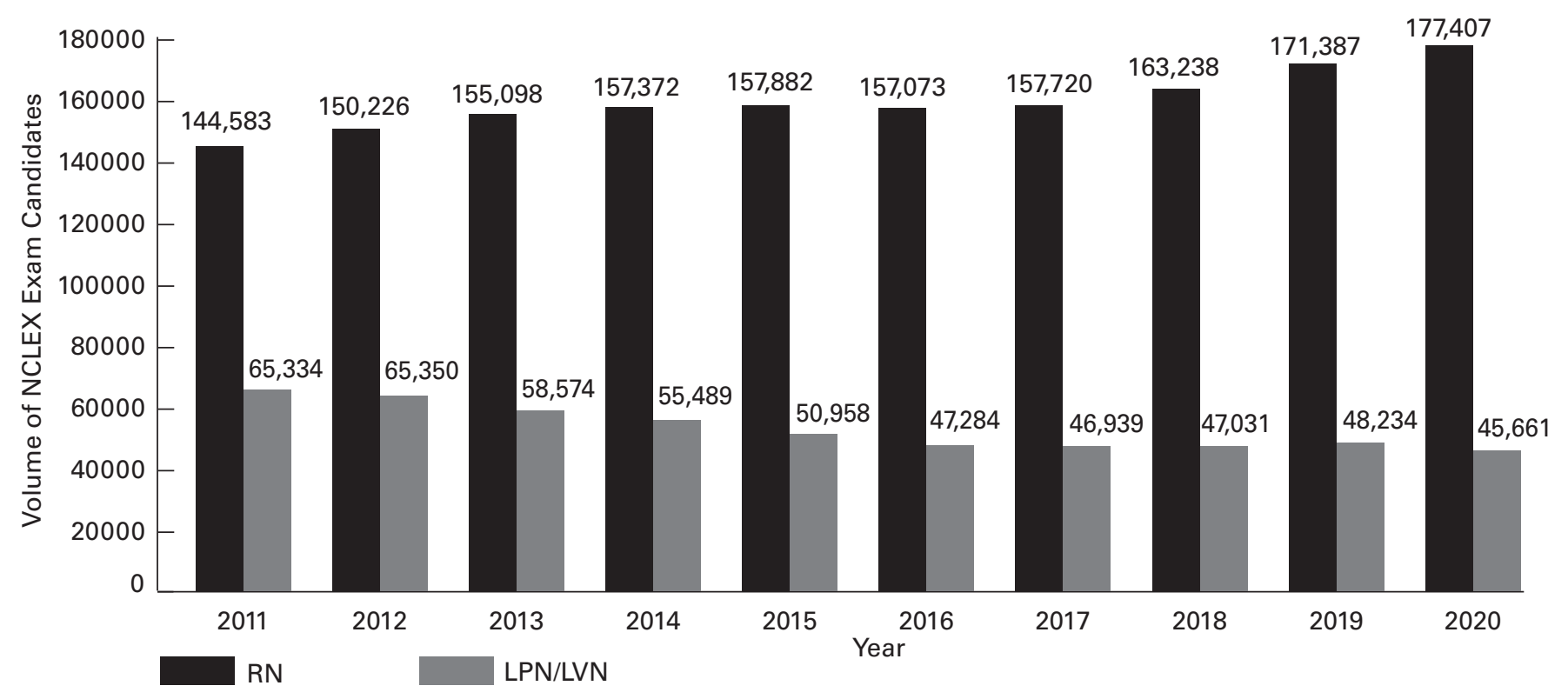

Note. $\mathrm{RN}=$ registered nurse; LPN = licensed practical nurse; LVN = licensed vocational nurse.

A 10-year analysis of U.S. RN first-time NCLEX takers by program type exhibited that although associate degree nursing (ADN) graduates accounted for the largest number of nursing program graduates for the majority of the 10-year period, the number of baccalaureate degree nursing graduates has grown considerably. In 2020, the number of baccalaureate-degree nursing graduates surpassed the number of associate degree graduates (NCSBN, 2021b). Furthermore, the growth of baccalaureate degree graduates over the 10 years is $52 \%$, while that of $\mathrm{ADN}$ graduates over the same 10-year period is $4.5 \%$ (Table 4). This increase is in line with the past Future of Nursing report (Institute of Medicine, 2011) recommendation to increase the percentage of BSN-educated nurses in the workforce. 
TABLE 4

Ten-Year Trend of U.S. RN First-time NCLEX Takers by Program Type, 2011-2020

\begin{tabular}{cccc}
\hline Year & Baccalaureate Degree & Associate Degree & Diploma \\
\hline 2011 & 58,146 & 82,764 & 3,476 \\
\hline 2012 & 62,535 & 84,517 & 3,173 \\
\hline 2013 & 65,406 & 86,772 & 2,840 \\
\hline 2014 & 68,175 & 86,377 & 2,787 \\
\hline 2015 & 70,857 & 84,379 & 2,607 \\
\hline 2016 & 72,637 & 81,653 & 2,745 \\
\hline 2017 & 75,944 & 79,511 & 2,222 \\
\hline 2018 & 79,235 & 82,000 & 1,968 \\
\hline 2019 & 84,298 & 84,794 & 2,247 \\
\hline 2020 & 88,643 & 86,520 & 2,180 \\
\hline
\end{tabular}

Note. $\mathrm{RN}=$ registered nurse.

\section{Graduate Nursing Education Trends in the United States}

The recent AACN Annual Surveys (Fang et al., 2020; Fang et al., 2021) revealed an increase in enrollments in master's, doctoral (research-focused), and doctor of nursing practice (DNP) programs (4.1\%, $0.9 \%$, and $8.9 \%$, respectively) despite pandemic-related concerns. The number of graduates also increased during the same period in master's (2.9\%) and DNP (14.6\%) programs, but there was a decrease (-5.7\%) in graduates in research-focused doctoral programs (Table 5).

\section{TABLE 5}

\section{Enrollment and Program Graduates Across Master's, Doctoral (Research-Focused), and Doctor of Nursing Practice Programs, 2019 and 2020}

\begin{tabular}{|c|c|c|c|}
\hline & 2019 & 2020 & $\%$ Change \\
\hline \multicolumn{4}{|l|}{ Enrollment } \\
\hline Master's & 146,059 & 152,054 & $4.1 \%$ \\
\hline Doctor of nursing practice & 36,096 & 39,301 & $8.9 \%$ \\
\hline \multicolumn{4}{|l|}{ Program Graduates } \\
\hline Doctoral (research-focused) & 803 & 757 & $-5.7 \%$ \\
\hline Doctor of nursing practice & 7,949 & 9,110 & $14.6 \%$ \\
\hline
\end{tabular}

In conjunction with the increase in enrollments and graduations, a small increase was seen from 2019 to 2020 in the percentage of enrollees who are part of an ethnic minority across all three levels of programs (35.3\% in 2019 to $37.1 \%$ in 2020 for master's enrollees; $33.3 \%$ in 2019 to $33.8 \%$ in 2020 for research-focused doctoral enrollees, and 36.0\% in 2019 to $37.1 \%$ in 2020 for DNP enrollees), as well as a slight increase in the percentage of graduates in DNP programs who are part of an ethnic minority.

There was a decrease in the percentage (from $31.9 \%$ in 2019 to $28.0 \%$ in 2020) of research-focused doctorally prepared graduates who are part of an ethnic minority (Fang et al., 2020; Fang et al., 2021). There was no change in the percentage of graduates in master's level programs in this category.

Slight decreases were also found for the same time period when comparing the percentage of male enrollees in master's (12.0\% in 2019 to $11.7 \%$ in 2020) and research-focused doctoral programs (11.1\% in 2019 to $10.5 \%$ in 2020) and male graduates in master's and DNP programs. However, an increase was seen in the percentage of male enrollees in DNP programs as well as male graduates in research-focused doctoral programs (Fang et al., 2020; Fang et al., 2021).

The AACN Annual Survey (Fang et al., 2021) compared enrollment and graduation data by area of study in master's level programs in schools reporting in both 2019 and 2020. The percentages of NP students and graduates have increased (4.5\% and 5.3\%, 
respectively) while the percentages of students and graduates in clinical nurse specialist (-8.1\% and $-13.5 \%$, respectively) and nurse anesthesia (-28.1\% and $-7.9 \%$, respectively) programs have decreased. Nurse-midwifery programs experienced increased enrollments $(2.8 \%)$ but a decrease in graduates $(-7.1 \%)$. Community/public health and forensic nursing experienced noteworthy increases from 2019 to 2020 in student enrollment while case management and clinical nurse leader programs showed evident decreases in the percentage of graduates in the same period (Table 6).

\section{TABLE 6}

\section{Enrollment and Graduation in Master's Level Programs in the Same Schools Reporting in 2019 and 2020}

\begin{tabular}{|c|c|c|c|c|}
\hline Program & 2019 & 2020 & Change in Number & $\%$ Change \\
\hline \multicolumn{5}{|c|}{ Clinical Nurse Specialist } \\
\hline Students & 792 & 728 & -64 & $-8.1 \%$ \\
\hline \multicolumn{5}{|l|}{ Nurse-Midwifery } \\
\hline Students & 1,578 & 1,622 & 44 & $2.8 \%$ \\
\hline \multicolumn{5}{|l|}{ Nurse Anesthesia } \\
\hline Students & 1,825 & 1,313 & -512 & $-28.1 \%$ \\
\hline Graduates & 813 & 749 & -64 & $-7.9 \%$ \\
\hline \multicolumn{5}{|l|}{ Clinical Nurse Leader } \\
\hline Students & 2,330 & 2,114 & -216 & $-9.3 \%$ \\
\hline Students & 90,329 & 94,367 & 4,038 & $4.5 \%$ \\
\hline Graduates & 28,018 & 29,499 & 1,481 & $5.3 \%$ \\
\hline \multicolumn{5}{|c|}{ Combined Nurse Practitioner/Clinical Nurse Specialist } \\
\hline Students & 52 & 55 & 3 & $5.8 \%$ \\
\hline Graduates & 20 & 25 & 5 & $25.0 \%$ \\
\hline
\end{tabular}

There are multiple entry points for becoming an NP. Enrollment and graduation data for master's and post-master's NP programs as well as post-baccalaureate and post-master's DNP programs were reported in the AACN Annual Surveys (Fang et al., 2020; Fang et al., 2021). A comparison of the data reported in 2019 and 2020 shows a notable increase in both family NP and psychiatric and mental health NP enrollment and graduation in the master's NP and post-baccalaureate DNP programs. The same increase can be seen when comparing enrollment and completion data in post-master's psychiatric and mental health NP programs; however, a decrease is seen in family NP enrollment and graduation in this category (Table 7). 
TABLE 7

\section{Enrollment and Graduation in Master's NP, Post-Master's NP, Post-Baccalaureate DNP, and Post-Master's DNP Programs, 2019 and 2020}

\begin{tabular}{|c|c|c|c|c|c|c|c|c|}
\hline \multirow[b]{2}{*}{ Focus Area } & \multicolumn{2}{|c|}{ Master's NP } & \multicolumn{2}{|c|}{ Post-Master's NP } & \multicolumn{2}{|c|}{ Post-Baccalaureate DNP } & \multicolumn{2}{|c|}{ Post-Master's DNP } \\
\hline & 2019 & 2020 & 2019 & 2020 & 2019 & 2020 & 2019 & 2020 \\
\hline Total Enrollment & 90,401 & 94,751 & 8,248 & 8,525 & 15,625 & 16,947 & 4,192 & 4,169 \\
\hline \multicolumn{9}{|l|}{ Family NP } \\
\hline Schools & 354 & 364 & 269 & 280 & 205 & 217 & 72 & 70 \\
\hline \multicolumn{9}{|c|}{ Pediatric Primary Care NP } \\
\hline Schools & 70 & 71 & 57 & 58 & 57 & 58 & 21 & 24 \\
\hline Students & 2,472 & 2,456 & 155 & 105 & 732 & 796 & 112 & 92 \\
\hline Graduates & 920 & 946 & 56 & 82 & 146 & 132 & 7 & 10 \\
\hline Graduates & 421 & 494 & 40 & 41 & 43 & 50 & 2 & 4 \\
\hline \multicolumn{9}{|l|}{ Neonatal NP } \\
\hline Schools & 28 & 28 & 22 & 22 & 23 & 22 & 11 & 9 \\
\hline Students & 789 & 832 & 46 & 73 & 262 & 311 & 29 & 29 \\
\hline Graduates & 280 & 269 & 16 & 15 & 56 & 58 & 5 & 5 \\
\hline \multicolumn{9}{|c|}{ Pediatric Acute Care NP } \\
\hline Schools & 28 & 26 & 31 & 34 & 25 & 23 & 9 & 9 \\
\hline Students & 631 & 671 & 87 & 128 & 326 & 363 & 28 & 29 \\
\hline Schools & 140 & 140 & 108 & 106 & 97 & 103 & 27 & 26 \\
\hline Students & 6,525 & 6,312 & 528 & 542 & 1,506 & 1,342 & 121 & 102 \\
\hline Graduates & 2,524 & 2,387 & 252 & 228 & 301 & 296 & 25 & 14 \\
\hline \multicolumn{9}{|c|}{ Adult Gerontology-Acute Care NP } \\
\hline Schools & 104 & 109 & 106 & 114 & 73 & 83 & 21 & 25 \\
\hline Students & 8,261 & 8,526 & 989 & 1,032 & 1,573 & 1,813 & 148 & 167 \\
\hline Graduates & 2,370 & 2,661 & 440 & 495 & 289 & 310 & 11 & 20 \\
\hline \multicolumn{9}{|c|}{ NP Dual Population Foci } \\
\hline Schools & 32 & 30 & 17 & 13 & 22 & 38 & 14 & 9 \\
\hline Students & 898 & 921 & 28 & 27 & 355 & 477 & 21 & 60 \\
\hline Graduates & 256 & 198 & 10 & 10 & 78 & 73 & 1 & 18 \\
\hline
\end{tabular}


The percentage of enrollments and graduates from master's programs continues to exceed those of DNP programs. The adult gerontology enrollment and graduation rates were increased in the acute care NP population, but the primary care student enrollment and graduation rates decreased. In the pediatric populations both the pediatric primary care NP and pediatric acute care NP enrollment and graduations increased generally with a slight reduction in post-baccalaureate DNP graduation in the pediatric primary care group. Post-master's NP pediatric acute care NP enrollment increased while graduation decreased.

The AACN annual surveys from 2020 and 2021 demonstrated that the COVID-19 pandemic has not negatively impacted enrollment in master's level, research-focused doctoral, and DNP programs. The following trends were identified when comparing the 2021 survey with the prior year:

- Increased percentage of NP program enrollment and graduation with a subsequent decrease in percentage of CNS and nurse anesthesia program enrollment and graduation and decrease in nurse-midwifery graduation

- Greater percentage of master's level enrollment and graduation as compared to DNP programs

- Increased percentage of enrollment and graduation in psychiatric and mental health NP master's, post-master's, post-baccalaureate DNP, and post-master's DNP programs

- Increased percentage of adult gerontology acute care NPs as compared to adult gerontology primary care NP enrollment and graduation

- Increased percentage of enrollment in community/public health and forensic nursing programs.

\section{Nurse Practitioner Program}

In December 2019, The National Organization of Nurse Practitioner Faculties (NONPF) and the AACN convened a national task force to review and revise the current Criteria for the Evaluation of Nurse Practitioner Programs (5th ed.) (NONPF, 2016).

These evaluation criteria, combined with accreditation standards, are the foundation for evaluation of NP programs and used by the programs themselves, as well as program accreditors, to evaluate the quality of NP educational programs (AACN, 2016; Accreditation Commission for Education in Nursing, 2017).

These standards are reviewed and revised through a consensus-based process every 3 to 5 years to ensure NP program quality. Nineteen organizations are participating in the development of The Standards for Quality Nurse Practitioner Education, 6th Edition, which culminates in the January 2022 release of the Criteria for the Evaluation of Nurse Practitioner Education Programs, 6th edition (NONPF, in press). The criteria are organized into 4 chapters: (a) standards focus on institutional support, (b) resources to support program quality, (c) curriculum, and (d) systematic evaluation processes to promote ongoing quality improvement. Criteria elaborate on the components of the standard and provide the necessary requirements to meet each standard.

The criteria are degree neutral and do not differentiate between master's or doctoral programs; they apply to all NP educational programs.

The task force accepted over 500 comments from multiple listening sessions and an interactive webinar following the release of the draft document. Most of the comments involved the increase of direct clinical hours from 500 to 1,000 hours with the option of 250 hours of simulation.

\section{PhD Nursing Education Programs in the United States}

Nurse researchers are crucial for generating evidence-based policies in areas such as nursing education. However, the overall percentage of nursing faculty with $\mathrm{PhD}$ degrees is decreasing. The total number of nursing faculty across the United States increased by $21 \%$ between 2013 and 2018; however, that growth was disproportionately among those holding DNPs. While faculty holding PhDs grew by $12 \%$, faculty with DNPs grew by $158 \%$ (Fang \& Zhan, 2021). Although DNP holders are filling the faculty gap to some extent, a growing number of nursing faculty hold PhDs in non-nursing disciplines (Algase et al., 2021). Algase et al. (2021) suggest that the knowledge these faculty bring from other disciplines may advance nursing science in several ways; however, the authors also raise important questions about these faculty, such as the driving force behind this trend.

With the dearth of PhD-holding faculty, focus has turned to increasing the pipeline of new PhDs. The completion rate of PhD students during the 2013-2018 period was 74.2\%, taking an average of 5.7 years to graduate. Those most likely to leave the program before graduating tended to be male students, part-time students, students in post-baccalaureate programs, students who were not faculty or were part-time faculty, or students with more than $24 \%$ of their courses being taught online (Fang \& Zhan, 2021). In 2019, the University of Pennsylvania convened a summit to discuss the state of PhD education (Broome et al., 2021). Several innovations, such as a focus on team science, were presented. The participants recognized that they must try different approaches to mentoring, including team and peer mentoring. The mentor must be able to connect the students with a larger network of researchers and scholars. Similarly, Morris et al. (2021) noted that facilitating growth in the way students think (e.g., exposing them to diverse opinions and thought processes) is important preparation for stewardship of the discipline in which PhD nurses will lead. Puzantian \& Darwish (2021), from Lebanon, also addressed innovations in PhD nursing programs. They asserted that traditional measurement courses focus 
on the psychometric evaluation of instruments measuring cognition and behavior; however, in the age of big data, precision medicine, and translational science, $\mathrm{PhD}$ students should be taught across the measurement spectrum.

\section{Measuring Outcomes: National Nursing Education Core Database}

Based on indications from a large mixed-methods study on nursing program quality indicators, which also resulted in regulatory guidelines for nursing education programs (Spector et al., 2020), NCSBN developed a nursing education core database, launched in fall 2020, intended to assist BONs in measuring outcomes for their nursing education programs. While most BONs already required an annual report of each of their nursing education programs, the database assists with this process, providing a common annual report template with a core set of evidence-based questions to all participating BONs. BONs may also customize the report template with their own additional questions and opt into 16 questions related to COVID-19.

The data are used by each participating BON (22 BONs were participating as of October 2021) to monitor their programs for warning signs that are highlighted in the report. The tool allows BONs to identify any areas of weakness so that programs can make changes before their approval statuses are affected and their NCLEX pass rates drop, keeping in mind that NCLEX pass rates are lagging indicators of nursing program performance. This allows nurse regulators and nursing education programs to be proactive in making improvements. Annually, NCSBN will analyze and report the aggregate data, revising and refining the associated regulatory guidelines (Spector et al., 2020), as necessary. Nursing regulatory bodies outside the United States have also expressed interest in participating in the project.

\section{The Essentials: Core Competencies for Professional Nursing Education}

On April 6, 2021, AACN's membership approved The Essentials: Core Competencies for Professional Nursing Education (the Essentials) (AACN, 2021b). This document departs from previous editions given the changes in higher education and the rapidly evolving healthcare system. The AACN asserts that new thinking and new approaches are necessary to educate nurses for the future. The new Essentials document also incorporates contemporary trends in nursing education, which include:

- Diversity, equity, and inclusion

- Four spheres of care, namely: disease prevention/promotion of health and well-being; chronic disease care; regenerative or restorative care; and hospice/palliative/supportive care

- Systems-based practice

- Informatics and technology

- Academic-practice partnerships

- Career-long learning.

A major change in the Essentials document is the recommended integration of competency-based education into the curricula, thereby holding students accountable for mastering the competencies at their level of education. The document also outlines competency domains, competencies, and sub-competencies with a levelled approach (AACN, 2021b), which would allow a seamless transition from entry level nursing to advanced nursing fields, such as APRNs. AACN has developed several resources, including webinars, for faculty to use when incorporating competency-based education into their curriculum (AACN, 2021b).

\section{Diversity, Equity, and Inclusion}

Diversity, equity, and inclusion (DEI) has become a renewed topic of interest after a series of events in 2020 sparked a national conversation about racial inequity (Morrison et al., 2021). Recent research points to the benefits of prioritizing DEI and highlights the barriers to true inclusion that still exist in nursing. In a literature review on DEI, using Melnyk's levels of evidence, Morrison et al. (2021) found that increased diversity in the healthcare workforce led to improved quality of care, better financial performance, more innovation, increased team communication, decreased health disparities, and positive outcomes; these improvements were achieved by developing policies and practices that generated a climate of inclusion. An ethnographic study of Black nurses in the United States (Iheduru-Anderson, 2021) sought to better understand how racism or racial bias affects attitudes and/or actions toward career development in academia and nursing leadership. Identified themes included discrimination and stereotyping, nursing while black (pressure to conform), fear (of job loss, being silenced, etc.), nursing leadership dynamics (paying lip service to diversity), and resilience and disillusionment ("Why bother?"). The researcher concluded that because nursing education provides the foundation for practice, it is critical to address racism in the curriculum. Similarly, in a phenomenological design, other researchers studied the experiences of 11 Black/African American nursing students (Hill \& Albert, 2021). They identified the themes of resolve to succeed, ineffective education models, a need for support of the college experience, and finding Black/African American mentors. Some of the barriers cited were inadequate college preparation, a feeling of isolation, and an inability to connect with other students. 
To create a more diverse nursing workforce, many schools of nursing are using holistic admissions that consider individual experiences and attributes as well as traditional metrics such as grades and test scores. Lewis et al. (2021) studied outcome measures of three cohorts of their accelerated bachelor of science in nursing (ABSN) program before they used holistic admissions $(n=274)$ and then three cohorts of ABSNs after implementing holistic admissions ( $n=283$ ). They found that while the diversity of their students increased, on-time graduation and licensure pass rates remained stable. These findings suggest that holistic admissions in nursing education can increase diversity, while at the same not adversely affecting outcomes. More research on the outcomes of holistic admissions is important for the future.

Bennett et al. (2021) studied the progression of students in their nursing program from 2012 to 2016 ( $n=2,498)$, tracking them from pre-nursing to taking the NCLEX. They found that $57 \%$ were lost prior to the nursing program application, and of those, losses were higher in the minority group (Bennett et al., 2021). A major barrier for Black/African American students was not succeeding in the science courses. However, once the minority students moved past the pre-nursing science barriers, they were likely to be successful in the program. In fact, $100 \%$ of the African American students passed the NCLEX on their first attempt. This study suggests that remedial programs should be implemented in the pre-nursing period rather than once the students have already entered the nursing program, when interventions are often given.

The Future of Nursing 2020-2030 identified the further diversification of the nursing workforce as a key step in addressing health inequity and social determinants of health (National Academies of Sciences, Engineering, and Medicine, 2021). The report committee calls for education programs to create environments of inclusion and consistent support for the economic, social, and professional needs of their students. The research described in the preceding paragraphs provides insight into the steps that may be taken to realize this recommendation.

\section{Promoting Equity}

With health equity as its central focus, the National Academies of Sciences, Engineering, and Medicine report (2021) also highlighted the importance of equity's promotion within the nursing curriculum in addition to the makeup of the program cohort. The report challenges nurse educators to go beyond mere inclusion of content on the social determinants of health and to integrate these discussions across the entire nursing curriculum, including through experiential learning opportunities in diverse communities. The report notes that BSN programs are more likely to contain health equity concepts than other prelicensure nursing programs (National Academies of Sciences, Engineering, and Medicine, 2021), which further demonstrates the value of the previous Future of Nursing report's call for an increase in BSN-educated nurses (Institute of Medicine, 2011). Additionally, the 2021 report notes that additional research into social determinants of health is essential to advancing the knowledge base of nursing practice through evidence-based findings. For this reason, it is vital that the supply of PhD-prepared nurses in the workforce remains steady (National Academies of Sciences, Engineering, and Medicine, 2021).

\section{Consistency in Global Standards and Strategies}

With the growing prominence of cross-border practice in the wake of the COVID-19 pandemic, consistency in practice and education standards, both within countries and across countries, is paramount.

In April 2021, the World Health Organization (WHO) published strategic directions for nursing and midwifery through the year 2025 (WHO, 2021a), which also provides direction for nursing education programs globally. These evidence-based practices and policies can help countries ensure that nurses are optimally educated for meeting their patients' needs and other population health goals. The WHO cites a growing global call for the minimum education of a nurse or midwife to be at the baccalaureate level. Policy priorities for nursing education include:

- Align the levels of education with optimized roles within the health and academic systems. With this priority, they recommend considering "bridge" programs for upgrading the credentials of students.

- Optimize domestic production of midwives and nurses to meet or surpass health system demand from both the public and private sector. They acknowledge that in many countries this will mean investments to facilitate faculty development and to address infrastructure and technology constraints.

- Design education programs to be competency-based, apply effective learning design, meet quality standards, and align with population health needs. As discussed previously, in the United States, AACN has also made this recommendation in "Essentials: Core Competencies for Professional Nursing Education."

- Ensure faculty are properly trained in the best education methodologies and technologies with demonstrated expertise in content areas. This will require advanced training of faculty, as well as investments in digital technologies and clinical simulation. 
With a similar eye toward the harmonization of nursing education standards, the Global Alliance for Nursing Education and Sciences (Baker et al., 2021) used a multinational methodology, reflecting consensus of leaders in nursing education, to develop the Global Pillars Framework to strengthen nursing education worldwide. These interrelated pillars are:

- Pillar I: Competency expectations for new graduates. Learning outcomes are classified under knowledge and practice skills; communication and collaboration; critical thinking, clinical reasoning, and clinical judgment; and professionalism and leadership.

- Pillar II: Guidelines for nursing education programs. Recommendations are organized under curriculum, admissions, and learning experiences.

- Pillar III: Guidelines for education institutions. Strategies are classified under faculty, instructors, and preceptors; resources; leadership and administration; and outcomes.

This framework assumes nursing students will be educated at the baccalaureate level. Baker et al. (2021) assert that globally, we must start now to create a harmonized and modernized approach to nursing education.

\section{Current and Future Nursing Students}

Educators must be prepared for entry of students not properly prepared for the rigors of a nursing education program. For over a decade, reports have outlined the decline in $\mathrm{K}-12$ education standards. This decline is alarming as it can impact learning in the higher levels of education (Loveless, 2021). Educators should be aware of these issues and nursing programs should be prepared to offer remediation and tutoring for students when necessary.

\section{Implications for Regulators}

The faculty shortage continues, and vacancies increased in 2021 (McFadden et al., 2021). In 2020, for the first time in 10 years, BSN programs had more NCLEX-RN test takers than ADN programs. In contrast, 2020 brought the lowest number of NCLEX-PN test takers in 10 years. These trends bear watching, as a shortage of LPNs/LVNS will heavily impact skilled nursing facilities.

Nursing programs were seriously impacted by COVID-19 in 2021, although faculty developed some innovative strategies. Regulators will be interested in the results of NCSBN's ongoing national longitudinal RN Prelicensure Nursing Cohort Study, which has been following the 2022 class of nursing students to determine the impact of COVID-19 on their education. This study will continue to follow the cohort into practice. One silver lining from the pandemic is that practice-academic partnerships have increased. Regulators are encouraged to work with faculty in developing these partnerships (Spector et al., 2021). To make future policy decisions, more research is needed on the outcomes of traditional clinical experiences, the use of a 2:1 ratio (clinical hours to simulation hours) in simulation, and virtual simulation. In the near future, nursing education programs can expect to evolve to integrate competency-based education into their curricula, as well as to develop tools to better support more diverse cohorts of students.

Participating panelists in NCSBN's “The Future of Regulatory Research Summit” took many of these uncertainties into considering when setting NCSBN's global research agenda (Alexander et al., 2021). Among the research items panelists identified for inclusion in the research agenda regarding education were the amount of in-person clinical training required for safe patient care; the comparability of outcomes between virtual and high-fidelity simulation; and the emerging competencies nurses will need in increasingly virtual care delivery systems. The research agenda also identified the need for further study of the DNP over the master's-prepared APRN roles, as well as the future role of predictive analytics and machine learning in nursing education.

Some students remain unvaccinated against COVID-19, while at the same time many healthcare facilities are requiring their staff to be vaccinated. NCSBN and key nursing organizations published a policy brief, with recommendations, to which BONs and educators can refer when these situations arise (NCSBN, 2021c). 


\section{Healthcare Delivery}

Healthcare delivery continues to reverberate from the changes caused by the COVID-19 pandemic. Furthermore, the pandemic has exposed and magnified long-standing weaknesses in the U.S. health system, including the vulnerability of long-term care facilities, the financial instability of rural and public hospitals, outdated technical infrastructure, preexisting baseline supply and medication shortages, and disparities in healthcare quality and outcomes across racial and ethnic groups (Assistant Secretary for Preparedness and Response Technical Resources, Assistance Center, and Information Exchange [ASPR TRACIE], 2021).

In many places, the health system implemented innovative responses such as the expanded use of telemedicine, virtual care platforms and remote patient monitoring, shifting of select services from inpatient to outpatient settings or the office into the home, workflow redesigns, reconfiguration of delivery systems to accommodate repeated surges of COVID-19 patients, scaling of testing, tracing, and vaccination capabilities, adjusted staffing models, and implementing electronic health record changes to reduce the burden of order entry and documentation (ASPR TRACIE, 2021; Balser et al., 2021; Wei et al., 2021). Atrium Health, a large nonprofit system that spans three southeastern states, created a "virtual hospital" to care for SARS-CoV-2-positive patients at home. Services were provided by a dedicated group of providers and nurses and consisted of daily telemonitoring for low-acuity patients to 24/7 hospitallevel monitoring of higher-acuity patients (Sitammagari et al., 2021).

These pandemic-era changes have created a powerful opportunity for the healthcare delivery sector to transform and not only become better prepared for future public health emergencies but also address the root causes of poor health, such as structural racism and systemic inequities (ASPR TRACIE, 2021; Balser et al., 2021). In their paper commissioned by the National Academy of Medicine's Emerging Stronger After COVID-19 initiative, Balser et al. (2021) lay out several urgently needed improvements (Figure 9).

\section{FIGURE 9}

\section{Domain-Specific Opportunities for Sector-wide Improvement}

- Bolsyer hospitals' financial positioning

- De-adopt low-value health services

- Extend COVID-19 payment reforms
- Reevaluate system purchasing

- Develop regulatory mechanisms for inventory tracking

- Replenish the SNS

Financial Resiliency

Supply Chain 2 .
- Update continuing education for clinicians and health professionals

- Invest in programs to combat burnout

- Standardize workforce regulations

Workforce Development Milîi
- Codify crisis standards of care

- Remodel the built environment of hospitals

- Bolster long-term care capacity

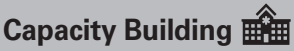

Source: Balser et al. (2021). Care systems COVID-19 impact assessment: Lessons learned and compelling needs. NAM Perspectives, Figure 4. Copyright 2021 (c) National Academy of Medicine.

\section{Quality of Care and Patient Safety}

Since the COVID-19 pandemic, nurses have encountered challenges ranging from operating without crisis standards of care (CSC) to several ethical dilemmas. Patient safety has also experienced challenges from the pandemic beyond the virus itself. Supply and staff shortages and the physical and emotional toll on providers and staff have created an environment where patient safety may be negatively impacted. However, the pandemic may provide an opportunity for regulators to recommit to the Just Culture approach and reevaluate policies for right-touch regulatory practices.

\section{Impact of COVID-19}

The COVID-19 pandemic has continued to disrupt usual healthcare operations in 2021. Furthermore, natural disasters, including wildfires along the West Coast and Hurricane Ida along the Gulf Coast have added to pre-existing supply chain issues and scarcities of critical resources, further overwhelming hospitals and health systems (Margus et al., 2020). The need to implement or operate under CSC has persisted, along with the need to recognize the impact CSC have on the standard approach to providing quality care.

When demand exceeds supply, healthcare systems require CSC to equitably and ethically allocate or ration finite resources. A case in point is Idaho's decision in September 2021 to adopt crisis standards for hospitals that authorize nurses who are caring for higherthan-usual patient loads to not check vital signs as often as they normally would (Baker \& Heyward, 2021). This shift in point-of-care 
decisions from an egalitarian to a utilitarian approach is likely to further disadvantage vulnerable and minority populations who already tend to receive lower quality care (Brous, 2021; Margus et al., 2020).

Although recommendations for jurisdictions to develop CSC guidelines have been in place for more than 10 years (Margus et al., 2020), the COVID-19 pandemic has laid bare the fact that many states still do not have CSC to guide providers on how to maintain standards of care during a public health emergency or disaster. An online search of all 50 states revealed that 14 states had no discernable plans to develop CSC; among the 17 states that have publicly released CSC protocols and recommendations, risk stratification criteria and allocation principles used to make difficult triage decisions vary greatly (Margus et al., 2020; Molina et al., 2021). A lack of preparedness for future disasters, public health or otherwise, was one of the concerns raised in The Future of Nursing 2020-2030, which called for policy initiatives to bolster the profession's preparedness (National Academies of Science, Engineering and Medicine, 2021).

\section{Ethical Concerns for Nurses}

The Code of Ethics for Nurses (ANA, 2015) is the foundation of nursing's social contract with society. It represents the core values and professional and ethical obligations that nurses have to their patients and the larger public (Olson \& Stokes, 2016). The Code states that "nurses follow a code of ethical conduct that includes moral principles such as fidelity, loyalty, veracity, beneficence, and respect for the dignity, worth, and self-determination of patients" (ANA, 2015, p. 14) and that "nurses have a duty to take the same care for their own health and safety" (ANA, 2015, p. 18). Over the past 2 years, these principles have been sorely tested.

During the pandemic, nurses have found themselves facing significant professional challenges, including a wide array of ethical dilemmas experienced by nurses in all types of practice settings. The fear of becoming infected with COVID-19, infecting loved ones or patients, insufficient supplies, lack of staff, and ever-changing federal, state, and local pandemic guidance have all contributed to an ethically complex practice environment (Billings et al., 2021; Combe, 2020; Morley et al., 2021). In some cases, due to restrictions on the presence of families in hospitals, nurses were unable to fulfill their ethical obligation to patient autonomy that includes the individual's right to make decisions about who contributes to their care (Gebreheat \& Teame, 2021). Nurses also questioned their duty to the patient when their own safety was endangered and reported feeling moral distress when striving to ensure high quality care while ethically managing limited resources (Billings et al., 2021; Gebreheat \& Teame, 2021).

With the implementation of CSC, nurses are being asked to make decisions regarding the allocation of resources, whether it be their personal protective equipment (PPE), hospital beds, or nursing staff. This shift from the individual patient to population-based care can cause an ethical conflict for nurses who, prior to the pandemic, committed to providing the highest quality care to every single patient but now must do what they can for as many as they can (Morley et al., 2020). Yet, despite the deep moral distress over not being able to provide care to their usual standards, frontline staff reported feeling strongly "that not [emphasis added] doing so would be unethical" (Billings et al., 2021, p.9).

Nurses' conduct outside of work may also have moral and ethical considerations. Throughout the pandemic, BONs have received complaints that some nurses are sharing misinformation about the virus and its treatment via social media. In response to these reports, NCSBN partnered with nursing organizations across the United States to craft a policy brief on the topic of vaccine disinformation among nurses, which states:

When identifying themselves by their profession, nurses are professionally accountable for the information they provide to the public. ... Nurses are urged to recognize that dissemination of misinformation not only jeopardizes the bealth and well-being of the public, but may place their license and career in jeopardy as well (NCSBN, 2021e, p.1).

These types of complaints are not unique to nursing; the Federation of State Medical Boards (2021) also issued a statement regarding the potential licensure implications for physicians who spread COVID-19 vaccine mis/disinformation.

\section{Healthcare Equity}

The National Academies of Sciences, Engineering, and Medicine continue to focus on the impact of health equity on the quality of healthcare in the United States. An Equity Agenda for the Field of Health Care Quality Improvement (O'Kane et al., 2021) identifies health equity as the central element for improving the quality of care in the United States. The authors include representatives from the National Academies of Sciences, Engineering, and Medicine and seven healthcare quality organizations, including the Centers for Medicare and Medicaid Services (CMS), the Institute for Healthcare Improvement, the Agency for Healthcare Research and Quality (AHRQ), and the National Committee for Quality Assurance. The report states, "for care to be considered high quality, it must be equitable. Inequitable care is low quality care and must be treated as such" (O'Kane et al., 2021, para.6). The paper identifies impediments to equity in healthcare such as racism, discrimination, and lack of reliable health data on minority communities and strategies to improve them, including rewarding organizations for equity, improving data, and implementation of new measurement strategies. This call for equity aligns with The Future of Nursing 2020-2030, which acknowledges the expanding role of nurses in reducing inequi- 
ties in healthcare. "The ultimate goal is the achievement of health equity in the United States built on strengthened nursing capacity and expertise" (National Academies of Science, Engineering and Medicine, 2021).

\section{Patient Safety}

As The Future of Nursing 2020-2030 (National Academies of Science, Engineering, and Medicine, 2021) acknowledged, throughout 2021, the unrelenting surges in COVID-19 cases continued to create an environment of stress, exhaustion and burnout as many hospitals found themselves operating at capacity, or following CSC, for sustained periods of time. Delayed diagnosis or misdiagnosis, supply and staff shortages, and the negative physical and emotional toll on providers and staff have created a fertile environment for gaps in patient safety. Frontline staff such as emergency and critical care physicians and nurses were especially impacted by the pandemic. A cross-sectional survey of 166 emergency medicine physicians from 39 states identified inadequate resources, work-related emotional strain, isolation from family, and increased workload during the pandemic as playing a role in increased feelings of burnout and job dissatisfaction (Nguyen et al., 2021). Interestingly, Morgantini et al. (2020) found that burnout in healthcare professionals during the pandemic was higher in high-income countries than in low- to middle-income countries and was associated with feeling pushed beyond one's training, being exposed to the virus from patients, and having to base life-or-death decisions on availability of critical resources.

As evidence has shown for some time, when humans are caught in a cycle of anxiety, fatigue, and stress, errors are more likely to occur (Stocking et al., 2021; Tejos et al., 2020). In a study of critical care nurses that concluded just a few months before the onset of the pandemic, Melnyk et al. (2021) found that critical care nurses who reported lower physical and mental health, presence of depressive and anxiety symptoms, and low professional quality of life had a $31 \%$ to $62 \%$ higher likelihood (odds ratio) of having made medical errors than nurses with better health and a higher professional quality of life. In another pre-pandemic study, direct and total intensive care unit nursing hours in a Taiwanese medical center were positively correlated with mortality rate (Chang et al., 2019). It is not unreasonable to hypothesize that those numbers most likely increased during the pandemic, and it will be important to confirm (or refute) these assumptions by replicating these types of studies when the pandemic is deemed to be over.

Emerging research exploring medical errors during the pandemic bear this out and suggest that a combination of human factors, system factors, and environmental stresses can increasingly compromise patient safety. For example, after reviewing the Pennsylvania Patient Safety Reporting System for COVID-19-related events, Taylor et al. (2020) found a variety of factors associated with patient safety concerns. Alarms and changes in patient condition went unnoticed due to isolation constraints and were linked to falls and selfextubation, and limited repositioning of COVID-19 patients led to pressure injuries. Tejos et al. (2020) describe an incident where a laboratory specimen was mislabeled by a junior nurse who had worked several extra shifts to cover for colleagues who had to quarantine. A culture of safety depends on an organizational climate that creates an atmosphere where staff feels supported and encouraged to report safety issues and concerns (Alagha et al., 2021). Such an organizational culture will be better positioned to withstand challenges to patient safety during times of crisis.

The burnout, along with the quarantining of SARS-CoV-2-positive staff, have resulted is widespread staffing shortages. Hospitals that responded to an HHS Office of the Inspector General (OIG) pulse survey conducted in February 2021 reported that the high turnover and competition for nurses and other types of staff created staff shortages that in some cases affected patient care. Nurses were required to work longer hours, extra shifts, and mandatory overtime. Some nurses were pulled from their usual patient care areas or duties to fill in for staffing gaps. Hospital administrators saw turnover among nurses increase from $2 \%$ before the pandemic to $20 \%$ in 2020, and nurse-to-patient ratios doubled in some cases from one nurse caring for six patients to caring for 12 patients. Several hospitals reported that they believed the increase in central line infections and lower patient satisfaction scores to be a direct result of tired and frustrated staff and the use of travel nurses who were not as familiar with the facility's policies and procedures (HHS OIG, 2021a). Similarly, a number of studies indicated that the rapid onboarding of nurses impeded adequate training and orientation, further contributing to job stress (ASPR TRACIE, 2021; Morgantini et al., 2020; Tejos et al., 2020).

\section{Implications for Regulators}

Even during a nationwide public health emergency, regulators and nurse leaders continue to be responsible for upholding rules and regulations of nursing practice, ensuring that the standards of care are met and that patients are protected.

\section{Standards of Care}

When CSC are implemented, the line between what constitutes an accepted standard of care during normal circumstances and care during extenuating circumstances becomes blurred. The COVID-19 pandemic has highlighted the need for regulators to work more closely with nurse leaders in making sure that both entities are familiar with the CSC in their state (if they exist) and that violations of the NPA are reported and investigated expeditiously.

Historically, nurse leaders in clinical settings have been unclear about what events constitute patient harm and should be reported or how to file a complaint with a BON, leading to significant underreporting (Martin et al., 2018; Martin \& Reneau, 2021). 
Evidence-informed tools such as the adverse event decision pathway developed by NCSBN (Martin \& Reneau, 2021), the complaint resolution screening tool developed by the Nevada BON (Sansom, 2017), and the Just Culture complaint evaluation tool piloted by the North Carolina BON (Burhans et al., 2012) can aid nursing leaders as well as regulators in reliable decision-making and judicious complaint resolution for practice violations reported during the pandemic.

It remains to be seen what the impact of the COVID-19 pandemic will be on the number and types of complaints received by regulators. However, regulatory bodies can benefit from engaging in comparative data analyses of practice-related complaints received pre-pandemic, during the pandemic, and post-pandemic and then using those results to formulate and implement best practice processes that will ensure the highest degree of public protection, no matter the external circumstances.

Some jurisdictions have incorporated language about ethical standards of care from the ANA Code of Ethics into their NPA (Olson \& Stokes, 2016). For example, the District of Columbia regulation for standards of conduct states that the "[registered] nurse shall adhere to the standards set forth in the 'Code of Ethics for Nurses' as published by the American Nurses Association" (Registered Nursing, 2004, § 5416.1). Delaware's NPA contains more general language: "Standards of nursing practice and position statements developed by general and specialty nursing professional organizations may be used to address scope of practice accountability" (Del. Admin. Code 24, 2021, § 7.1).

Regardless of the specificity of these standards, ethical principles and professional accountability are integral to licensure of all nurses. Nursing regulators are not immune to the public discourse surrounding COVID-19 vaccination or mask mandates and other pandemic-related hot button issues. Complaints about nurses whose actions during the COVID-19 pandemic could be seen as violating professional and ethical standards should receive the same diligent appraisal as other types of complaints. That said, the decision to adjudicate such complaints should be guided by a right-touch regulatory approach. Right-touch regulation exhorts regulators to maintain a delicate balance "between mitigating the risk of harm and applying discipline in a fair and consistent manner" (Russell, 2016, p. 40).

\section{Public Protection}

Even in these unprecedented times, the mission of nurse regulators to protect the public has not changed. When a complaint is received, evaluation of the merits of the complaint should be made through a human factor lens and weighed against the extenuating circumstances created by the COVID-19 pandemic. Humans function within systems, and regulators must remain committed to thoroughly, yet compassionately, examining and analyzing the environmental and organizational factors that might have contributed to adverse patient safety events during the pandemic. By considering the contributing role of the pandemic in errors committed by licensees, nursing regulatory bodies will show their commitment to a Just Culture approach that ensures the level of regulation and discipline is proportionate to the level of risk to the public (Burhans et al., 2012). Investigators must keep in mind the changes in hospital and care protocols brought on by the pandemic, the implications of over-capacity facilities, and the challenges related to supply shortages.

The COVID-19 pandemic, with its unusual combination of systemic stressors, provides an opportunity for regulators to recommit to the Just Culture approach and reevaluate policies for right-touch regulatory practices. NCSBN brought panelists together to set the global research agenda (Alexander et al., 2021), leading to calls for further research on outcomes-based evidence of the effectiveness of right-touch regulation and on devising new regulatory approaches that proactively reduce risk. Specifically, the agenda calls for exploration of educational models that prevent discipline from being necessary and disciplinary measures that preserve patient safety while also refraining from driving nurses out of the profession. The agenda also calls for research that assists regulators in applying discipline consistently and fairly, whether through algorithm-assisted case management or the development of tools that facilitate sharing of disciplinary data across international borders. Notably, and in line with the theme of The Future of Nursing 2020-2030 (National Academies of Sciences, Engineering, and Medicine, 2021), the panelists noted how little research exists on the effects of inherent bias on the complaint and discipline process and called for studies that explore the pervasiveness bias and develop strategies to mitigate its effects (Alexander et al., 2021).

Experts are predicting that the SARS-CoV-2 virus, which cause the COVID-19 disease, will be with us for the foreseeable future (i.e., become endemic). Endemicity will lessen transmission, hospitalizations, and death, but potential seasonal spikes in incidence are expected (Feldscher, 2021), which means that nurse leaders and regulators must remain vigilant. It is also an opportunity to partner with healthcare and nursing leaders in their jurisdiction as well as national organizations (e.g., Quality and Safety Education for Nurses, The Joint Commission, and AHRQ) in developing mitigation strategies (e.g., strengthening institutional support such as employee assistance programs and mental health services) aimed to prevent an increase in errors and adverse safety events during times of severe stress for healthcare workers. The Future of Nursing 2020-2030 (National Academies of Sciences, Engineering, and Medicine, 2021) asserts that the response to the negative outcomes associated with provider stress and fatigue will require coordinated effort across entire health systems. 


\section{Global Technology}

Although much of the conversation surrounding technology in the COVID-19 pandemic has focused on the ubiquity of telehealth, the pandemic has also accelerated the adoption of —or exacerbated the need for—other technological advancements in healthcare that have been trending for some time.

\section{Healthcare Robots}

As Russell Taylor of the Johns Hopkins Whiting School of Engineering explained, "You go into a pandemic with the robots you have, not the robots you wish you had" (Graham, 2021, para.5). Taylor asserted that due to expense and the possibility of obsolescence by the time they are needed, advanced stockpiling of healthcare robots is unfeasible. However, the pandemic and other public health disasters have allowed engineers and healthcare leaders to identify areas of greatest need and work together to innovate solutions.

In the case of the COVID-19 pandemic, researchers at Johns Hopkins University identified three such areas: (a) minimizing contact, (b) increasing provider efficiency, and (c) reducing the use of PPE, which must be donned and doffed each time a provider enters a new infectious patient's room (Graham, 2021). One solution engineered at Johns Hopkins to help with all three of these needs was a robot that allows a provider to remotely manipulate the touch screen controls of a ventilator. The system allows a user outside the patient's room to view the touch screen via camera and control a stylus that moves on an omnidirectional track over the screen to touch the appropriate selections. In addition to preventing contact with an infected patient, the system frees the provider's time reduces reliance on valuable resources because PPE is not required (Johns Hopkins University, 2020). Not only do the researchers foresee this technology being translated to other infectious diseases (Johns Hopkins University, 2020), but they also envision continual expansion of what robots can do. Increased dexterous manipulation and sensitivity to sensations such as temperature, texture, and pressure could allow the next generation of robots to, for example, sanitize patient rooms or even perform some nursing tasks (Su et al., 2021; Graham, 2021).

As machine learning grants robots increased autonomy with each advancement, Su et al. (2021) identified three considerations when a human provider might delegate to a robot:

(1) bow can the robot's task be specified clearly enough, so the robot knows exactly what to do; (2) bow can one ensure that the robot will perform the specified task safely and correctly; and (3) bow to manage unexpected events and uncertainty (p. 186).

The authors suggested that shared autonomy, when the robot's features are guided by the human provider's expertise, should remain the current approach.

\section{Artificial Intelligence}

Writing for the National Academy of Medicine, Lomis et al. (2021) made their prediction about the hope and promise of future artificial intelligence (AI) applications in healthcare, such as increased access and quality of care, enhanced privacy, and the alleviation of administrative burden. Away from the bedside, there are also promising opportunities for AI to transform healthcare regulation. Indeed, in NCSBN's global research agenda (Alexander et al., 2021) one of the identified research questions asked how AI might increase consistency and efficiency in regulatory processes. Regulators around the world are beginning to test AI's potential in this area.

One area in which regulators are hoping that AI will be transformative is the discipline process. Resolving complaints against healthcare practitioners is a complex process with a high cost in time and resources, and it is imperative that the process is applied consistently and fairly across all licensees or registrants. At the same time, it is equally imperative that high-risk complaints are identified efficiently and early in the investigative process. To this end, three nursing regulatory bodies in the United Kingdom, United States, and Australia partnered to explore the possibility of an AI-based assistive tool that could relieve some of the administrative burden on investigators. Analyzing anonymized data from over 5,000 cases provided by the three regulatory bodies, investigators sought to test whether an AI tool could learn to predict the risk level of new complaints, identify similar cases for comparison, and provide references to the applicable statutes or regulations. The tool's accuracy at identifying high-risk cases varied depending on the regulatory body and ranged from $65 \%$ to $78 \%$; however, the researchers believe that with a larger data set, as would happen through daily use, the tool's accuracy could be further increased (Jago et al., 2021).

As further uses for tools such as this are explored over the next few years, regulators will have to be mindful that use of AI complies with existing laws, particularly those surrounding privacy and discrimination. While recent discussions of AI use in healthcare have focused on the legalities of AI in predicting COVID-19 risk (Krass et al., 2021), some of the guiding principles are also applicable to the use of AI in regulatory work, particularly those related to discrimination, as unintentional bias in the data set inclusions or the way in which the programming interprets them may lead to disparate impact. Outputs of emerging AI tools should therefore be monitored and analyzed to mitigate this risk (Krass et al., 2021; Lomis et al., 2021). 
Current research suggests that AI is best used to support human judgement (as by quickly providing relevant information), rather than replace it (Jago et al., 2021; Lomis et al., 2021; Cato et al., 2020). Lomis et al. (2021) warned that the application of AIsupplied information by a human user is also subject to misinterpretation and bias, even if none exists in the AI programming itself. For this reason, there are calls for the use of AI to be integrated into healthcare professional curricula in preparation for a future in which practitioners will have to learn how to apply the knowledge an AI provides rather than memorize that knowledge themselves (Lomis et al., 2021; Cato et al., 2020).

In addition to learning about AI, some researchers see applications for AI tools in the education process itself. In line with the AACN Essentials recommendation that nurse educators shift toward competency-based education, educators envision a precision education system (like the precision medicine initiative) that would individualize the resources, training, and assessment of each nursing student to optimize the chance of success (Lomis et al., 2021).

\section{Ethics of Artificial Intelligence}

In 2021, the WHO published their guiding AI document, Ethics and Governance of Artificial Intelligence for Health. This document outlined six key principles for the ethical implementation of AI into healthcare:

- Just as other researchers have put forward the idea of shared autonomy, the WHO recommends that "the use of AI or other computational systems does not undermine human autonomy" (p. xii). This not only means that decision-making power should ultimately rest with the human provider rather than the machine, but that providers possess the knowledge and resources to effectively make use of AI tools.

- "AI technologies should not harm people" (p. xiii). While this seems straightforward, this recommendation speaks to public protection and calls for regulatory oversight of AI, as well as clear indications for an AI tool's use, and cautions that AI should not be used if another approach carries less risk.

- Transparency and understandability are key for all users, including AI developers, providers, patients, and regulators. An AI's algorithms and processes should be understood well enough that its actions and conclusions can be explained to all stakeholders.

- Regarding accountability, the WHO introduces the concept of the "human warranty," or the establishment of review by stakeholders "upstream and downstream of the algorithm by establishing points of human supervision" (p. xiii). This supervision includes mechanisms for investigation and mitigation of any adverse events in which the AI's algorithms were involved.

- The WHO calls for AI technology that is inclusive and equitable, that is shared widely so that as many as possible benefit from it, and that is used to minimize disparities rather than increase them.

- Finally, AI should be responsive and sustainable, constantly assessed for optimization, efficiency, and minimal impact on the global environment (WHO, 2021b).

\section{Cybersecurity}

This report would be remiss if it did not mention the growing threat of cyberattacks. Regulators must also be vigilant about a growing slate of cybersecurity risks, several specifically related to the COVID-19 pandemic. In April 2020, the U.S. Department of Homeland Security's Cybersecurity and Infrastructure Security Agency and the U.K.'s National Cyber Security Centre issued a joint warning that cyber criminals are exploiting COVID-19 to launch cyberattacks. Cybercriminal groups used COVID-19 related subject headings and domain names as lures in phishing attempts and the distribution of malware, and they preyed upon the vulnerabilities of many organizations' technology infrastructures and virtual communication platforms as they adapted to remote work (Cybersecurity and Infrastructure Security Agency \& U.K.'s National Cyber Security Centre, 2020). Malicious actors have been known to impersonate trustworthy subject matter experts, or even an organization's own personnel, to collect login credentials and gain access to protected information (Hooker et al., 2021).

At the American Bar Association, the White Collar Crime Committee of the Criminal Justice Section cited the aforementioned cybersecurity warning and advised the following specific steps to prevent or mitigate a security breach:

- Ensure that software updates (which often fix system vulnerabilities) are applied in a timely manner

- Develop remote work policies that preserve information security

- Employ screen-sharing settings that prevent unauthorized individuals from joining virtual meetings

- Require passwords or "waiting room" functions for telemeetings rather than public settings (Hooker et al., 2021).

\section{Telehealth}

The COVID-19 pandemic continued to prompt tremendous growth in telehealth throughout 2021. By some estimates, the pandemic "accelerated the shift toward virtual care by seven to 10 years" (Nundy, 2021). A McKinsey \& Company analysis (Bestsennyy et al., 2021) found that by July 2021, telehealth utilization had stabilized at levels 38 times higher than before the pandemic, with between $13 \%$ and $17 \%$ of office and outpatient visits conducted via telehealth across all specialties after spiking to more than $32 \%$ in April 
2020. Similarly, the authors found that "consumer and provider attitudes toward telehealth have improved since the pre-COVID-19 era," though these attitudes have also declined slightly since peaking in spring 2020. The authors suggested that public confidence, particularly related to information security, is one of the barriers to optimal telehealth adoption, and they hypothesized that a hybrid virtual/in-person healthcare delivery system is likely in the future (Bestsennyy et al., 2021).

Public confidence is not the only barrier to widespread telehealth adoption. For instance, The Future of Nursing 2020-2030 notes that one third of rural communities lack the high-speed internet infrastructure required to make telehealth reliable (National Academies of Science, Engineering and Medicine, 2021). A September 2021 data brief from the U.S. HHS OIG reported that while states are increasing their reliance on telehealth to provide behavioral health services to Medicaid enrollees, they are encountering multiple challenges, including a "lack of training for providers and enrollees, limited internet connectivity for providers and enrollees, difficulties with providers' protecting the privacy and security of enrollees' personal information, and the cost of telehealth infrastructure and interoperability issues for providers." (HHS OIG, 2021b, p. 2). The OIG surveyed Medicaid directors from 37 states and noted that 34 reported more than one challenge in providing telehealth, including difficulties obtaining informed consent, and, as 17 states reported, difficulties with provider license portability (HHS OIG, 2021b). The OIG recommended that the CMS collect and share best practices from states related to their experiences adopting telehealth and the pandemic response in general. The data brief noted that "CMS concurred with our one recommendation" (HHS OIG, 2021b, p. 2).

With increased telehealth adoption spanning both urgent and primary care, the Society to Improve Diagnosis in Medicine launched a project to identify and prioritize research questions related to telediagnosis. Throughout the early half of 2021, researchers working under the Society's Coalition to Improve Diagnosis reviewed existing literature and interviewed stakeholders to compare their telehealth experiences. The authors found that "published evidence regarding the effectiveness of telemedicine for diagnosis-telediagnosis-is fairly limited and mixed," and "while some evidence shows high rates of satisfaction among patients, other data shows that such convenience may come at a cost" (Graber \& Schrandt, 2021, p. 3).

\section{Policy and Regulations for Telehealth}

Since former U.S. Secretary of HHS Alex Azar first declared a public health emergency on January 31, 2020, that declaration has been renewed approximately every 90 days (Scott, 2021). Some regulatory changes facilitating telehealth usage have been made permanent. For example, CMS expanded reimbursable telehealth codes for the 2021 physician fee schedule. However, other changes may expire when the public health emergency ends, and a great deal of uncertainty and speculation surround the question of which changes will become permanent (Bestsennyy et al., 2021).

Several congressional bills attempt to address the long-term expansion of telehealth, and both the American Medical Association (AMA) and the American Telemedicine Association (ATA) support "a permanent expansion of telehealth services on federal and state levels" (Scott, 2021). The CONNECT for Health Act of 2021, introduced in the U.S. Senate on April 29, 2021, is one such bill that "aims to expand the use of telehealth by removing geographic requirements for telehealth services and expanding originating sites permanently" (Scott, 2021).

In August of 2021, the Biden administration announced a Health Resources and Services Administration award distribution of $\$ 19$ million intended to promote innovation and outcomes research related to telehealth (HHS Press Office, 2021a). Meanwhile, the HHS announced $\$ 10.7$ million in funding to support the integration of telehealth into pediatric mental healthcare (Center for Connected Health Policy, 2021).

\section{Health Insurance Portability and Accountability Act Requirements}

One of the barriers to telehealth that providers grappled with at the onset of the pandemic was the additional considerations necessary related to patient privacy. Telehealth creates unique requirements for compliance with the Health Insurance Portability and Accountability Act (HIPAA) because instead of providers interfacing directly with patients during in-person appointments inside closed offices, the digital transfer of patient information requires additional layers of security (Scott, 2021). To facilitate the rapid adaptation to telehealth necessitated by the pandemic, on March 17, 2020, the U.S. Office for Civil Rights, which enforces HIPAA, announced that it would "exercise its enforcement discretion" and forego imposing penalties on providers that run afoul of HIPAA compliance during the public health emergency while attempting to provide telehealth care in good faith (U.S. Office for Civil Rights, 2020).

This suspension is temporary, however, and organizations like the ATA warn that providers should use the reprieve to integrate any necessary precautions that will bring them into HIPAA compliance. Whereas presently, providers may go unpenalized for using insecure platforms as stopgap telehealth delivery (e.g., using the FaceTime application to examine patients), this accommodation is unlikely to hold after the pandemic (Butcher, 2021). Kyle Zebley, vice president of public policy for the ATA, predicts that "the reinstatement of HIPAA requirements is inevitable, and healthcare organizations need to prepare accordingly. They need to have their regulatory and legal offices getting ready to follow the spirit and letter of the law" (Scott, 2021, para. 16). 
Given the longevity of the public health crisis, some experts predict that patients are likely to become accustomed to the option, making a return to the pre-pandemic environment of care delivery unlikely. In June 2021, Smithsonian magazine's Lola Butcher predicted that "Medicare's vast expansion of services that can be delivered by telemedicine is likely to hold." Butcher writes that "as they consider telemedicine restrictions going forward, regulators are going to be hearing from patients who, until now, have not been vocal telemedicine advocates" (Butcher, 2021).

\section{Core Competencies}

Given the emphasis on telehealth training, the focus on emerging core competencies for telehealth education, particularly in advanced practice nursing, has been increasing.

Arends et al. (2021) developed 22 competencies out of a collaboration between urban and rural providers, health insurance administrators, healthcare system regulators and leadership, and educators. These competencies focus on providing telehealth care and "cultivating learners' awareness of the benefits and limitations of telehealth" (Chike-Harris et al., 2021, p. 296). When these evidence-based competencies were employed, the authors found that "each competency demonstrated a significant increase in [family nurse practitioner (FNP)] student confidence and ability when comparing the pretest and posttest mean" among a group of 156 female and 15 male FNP students (Arends et al., 2021).

Between 2019 and 2020, the Health Resources and Services Administration funded a group of 59 advanced practice nursing faculty to develop a telehealth education toolkit that would assist faculty in preparing telehealth curricula. To that end, a task force of 12 APRN faculty from a variety of specialties identified and developed a set of telehealth competencies via a three-phase modified Delphi study (Rutledge et al., 2021).

The resulting Categories of Telehealth Competencies were based on the Four Ps of Telehealth Framework: (a) planning for the implementation of a telehealth program; (b) preparing for telehealth implementation; (c) providing telehealth services; and (d) performance evaluation of the telehealth program. The authors noted that the telehealth competencies "can be used to enhance or develop telehealth curriculum in graduate health professions programs as a stand-alone course or integrated across the curricula." Although live telehealth experience is difficult to obtain in many clinical placements, the authors found that by "combining simulation with didactic preparation, the most common approach to nursing education, students develop not only knowledge but also competence and comfort with telehealth" (Rutledge et al., 2021).

Chike-Harris et al. (2021) argued that the regulatory aspect of crossborder APRN practice is a knowledge gap for many APRNs that should be addressed in their curriculum, as many APRNs do not realize that care is considered to take place at the patient's location, not the provider's location. The regulatory implications of this are that the APRN must not only be licensed in the state where the patient is receiving care but must also follow all relevant regulations in that state related to APRN practice (e.g., if a patient is in a state that requires an APRN to practice collaboratively with a physician, the APRN must comply, even if the APRN is located in a state that allows independent APRN practice). The authors advocate experiential activities, such as simulations, to reinforce this aspect of practice, as well as the use of clinical practicums at telehealth-specific sites to increase familiarity with the modality. For faculty, this familiarity can be achieved through continuing education work, research, or building partnerships with telehealth organizations (Chike-Harris et al., 2021).

\section{Healthcare Fraud}

On September 17, 2021, the Department of Justice (DOJ) announced criminal charges against 43 defendants in 11 U.S. jurisdictions_ 42 of whom were licensed medical professionals_-for committing healthcare fraud amounting to approximately $\$ 1.4$ billion. Much of this fraud was carried out via telehealth. The DOJ cited court documents in its allegation that:

Certain defendant telemedicine executives allegedly paid doctors and nurse practitioners to order unnecessary durable medical equipment, genetic and other diagnostic testing, and pain medications, either without any patient interaction or with only a brief telephonic conversation with patients they had never met or seen (DOJ Office of Public Affairs, 2021, para. 9).

Altogether, these individuals submitted more than $\$ 1.1$ billion in false and fraudulent telemedicine claims to Medicare and other government insurers (DOJ, 2021). The previous year, the DOJ had announced charges against more than 340 healthcare providers, including more than 100 doctors, nurses, and other licensed healthcare staff who submitted more than $\$ 6$ billion in false and fraudulent claims to Medicare and Medicaid and private insurance companies. Once again, most of that money-more than $\$ 4.5$ billion-”related to fraudulent activity involving telemedicine” (Tycko \& Zavareei LLP, 2021).

Providers might fraudulently inflate their billing in a variety of ways. They could misrepresent the amount of time spent on a telehealth appointment or the type of virtual service provided, or bill for a service that never took place, in addition to the kickback 
schemes described above. Telehealth providers can employ certain strategies to mitigate risk of this behavior in employees. Legal experts point out that the surge in telehealth hiring makes thorough screening and background checks of new hires more important, along with sufficient training, activity monitoring via data analytics, and the development of mechanisms for investigation and reporting of suspicious activity in the remote environment (Hooker et al., 2021).

\section{Implications for Regulators}

The telehealth studies mentioned indicate the important role that telehealth nurses and APRNs can play in expanding access to care, reducing health inequities and burdens on healthcare systems, and decreasing the risk posed to patients visiting hospitals during an ongoing pandemic. Regulators can ensure that patient safety and the standard of care remain high by focusing on rules and compliance, particularly in relation to warning signs of telehealth fraud and potential breaches of HIPAA as pre-pandemic restrictions return.

Although many states temporarily waived licensure requirement for out-of-state healthcare professionals to allow for the provision of telehealth services during the pandemic, those waivers have already expired or will expire as the pandemic wanes. Physicians have responded by proposing to define telemedicine as interstate commerce, expand the medical licensure compact, and increase adoption of telemedicine-specific licenses that will help ease the regulatory burden that reduces access to care (Mullangi et al., 2021). Nursing regulators should anticipate a similar push for nurses, especially APRNs.

Looking to the future of telehealth, NCSBN's global research agenda (Alexander et al., 2021) acknowledges the importance of license mobility in the increasingly borderless healthcare environment created by the recent growth of telehealth. The agenda recommends the development of regulatory tools that would facilitate such a workforce: (a) the establishment of regulatory standards across nations, (b) the sharing of licensure and registration records, and (c) further exploration of the impact of mutual recognition agreements and the best practices in enacting them. The global research agenda also raises questions about the prospect of practitioner discipline in the case of an error committed via telehealth across international borders-a growing possibility given telehealth's explosive expansion. The agenda calls for studies that explore comprehension of, and adherence to, local regulatory requirements by telehealth organizations. 


\section{Legislation and Policy Issues}

State and federal legislation in 2021 have continued to focus on the COVID-19 response, particularly for maintaining qualified nurses, regulating telehealth, and addressing occupational licensure. The pandemic highlights licensure compacts as the most efficient solution for practice mobility regardless of location. Emergency waivers and provisions that waived collaborative agreement requirements for APRNs are expiring as some states ease their pandemic emergency declarations.

\section{State-Level Action}

As legislators adapted procedures to conduct business safely throughout the COVID-19 pandemic, whether in person or remotely, many of the bills debated were in direct response to COVID-19. Chief among these pandemic response bills were those addressing vaccine mandates, the nursing workforce, telehealth, and occupational licensure.

\section{COVID-19 Response Bills}

As vaccinations became available for Americans, a fear of mandatory vaccines limiting personal freedoms grew within various states. This fear resulted in 12 states enacting legislation prohibiting vaccine mandates and vaccine passports in various circumstances (Alabama S.B. 267, Arkansas S.B. 615, Arizona S.B. 1854, Indiana H.B. 1405, Iowa H. 889, Missouri H.B. 271, North Dakota H.B. 1465, New Hampshire H.B. 220, Oklahoma S.B. 658, Tennessee S.B. 187, Texas S.B. 968, and Utah H.B. 308). Vaccine passports require proof of vaccination prior to accessing various businesses, government buildings, and schools; traveling; or attending large gatherings (Davis, 2021). Arizona, Florida, Georgia, Idaho, Montana, South Carolina, South Dakota, Texas, and Wyoming banned the implementation of vaccine passports via executive orders or directives from their governors (Davis, 2021). Conversely, both Hawaii and New York have implemented vaccine passport programs (Davis, 2021).

Arizona Senate Bill 1824 stipulated that any city, town, or county of the state is prohibited from establishing a COVID-19 vaccine passport or requiring a business to obtain proof of a person's COVID-19 immunization upon entry (Ariz. S.B. 1824, 2021). In a similar fashion, New Hampshire enacted House Bill 220 in July, which provides that no person shall be "compelled to receive an immunization for COVID-19 in order to secure, receive, or access any public facility, any public benefit, or any public service from the state of New Hampshire, or any political subdivision thereof' (N.H. H.B. 220, 2021).

\section{Maintaining a Qualified and Diverse Nursing Workforce}

The Future of Nursing 2020-2030 posited that a challenge facing the profession in the current decade is ensuring that the nursing workforce reflects the people with whom they interact and is prepared to address social determinants of health (National Academies of Sciences, Engineering, and Medicine, 2021).

Several states have pending legislation to maintain a qualified and diverse workforce. Notably, California Assembly Bill 1306 would authorize the Office of Statewide Health Planning and Development to fund internships and fellowships to address barriers to entry in the health professions for students from underrepresented and low-income backgrounds (Calif. A.B. 1306, 2021). This bill addresses the urgent and growing need for talented and diverse healthcare workers in California (Calif. A.B. 1306, 2021). This bill will carry over into California's 2022 legislative session when it reconvenes.

Significant nursing workforce shortages and nursing burnout have only been exacerbated by the COVID-19 pandemic. As a result, states have broadened the group of qualified practitioners to mobilize in response to the pandemic. One such group is nursing students and recent graduates. Massachusetts codified emergency measures in Senate Bill 2475 and Senate Bill 2472, which provide that a student who graduated from an RN or LPN/LVN program, or who is a senior nursing student in their last semester, may not be subject to the prohibitions against the unlicensed practice of nursing provided that they are employed and directly supervised while providing healthcare services in response to the COVID-19 pandemic (Mass. S.B. 2475, 2021; Mass. S.B. 2472, 2021). In Tennessee, nursing graduate practice was expanded without a direct connection to the COVID-19 response in House Bill 1353, which authorizes a nursing graduate to engage in the practice of professional nursing without a license while under the supervision of an individual licensed to practice professional nursing for 120 days from the date of receipt of the first authorization to take the NCLEX-RN (Tenn. Gen. Assemb., 2021).

\section{Regulating a Telehealth Environment}

The nursing workforce has not only had to adapt to incredibly stressful workloads and expand the field of practitioners qualified to respond to a pandemic, but nurses have also had to adjust the ways in which they provide care-namely through the exponential expansion of telehealth (Bestsennyy et al., 2021). To ensure the safety of patients and practitioners alike, states have had to adjust 
the regulatory environment around virtual visits. While many states authorized out-of-state practitioners to provide care to patients without a license via telehealth in executive orders, many also codified these changes during the 2021 session (Alaska House Bill 76, Arizona House Bill 2454, Vermont Senate Bill 117, and West Virginia House Bill 2024).

West Virginia House Bill 2024 permits healthcare practitioners licensed in good standing in other states to practice in West Virginia using telehealth services, provided that they first register as an interstate telehealth practitioner with the appropriate board (W. Va. H.B. 2024, 2021). Additionally, Vermont enacted Senate Bill 117 to extend telehealth licensure waivers until March 31 , 2022 (Vt. S. 117, 2021). The waiver allows healthcare professionals who hold a valid license, certification, or registration in good standing in any other U.S. jurisdiction to provide healthcare services to a patient located in Vermont via telehealth (Vt. S. 117, 2021).

\section{Occupational Licensure}

The conversation around occupational licensing has changed significantly over the course of the year. When 2020 began, occupational licensing was looked at through the lens of criminal justice reform (Carpenter, 2020), reducing regulatory barriers to employment (Peterson \& Slabinski, 2020), and state legislation related to universal licensing aimed at improving portability (Arnold, 2020). When the COVID-19 pandemic began, the focus shifted to address potential licensing issues and ways to allow healthcare providers to go where they were most needed.

Similar to telehealth licensure waivers, state legislatures extended in-person practice licensure waivers to out-of-state practitioners in order to aid in the COVID-19 response and maintain high quality patient care. Wisconsin enacted Assembly Bill 148 to authorize healthcare providers, including nurses, who hold a valid, unexpired license in good standing in another state or territory to provide services for which they are licensed within Wisconsin either in person or via telehealth (Wisc. A.B. 148, 2021). Under this bill, practitioners may practice in Wisconsin under a temporary credential that allows the practitioner to provide services only during the period covered by a national emergency and is effective until 30 days after the national emergency ends (Wisc. A.B. 148, 2021). Under any other circumstances, the practitioner may apply for a temporary credential within 30 days of providing healthcare services and shall include within the application an attestation of the date they began providing care, that they hold a valid license not under investigation, and they have applied for a permanent credential (Wisc. A.B. 148, 2021).

Many states have now codified these licensure exemptions beyond the COVID-19 state of emergency (Louisiana House Bill 197, Missouri House Bill 1263, Oklahoma House Bill 2873, and South Dakota House Bill 1077). In April 2021, Nebraska signed Legislative Bill 390 into law, thus enacting the Uniform Credentialing Act (Neb. L.B. 390, 2021). This act provides that a person who has a credential that is current, valid, and in good standing in another state or territory of the United States (including the District of Columbia) may be issued a credential in Nebraska if they meet the education and training requirements necessary and if they pay a fee (Neb. L.B. 390, 2021). This act applies to the APRN Practice Act, the CNM Practice Act, the CRNA Practice Act, the CNS Practice Act, Nurse Practice Act, and NP Practice Act (Neb. L.B. 390, 2021). Throughout the public health emergency, many governors also issued waivers related to state licensing for healthcare workers provided they were in good standing in their originating state (NCSBN, 2021f).

\section{Licensure Compacts}

The Future of Nursing 2020-2030 calls for nationwide adoption of licensure compacts as one of the most effective ways to remove barriers to health equity (National Academies of Science, Engineering and Medicine, 2021). While numerous states have taken legislative action over recent years to reduce the burden of maintaining multiple state licenses to provide care to patients across state lines, licensure compacts remain the most efficient solution for practice mobility, regardless of location.

The Nurse Licensure Compact (NLC) added three states and a territory to its list of members in 2021, bringing the total membership to 38. Ohio, Pennsylvania, and Vermont are the newest states to the NLC, and Guam became the first U.S. territory to become a member of the NLC. As of November 2021, the U.S. Virgin Islands had NLC legislation pending as well.

The Interstate Medical Licensure Compact, a licensure compact for physicians, currently has 34 member states, including those member states with implementation pending or delayed (Interstate Medical Licensure Compact, n.d.). Additionally, the Physical Therapy Licensure Compact is enacted in 33 member states (Physical Therapy Compact, n.d.). The Psychology Interjurisdictional Compact (PSYPACT) has been enacted by 25 state legislatures and the District of Columbia (Psychology Interjurisdictional Compact, n.d.). The Recognition of EMS Personnel Licensure Interstate Compact (REPLICA) has been enacted via legislation in 22 states (Interstate Commission for EMS Personnel Practice, n.d.). In 2021, the Audiology and Speech-Language Pathology Interstate Compact (n.d.) became operational, as 15 states have now enacted compact legislation. The Occupational Therapy Licensure Compact is now enacted in nine states (Occupational Therapy Licensure Compact, n.d.). Finally, the newly introduced Counseling Compact has been enacted in two states (Counseling Compact, n.d.). Both the Occupational Therapy Licensure Compact and the Counseling Compact will become operational when their respective compacts are passed by 10 states. 
In March 2021, the Department of Defense announced the approval of a series of grants in partnership with the Council of State Governments (U.S. Department of Defense, 2021). These grants will allow five professions_teaching, social work, cosmetology, massage therapy, and dentistry/ dental hygiene-to work with the Council of State Governments' National Center for Interstate Compacts to develop model interstate licensure compact legislation (U.S. Department of Defense, 2021).

The continued development of interstate compacts improves licensure portability, which not only benefit members of the profession at large but also assist members of the military and military spouses in maintaining continuity of employment despite frequent relocation due to active service.

\section{APRN Compact}

The 2021 legislative session saw the first introductions of the newly adopted 2020 APRN Compact. In North Dakota, House Bill 1044 was enacted into law with nearly unanimous legislative support (N.D. H.B. 1044, 2021). Delaware's APRN Compact legislation was also successful, and the efforts behind the APRN Compact legislation were able to propel further removal of restrictions for APRNs left over from statutory changes in 2017. Delaware House Bill 141, the companion bill to the compact, removed the requirement that new licensees practice under a collaborative agreement with a physician for their first 4,000 hours of practice and removed the board of medicine from having a role in oversight over APRNs who own their own businesses (Del. Admin. Code 24, 2021). Commenting on the enactment of both APRN bills, Pamela C. Zickafoose, EdD, MSN, RN, who is the executive director of the Delaware Board of Nursing, remarked:

This is an historical event for Delaware nursing history and APRN licensure. APRNs will be able to provide healthcare services that our citizens need. New practices will open to bridge current gaps and improve access to primary care providers. APRN compact licensure will allow increased cross-border practice, facilitating nurse mobility and telehealth (Quinn, 2021, para. 4).

The APRN Compact will go into effect when seven states enact it. Enactments in Delaware and North Dakota bring APRN licensure mobility all the closer to reality.

In addition to legislative success, the APRN Compact gained prominent national endorsements and state support from diverse stakeholders representing patient care, nursing, and business. Nationally, the APRN Compact has received endorsements from nursing organizations including the American Organization of Nurse Leaders and the National League for Nursing. The National Rural Health Association endorsed the APRN Compact, highlighting the importance of the APRN Compact in increasing access to care for rural communities. Telehealth organizations, including the ATA, expressed support for the APRN Compact. In a letter of support to North Dakota Representative Gretchen Dobervich, the ATA remarked that "the APRN Compact not only would continue to protect patients but also would help drive better care coordination and healthcare outcomes for constituents throughout the state" (Zebley, 2021, p.2). The Alliance for Connected Care, a telehealth organization whose board members include business organizations such as Stanford Health Care, CVS Health, Amazon Web Services, and Walmart, has endorsed the APRN Compact (NCSBN, n.d.). In a letter supporting Delaware House Bill 21, the APRN Compact legislation, the Alliance for Connected Care stated:

One of the biggest barriers to telehealth becoming a regular patient and provider choice is the administrative burden caused by the variation in licensure requirements from state to state. The APRN Compact would belp alleviate such administrative burdens through establishing multistate compacts that have reciprocity and that do not require additional licensing, while simultaneously helping to improve patient access to quality bealth care (Drobobrac, 2021, para. 3-4).

Examples of support at the state-level include nurses' associations, AARP, APRN professional groups, and hospitals (Quinn, 2021; Pfenning, 2021).

The COVID-19 pandemic has increased the demand for healthcare workers to be able to practice across state lines (Hentze \& Herman, 2021). The pandemic has increased awareness of and demonstrated the utility of interstate compacts for healthcare professionals. The further enactment of compacts is seen as necessary for maintaining and further expanding the utilization of telehealth after the COVID-19 pandemic (Appleby, 2021). The APRN Compact can make licensure mobility for APRNs a reality, and the 2022 legislative session is likely to bring APRNs and patients even closer to that reality.

\section{Military Licensure}

A persistent legislative trend has been the removal of barriers to licensure for members of the military, with a particular focus on removing these barriers for military spouses and dependents. Most military families will move every 3 years, and within these families more than $30 \%$ of military spouses in the workforce are in a career that requires a professional license with state-specific requirements 
(National Military Family Association, n.d.). For these spouses, relocation can cause serious career setbacks and a loss of wages as obtaining a new license is both financially cumbersome and time-consuming (National Military Family Association, n.d.).

To help ease the burden of relocation as well as entice military families to settle in the state, Michigan adopted Senate Bill 157 and Senate Bill 312, which simplifies the process of obtaining a license in Michigan for active-duty service members, veterans, and dependents who previously held an occupational license in another state or country as well as waiving the fee for licensure (Mich. S.B. 157, 2021; Mich. S.B. 312, 2021; Michigan.gov, 2021). House Bill 4377 requires the Department of Licensing and Regulatory Affairs to issue a license, certificate, or registration without examination to an applicant who is a member of the armed forces, a veteran, or a dependent of a member of the armed forces who holds a valid license or registration in good standing in another state for at least 1 year (Mich. H.B. 4377, 2021). Finally, House Bill 4376 extended the waiver of initial license or registration fee to include not only veterans but also active-duty service members and their qualifying dependents (Mich. H.B. 4376, 2021). Throughout the 2021 legislative session, four other states enacted similar legislation to ease the burden of licensure for members of the military and their families (Arkansas S.B. 78, Hawaii H.B. 961, Maine S.B. 160, and Wyoming S.B. 18).

\section{Federal Level Action}

The focus of healthcare regulation throughout the pandemic at the federal level has been on the ability to mobilize healthcare workers to regions with the most need. Many states were able to leverage the powers facilitated by the Emergency Management Assistance Compact (EMAC), a federal disaster relief compact ratified at the federal level and entered by nearly all U.S. jurisdictions. The EMAC allows for the sharing of resources between states and, in this case, granted states the ability to facilitate private telehealth, reducing the strain on their healthcare system (EMAC, n.d.).

The CMS also issued temporary waivers that eased the strain on the healthcare system in a variety of ways. The first was to allow providers to bill for services delivered to patients located outside of their state of licensure, which would otherwise be a barrier to telehealth provision. Because CMS does not have the authority to make this waiver permanent, it will be rescinded following the end of the federal Public Health Emergency declaration. CMS also issued waivers regarding full practice authority for CRNAs, allowing these practitioners to practice independently of a physician, strengthening the overall healthcare system. Additionally, under these waivers, nurse aide examinations were waived, allowing those who completed the required education to enter the field without completion and passage of the examination (CMS, 2021).

The Future of Nursing 2020-2030 identifies policy change as one of the most effective ways to ensure that the healthcare workforce is prepared to meet the next disaster or public health emergency (National Academies of Sciences, Engineering, and Medicine, 2021). To that end, members of Congress have also introduced pieces of legislation to assist in the provision of healthcare during a public health emergency.

The Equal Access to Care Act (2020), sponsored by Senators Ted Cruz (R-TX) and Marsha Blackburn (R-TN), would allow healthcare providers to deliver telehealth services in any U.S. jurisdiction with only one license. The provider would not need to be licensed in the state where the patient is located to deliver telehealth services. It would move the location of care to the location of the provider, requiring the provider to follow the practice laws and regulations in the state where they are licensed as opposed to the state where the patient is located.

The Temporary Reciprocity to Ensure Access to Treatment (TREAT) Act (S. 4421/H.R. 8283, 2020), sponsored by Senators Chris Murphy (D-CT) and Roy Blunt (R-MO) and Representatives Bob Latta (R-OH) and Debbie Dingell (D-MI), seeks to provide temporary licensing authority for healthcare professionals to practice in-person or via telehealth anywhere in the United States with a license in good standing in only one jurisdiction during a period where both a Public Health Emergency has been declared by the HHS secretary and a national emergency has been declared by the U.S. president. This bill has taken steps to address concerns related to state-based licensing and interstate compacts such as the NLC. The TREAT Act has been endorsed by academic medical institutions, staffing organizations, and hospital associations (Murphy, 2020).

There have also been conversations regarding the role of state licensing boards in determining the qualification of providers. Some conservative think tanks have been calling for a private certification system that would determine the quality of providers as well as the scope of practice for each level of provider (Svorny \& Cannon, 2020). Those who argue for this system believe that malpractice insurance is enough protection for patients and that reviews from patients are a sufficient way to determine which providers are safe and competent. Although these conversations have been happening for years, COVID-19 has renewed calls for a national or federal license for occupations such as nursing.

\section{APRNs, Emergency Waivers, and Provisions}

Despite many states seeing waves of confirmed COVID-19 cases higher than what they saw at the 2020 peak of the pandemic, as of mid-September 2021, 23 states have rescinded or let expire their declaration of emergency. With the end of the emergency declara- 
tions came the expiration of many emergency waivers and provisions that were put into place to assist the state in responding to the pandemic - including waivers that impacted APRN licensure and regulation.

Toward the start of the pandemic, close to a dozen states acted, either through emergency legislation or executive order, to waive collaborative agreement requirements for APRNs. Collaborative agreements, generally, are statutorily required written agreements between an APRN and a physician that are required for the APRN to practice, prescribe, or both. These agreements have no nexus to public safety and can significantly limit access to care (Endicott, 2019). In some states, existing restrictions meant APRNs who wanted to volunteer to assist with the COVID-19 response were not able to do so. Restrictions at times also prevented APRNs from shifting their practice to telehealth, a shift necessary to protect patients and providers and to preserve resources such as PPE that experienced nationwide shortages (Patel, 2021). These waivers were necessary for APRNs to assist in the COVID-19 response efforts and allowed flexibility for both providers and facilities to manage the response (Masters, 2020). A survey looking at the impact of the Massachusetts waiver found that NPs practicing in behavioral health reported the waiver positively impacted their clinical work (O'Reilly-Jacob \& Perloff, 2021). The authors suggest this "possibly reflects the higher demand for mental health care during the pandemic or the disproportionate effect of mandated physician supervision on psychiatric care,” (O’Reilly-Jacob \& Perloff, 2021, p. 285).

Though waivers in states such as Kansas and New York have expired (Kansas State Board of Nursing, 2021; N.Y. Exec. Order No. 210, 2021), others have renewed the provisions. Kentucky lawmakers extended the APRN waiver until January 15, 2022, through House Joint Resolution 1, which was enacted during a special session (Ky. Gen. Assemb. H. J. Res. 1, 2021). As of publication, Louisiana Governor John Bel Edwards continues to renew Louisiana's state of emergency and related emergency provisions, including the collaborative practice agreement waiver, each month. As of mid-September 2021, APRNs in Louisiana can continue to provide greater access to care for patients across the state, and facilities overwhelmed by the Delta variant are able to utilize the waiver when recruiting APRNs to the state (La. Proclamation No. 168, 2021). Louisiana's legislature considered a bill to make the waiver permanent (Farris, 2021), but though similar efforts in Massachusetts were successful, the Louisiana bill did not cross the finish line in the 2021 legislative session (Credentialing Resource Center, 2021).

While it is possible that state lawmakers will reinstate these waivers if deemed necessary for the pandemic response, political considerations make that possibility scant. Experts argue that rolling back or letting waivers expire now, amidst the continued surges and uncertainty of the virus' next move, will restrict healthcare access (Poghosyan, 2021). The Future of Nursing $2020-2030$ predicts that states will face pressure to leave new policies in place and will have difficulty justifying a return to pre-pandemic restrictions on APRN practice (National Academies of Sciences, Engineering, and Medicine, 2021).

\section{APRN Consensus Model}

The Consensus Model for APRN Regulation, Licensure, Accreditation, Certification, and Education (APRN Consensus Model), adopted in 2008, is the national model for APRN regulation and practice, seeking to align APRN regulation in the United States. The model includes seven elements: (a) APRN title, (b) recognition of four APRN roles, (c) licensure as both an RN and APRN, (d) graduate-level education or higher, (e) initial and continuing maintenance of national certification, (f) independent practice, and ( $\mathrm{g}$ ) independent prescribing. As of September 2021, 17 states and the Northern Mariana Islands have adopted all seven elements for each of the four APRN roles (NCSBN, 2021h). Several states introduced legislation to remove barriers to APRN practice and regulation. Two states met the American Association of Nurse Practitioners' criteria for preserving full practice authority-the ability for APRNs to practice to the full extent of their scope under the exclusive oversight of the BON (American Association of Nurse Practitioners, 2013) _ in statute, bringing the commonly cited number of states from 22 full practice authority states for NPs to 24 since January 2021. The two additions were Delaware, with the enactment of the APRN Compact companion legislation House Bill 141, and Massachusetts, which enacted An Act Promoting a Resilient Health Care System That Puts Patients First. Governor Charlie Baker of Massachusetts remarked:

Massachusetts has long been a leader in ensuring health care quality and access and with this new law, we are making further progress in building a strong, accessible and affordable health care system, a goal that is more important now than ever (Governor's Press Office, 2021, para. 5).

Legislation in Virginia reduced the number of hours needed for a nurse practitioner to hold a collaborative agreement prior to full practice authority, a so-called transition to practice period, from 5 to 2 years, mirroring the COVID-19 emergency provision that reduced the requirement (Virginia Council of Nurse Practitioners, 2021). Like the emergency provision, the legislation is also set to expire on July 1, 2022, making further legislative action necessary to make the provision permanent (Virginia Council of Nurse Practitioners, 2021). Utah also looked to alter their transition to practice period in the 2021 legislative session. The transition period required for Utah APRNs who own their own businesses was reduced from 2,000 to 1,000 hours by the enactment of House Bill 287 (Hinton, 2021). In addition to the reduction, the bill removed the requirement for an APRN to enter into an agreement with a physician to prescribe Schedule II controlled substances (Hinton, 2021).

Volume 12 Supplement January 2022

www.journalofnursingregulation.com 
NCSBN's NursingAmerica campaign remained active in the 2021 legislative session. After participating in efforts to enact waivers in numerous states in 2020, the NursingAmerica campaign sought to advance legislation in Florida, Kansas, Kentucky, Mississippi, and North Carolina in the 2021 legislative session (NCSBN, 2021i). Significant progress was made in Mississippi, where legislation recognizing the clinical nurse specialist role and providing for full practice authority for all APRNs passed the state's House of Representatives for the first time (Kittredge, 2021). In North Carolina, the SAVE Act was introduced in March 2021 and aims to remove barriers for APRNs across the state and eliminate oversight by the North Carolina Medical Board (N.C. S.B. 249, 2021). The bill received more than 100 co-sponsors, a promising sign for expanding access to care across the state (Sherman, 2021). The SAVE Act also received key support from BlueCross BlueShield of North Carolina, which believes efforts such as this bill will help improve access, transition care to lower cost settings, and maintain quality (Evans, 2021). These important efforts will continue as we head into the 2022 legislative session.

\section{Future of Nursing Report}

The National Academies of Sciences, Engineering, and Medicine's 2021 report The Future of Nursing 2020-2030 dedicates significant discussion to the future of APRN practice. The report predicts the importance of APRNs practicing to the full scope of their education without restriction, especially in areas such as opioid treatment and the provision of primary care in light of the continuing primary care physician shortage. Of note, the report committee acknowledged the correlation between poor health outcomes in underserved communities and restrictions on APRN practice. One of the report's recommendations is the use of federal authority to supersede state laws that restrict APRN scope of practice (National Academies of Sciences, Engineering, and Medicine, 2021).

The report further acknowledges that the full extent of services provided by both APRNs and physician assistants (PAs) is not understood, due to an undercount of these services as a result of common medical billing practices. Many such providers bill services as "incident to a physician's service," causing the care to appear to have been provided by the collaborating physician. The report notes that the Medicare Payment Advisory Committee advised in 2019 that such "incident to" billing be eliminated so that the true extent of APRN and PA care can be determined.

\section{The CRNA Title}

The CRNA title has been in use for more than 60 years (American Association of Nurse Anesthesiology [AANA], 2021a) and is established in statute in multiple states across the United States. In a rebranding that is part of a larger movement to expand the title, the American Association of Nurse Anesthetists, which serves as the national professional organization for CRNAs in the United States, has officially changed the name of the organization to the American Association of Nurse Anesthesiology (AANA, 2021b).

This proposed change has prompted opposition from the American Society of Anesthesiologists (2021) and other physician groups. The AANA responded stating the new title "accurately and strongly communicates that the AANA represents members of the nursing profession who provide anesthesia and are experts in anesthesiology" (Henderson, 2021, para. 15).

Changing a professional title is an extensive process that requires legislative and regulatory revision (Fotsch, 2016). The Consensus Model provided clarity and uniformity for APRN role titles after years of APRNs being identified by a patchwork of clinical specialty designations, federal government terms like mid-level provider (Drug Enforcement Administration, n.d.), and other titles unique to each state (Fotsch, 2016). APRN role title uniformity assures the public that the individual CRNA has met the necessary requirements of education, certification, and regulation in all practice settings and across borders; thus, research is needed to demonstrate the practical implications of this title change.

A decision by a professional organization does not automatically change current regulation by a given professional licensing board. However, BONs in Florida and New Hampshire have granted the authority to use this new title. In Florida, the BON issued a declaratory statement allowing an individual CRNA to use the certified registered nurse anesthesiologist descriptor when the CRNA title was not required by his or her licensure (State of Florida Board of Nursing, 2019). The New Hampshire BON issued a position statement allowing CRNAs to use the descriptors nurse anesthesiologist and certified registered nurse anesthesiologist in professional communications (New Hampshire Board of Nursing, 2018). Physician groups issued a declaratory statement in response, opposing the use of the term anesthesiologist for nurses, arguing that it applies to the practice of medicine and may only be used by an individual licensed to practice medicine. The question went to the New Hampshire Supreme Court, petitioned by the New Hampshire Association of Nurse Anesthetists (NHANA). The court affirmed the position of the board of medicine. However, the court was divided as to whether the board of medicine has the authority to make such a declaration for a CRNA who is regulated under the BON (New Hampshire Supreme Court, 2021).

The nurse anesthetists were not the only group to rebrand in 2021. Despite concerns raised by the America Association of Physician Assistants about the significant expense to implement the title change and the possibility of a renewed debate on the PA scope of practice (Coplan et al., 2021), the American Academy of Physician Assistants House of Delegates approved a resolution to 
change the official professional title from physician assistant to physician associate (and the name of their organization along with it) (American Academy of Physician Associates, 2021). They too drew physician opposition; the AMA released a statement, which read, in part, "We believe this latest effort is incompatible with state laws and are prepared to work with interested state and specialty medical societies to address any efforts to implement this title change in state or federal policy" (AMA, 2021a, para. 1). 


\section{COVID-19 and Opioid Morbidity and Mortality}

As COVID-19 infections and deaths rose in 2020, the deaths from drug overdoses also rose. By December 2020, the Centers for Disease Control and Prevention (CDC) issued an official Health Advisory directed to public health departments, healthcare professionals, first responders, harm reduction organizations, laboratories, and medical examiners and coroners, which indicated "substantial increases in drug overdose deaths across the United States, primarily driven by rapid increases in overdose deaths involving synthetic opioids excluding methadone (hereafter referred to as synthetic opioids), likely illicitly manufactured fentanyl" (CDC, 2020, para. 1). The largest increase in deaths took place between March and May 2020, coinciding with the implementation of widespread mitigation measures for the COVID-19 pandemic. The advisory also noted a changing geographic distribution of overdose deaths involving synthetic opioids, with the largest percentage increases occurring in states in the western United States, as well as significant increases in overdose deaths involving psychostimulants with abuse potential, such as methamphetamine (CDC, 2020).

Drug overdose deaths continued to rise, and by September 2021, the National Center for Health Statistics (2021) noted that there was a $30.4 \%$ increase in drug overdose deaths from February 2020 to February 2021. This increase resulted in more than 93,000 deaths in 2020 and represents the largest single-year percentage increase on record since 1999 (Baumgartner \& Radley, 2021).

Only South Dakota showed a decrease in drug overdose deaths; all other states, not just those often associated with the opioid epidemic, showed increases. Similarly, all demographic groups experienced more overdose deaths, but males, younger age groups, and communities of color in particular showed large increases in death (Baumgartner \& Radley, 2021). Dr. Nora Volkow, director of the National Institute on Drug Abuse, indicated that the "highest increase in mortality from opioids, predominantly driven by fentanyl, is now among Black Americans" (Goodnough, 2021, p. 8). Volkow continued, "When you look at mortality from methamphetamine, it's chilling to realize that the risk of dying from methamphetamine overdose is 12-fold higher among American Indians and Alaskan Natives than other groups" (Goodnough, 2021, p.8).

\section{Reasons for the Increase}

Scientists and authors opine reasons for this large increase in overdose deaths during the pandemic. Some point to a distuption in the drug market that led to drug purchases from new and unfamiliar sources, the inability to obtain naloxone, and barriers to accessing treatment for substance use disorders (Severance-Medaris, 2021). Most medication-assisted treatment (suboxone or methadone), support groups, and 12-step programs require in-person visits. Disruption to access for the usual in-person treatments may be associated with increase overdose deaths (Currie et al., 2021).

\section{Buprenorphine Use and Access}

Buprenorphine, an opioid partial agonist, is one of the drugs used as medication-assisted treatment for opioid use disorder. When taken as directed, it can reduce physical dependency and lower the risk of harm in the event of an overdose (Substance Abuse and Mental Health Services Administration [SAMHSA], 2021a). Currie et al. examined how prescribing of buprenorphine for opioid use disorders evolved from 2018 to September 2020 for new and existing patients. The data revealed that while existing patients maintained access to buprenorphine treatment during the early months of the pandemic, the number of new patients receiving buprenorphine for opioid use disorder during the early months of the pandemic decreased by almost 25\% and remained depressed through August 2020, even then only reaching $90 \%$ of projected levels. The study results imply that 36,954 fewer patients entered opioid use disorder treatment, which may have been associated with increases in overdose deaths (Currie et al., 2021).

Since the beginning of the use of buprenorphine for opioid use disorder, authority to prescribe buprenorphine has been restricted. Initially, federal statute limited buprenorphine treatment to physicians, required multiple hours of mandatory training to receive authority in the form of a waiver, and restricted the number of patients each provider may treat (SAMHSA, 2021b). Legislation over the past decade has increased providers' patient limits and extended prescribing authority to other providers, including APRNs (Comprehensive Addiction and Recovery Act, 2016; Substance Use-Disorder Prevention That Promotes Opioid Recovery and Treatment for Patients and Communities Act, 2018).

Nevertheless, APRNs still experience regulatory barriers to offering buprenorphine treatment. A 2020 research study described these barriers and facilitators to APRNs offering buprenorphine treatment. The study concluded that "requirements that physicians oversee APRN prescribing of buprenorphine may have slowed the growth of the opioid treatment workforce. Other regulations, organizational culture, and community support of buprenorphine treatment also affect APRN engagement in offering buprenorphine treatment" (Spetz et al., 2021, p. 5). Difficulty securing a collaborating physician can be challenging enough for many APRNs (Martin \& Alexander, 2019); the ability to find a collaborating physician who prescribes buprenorphine and can oversee the APRN's prescribing of buprenorphine creates an even greater challenge. A large percentage of small and remote rural counties (69\%) were found to 
have no healthcare providers with a buprenorphine prescribing waiver, as compared to $22 \%$ in urban counties. It is projected that, if barriers were removed, NPs and PAs with buprenorphine prescribing ability could increase buprenorphine treatment for patients in rural populations by 15.2\% (Andrilla et al., 2019). All 50 states now allow NPs to prescribe buprenorphine either independently or through a relationship with a physician (Cos et al., 2021).

Many practitioners describe the extensive training, counseling, and other ancillary services that are required to obtain the waiver to treat up to 100 patients with buprenorphine as a barrier to treating more people. The barriers, plus the rising overdose deaths in 2020 and 2021, led the HHS in April 2021 to release new buprenorphine practice guidelines that temporarily removed a longtime requirement tied to the extensive training for the waiver for prescribing of buprenorphine (HHS Press Office, 2021b). The Office of National Drug Control Policy Acting Director Regina LaBelle stated:

Addiction treatment should be a routine part of healthcare, and this new guideline will make access to quality treatment for opioid use disorder more accessible. The guideline is another important step forward in our efforts to bend the curve of the overdose and addiction epidemic (HHS Press Office, 2021b, para. 7).

Additional regulatory flexibility for prescribing opioid use disorder treatments was also enacted by the U.S. Drug Enforcement Administration to help mitigate some disruption to effective treatment during the pandemic (Stringer et al., 2021). For example, exceptions were made for stable patients in certified outpatient treatment programs to receive take-home doses of medication-assisted treatment to reduce in-person visits and regulations were relaxed around teleprescribing medications for opioid use (SAMHSA, 2020).

\section{Reexamining Regulatory Requirements}

Some in the substance use disorder field have proposed expanded access to care for those with opioid use disorder for many years and are now asking that the regulatory flexibilities that were implemented during the pandemic be made permanent. This is an opportune moment to reexamine regulatory requirements that may act as barriers and to consider the impact of improved access in saving lives (Stringer et al., 2021). These calls to remove barriers and expand access to substance use disorder care have been echoed by professional organizations (AMA, 2021b) as well as the congressional Bipartisan Addiction and Mental Health Task Force (Congresswoman Ann McLane Kuster, 2021).

Although access to buprenorphine may temporarily increase from the HHS measure removing the training required for buprenorphine prescribing authority, this is not a permanent change. More can be done to increase access to this life-saving treatment. The ANA, recognizing the disruptions of treatment options for many because of the pandemic and the barriers to treatment for those with opioid use disorder, advocated for the elimination of the requirement to obtain a waiver for prescribing buprenorphine for maintenance or detoxification treatment (ANA, n.d.).

\section{Implications for Regulators}

The recent study by Spetz et al. (2020) indicated that calls to close the gap between treatment need and treatment delivery is well documented. The following list further outlines the agenda for closing that gap:

- The health workforce must be better prepared, and structural barriers to life-saving care must be removed at both the federal and state levels (Spetz et al., 2021, citing National Academies of Sciences, Engineering, and Medicine, 2019; Shrank et al., 2021; Alegría et al., 2021).

- Supporting the unrestrictive scope-of-practice regulations for NPs and other APRNs (Spetz et al., 2021, citing Institute of Medicine, 2011; National Academies of Sciences, Engineering, and Medicine, 2021) will provide APRNs with greater autonomy; these providers may be better positioned to close the gap.

- "Standardized curricula in care of people with substance use disorders, including medication treatment, for both prelicensure and advanced practice education, will help nurses understand the field of addiction, address fear and stigma, and better prepare this needed workforce" (Spetz et al., 2021, p. 16). 


\section{NCSBN Regulatory Initiatives}

For more than 40 years, the NCSBN has provided U.S. and international regulators with forums where they have collaborated on projects that have ultimately protected the public's health, safety, and welfare in their home states, provinces, territories, and countries. The COVID-19 pandemic has accentuated the need for equitable healthcare, delivered by safe and competent professionals, in every region and across every border. NCSBN has several projects underway that will advance regulatory excellence worldwide in the years to come.

\section{International Center for Regulatory Scholarship}

NCSBN's International Center for Regulatory Scholarship (ICRS) was established in 2019 to support and empower international healthcare regulators through specialized educational programs and unparalleled networking opportunities. ICRS is continuously growing, and two of its programs are now open to the public.

The first is the ICRS certificate program, a competency-based online and blended course of study for healthcare regulators and others whose work is concerned with public health. The program offers courses along three distinct pathways: (a) Governance \& Leadership, (b) Public Policy \& Legislation, and (c) Research \& Measurement. This international regulatory program currently has over 250 participants from the United States, Canada, Kenya, and Singapore who are enrolled in courses such as Power Dynamics of Negotiations, Introduction to Administrative Law for Regulators in Canada, and Data Analysis With Python. After earning six program credits, participants are invited to complete the final milestone, the ICRS Advanced Leadership Institute. The very first biennial ICRS Advanced Leadership Institute, which is being planned for April 2022 in Washington, D.C., will feature world renowned speakers, networking sessions, and a celebratory graduation dinner and ceremony. Ultimately, this unique program, which is offered to participants from NCSBN affiliates at no charge and to participants from outside organizations for nominal fees, prepares graduates to collaborate with interdisciplinary peers to solve the public health challenges of tomorrow.

The second ICRS program open to the public is the COVID-19 Series, which is a set of four complimentary online short courses that address COVID-19 epidemiology, nursing care, law and ethics, and hoaxes. These self-paced offerings were introduced in the early months of the pandemic when there were few fact-based resources available for nurses and other healthcare workers, and so they were enthusiastically welcomed by professional organizations and institutions of higher learning. Therefore, as of August 2021, nearly 50,000 unique users— primarily nursing students, new nurses, and experienced nurses—had achieved 75,000 course completions. Users can choose to complete one of these courses or all four, whichever combination they feel will prepare them best for working during the COVID-19 pandemic.

The ICRS certificate program accepts applications on a rolling basis, and the COVID-19 Series is open for enrollment with no application required. ICRS also has plans to launch additional courses and programs in the future. To learn more, please visit the ICRS website at www.icrsncsbn.org.

\section{Nurse Licensure Guidance Tool}

The Nurse Licensure Guidance Tool was developed by NCSBN as an innovative web instrument that provides comprehensive information on the nurse licensure requirements in each U.S. state. Before this tool's launch, domestically and internationally educated nurses searched the Internet for the states' disparate licensure requirements, but these nurses sometimes landed on third-party webpages that contained inaccurate or out-of-date information.

The Nurse Licensure Guidance Tool serves as a gateway, taking users directly to the states' licensing applications and the states' NPAs. The NPAs contain the most valid information for gaining the license needed to practice as an RN or LPN/LVN in a single U.S. jurisdiction and relay whether the state is a member of the NLC. In addition, the tool provides state-specific information regarding distance education, which is important because nursing programs require clinical experience involving direct or remote care.

The Nurse Licensure Guidance Tool has been used by U.S. nurses and international nurses from at least 103 countries, with approximately 9,000 U.S. and 2,000 international users each month, and it can be found on the NCSBN's website at www.ncsbn.org/ nurse-licensure-guidance.

\section{Pioneering Research}

NCSBN supports patient safety and public protection in the nursing profession with its rigorous research program. Several important studies are in progress, and the forthcoming results will be shared with the regulatory public through the Journal of Nursing Regulation and other academic journals that inform domestic and international healthcare policy. 
The first two stages of a multiphase exploration of the effects of COVID-19 on nursing education are underway. The purpose of the first phase, the National Prelicensure RN Program Baseline Survey, is to indicate the extent to which prelicensure RN programs changed instructional and clinical delivery formats while adapting to COVID-19 mitigation measures early in the pandemic. The second phase, the National Prelicensure RN Study: Assessing the Impact of COVID-19 on Nursing Education, is a longitudinal study that examines both the changes to clinical and instructional formats as well as the effects these changes may have on the nursing class of 2022. The insights derived from these phases have the potential to help administrators recalibrate nursing programs during future crises that inhibit in-person learning.

Other ongoing studies include the APRN COVID-19 Waiver Impact Study, which will provide much-needed data on the effect of emergency waivers on supervisory/collaborative agreements between APRNs and physicians in Louisiana, Kentucky, Maine, and West Virginia, and the Global Regulatory Atlas COVID-19 Study, a survey of nursing regulatory bodies around the world that is designed to discern whether regulatory changes were made in response to COVID-19 and whether these changes have affected health-related outcomes. In addition, the results of the longitudinal prospective Guidelines for Monitoring Substance Use Disorder in Nurses Study are expected to support evidence-based guidelines for alternative-to-discipline and monitoring programs that facilitate afflicted nurses' safe return to practice, and the 2022 National Nursing Workforce Survey, a biennial project conducted with the National Forum of State Nursing Workforce Centers, will provide updated data on the supply of nurses in the United States, critical information needed for ensuring a safe and effective healthcare system. Whether domestic or international in focus, these studies will yield information that nursing and other healthcare leaders will surely find valuable.

COVID-19 reprioritized NCSBN's research agenda in the short-term because data has been needed for evidence-based decisionmaking. The results of these studies will not be short lived, however. This research-derived information will serve as foundations for future NCSBN studies that will respond to the contemporaneous issues.

\section{NURSE ID: Unique Nurse Identifiers}

Nurses have always been responsible for contributing to positive patient health outcomes, but they have not always received the recognition they deserve because they have not often been named in patient records. In The Future of Nursing 2020-2030, the committee advocates for the creation of a national nurse identifier that will harmonize records between hospitals, health systems, employers, and BONs to create a single, accurate record of a nurse's career and regulatory history (National Academies of Sciences, Engineering, and Medicine, 2021). NCSBN's global research agenda (Alexander et al., 2021) also asks the question of how the patient-level data associated with a specific nurse's practice can be linked and aggregated to provide a complete picture of that nurse's practice.

To realize this goal, NCSBN has developed NCSBN ID, a system of unique nurse identifiers automatically generated for all LPNs/LVNs, RNs, and APRNs at the time they register for the NCLEX in the United States and its territories. Nurses who passed the NCLEX before this system was rolled out have also been assigned unique nurse identifiers through a matching process. NCSBN IDs are publicly available through Nursys, NCSBN's database of current licensure and discipline information for U.S.-based nurses, and NCSBN is working closely with nursing regulatory bodies in Canada to implement this system in that country as well.

When number-based unique nurse identifiers are incorporated into electronic health records and other information technology structures, nurses' contributions to patient safety and population health outcomes as well as to operational efficiencies and levels of clinical effectiveness will be tracked and analyzed.

Some nurses, of course, are licensed in more than one state, province, territory, or country. When the bilateral Canada-United States project is complete, NCSBN plans to also engage other international nursing regulatory bodies to enroll in NCSBN ID. Through NCSBN's matching system, it will identify nurses who hold multiple licenses, merging jurisdictional- and country-specific licensure and discipline information under single NCSBN IDs that document nurses' complete histories. Therefore, while NCSBN ID will put a spotlight on nurses' positive contributions, it will also alert licensing bodies to potential hazards when nurses who were disciplined for negative patient health outcomes in one geographical location apply for licenses in additional jurisdictions.

NCSBN envisions a future when all the nursing regulatory bodies of the world will participate in the NCSBN ID system, sharing the critical information that will keep societies safe. In time, NCSBN ID will underscore the value nurses bring to healthcare teams worldwide and may provide invaluable data to health systems and researchers who are trying to understand and strengthen the nursing workforce. 


\section{Summary: What Regulators Can Expect in 2022 and Beyond}

COVID-19 has commandeered healthcare priorities in 2020 and 2021, but the international healthcare community will need to continue to cooperate if it is to confront old health challenges along with new ones that will emerge long after this pandemic. Diseases clearly do not recognize borders, traversing them freely and infecting vulnerable populations wherever they go.

The good news is that the effects of evidence-based nursing regulation also have the ability to flow unrestricted. NCSBN will continue to facilitate conversations between domestic and international nursing regulatory bodies and will share vital information to embolden policy, ensuring that people, regardless of whether they live in rural villages or bustling cities, have access to quality nursing care overseen by nursing regulatory bodies mandated to protect their publics.

The following addresses just some of the existing and new challenges expected in 2022 and beyond:

- The introduction of this report reflected on the past 2 years and the challenges and resiliency of regulators, the nursing workforce, educators, and practitioners during the worst healthcare crisis in over a century. It has already been noted that aspects of the pandemic will have a lasting effect on American life including the workforce. Data suggest that the pandemic has and will continue to exacerbate the nursing shortage with nurses not near retirement leaving the profession due to stress and burnout. Early warnings of this impending exodus highlight the importance of initiatives described in this report that focus on reducing barriers to licensure and mobility and technological advances that reduce exposure to contagions, improve efficiency, and decrease the need for PPE. Regulators should also strive to develop new methods for remediation for practice errors and prevention of substance use disorder.

- Regulators should expect a continued disruption in their own workforce. Studies indicate there will be a continued desire for remote working opportunities. Regulators should also be aware of a growing number of cybersecurity risks and ensure that their IT systems are equipped to prevent cyberattacks.

- Just as there has been a rapid shift to remote working, there has been an increase in online nursing education. While this shift exponentially increased because of the pandemic, it may no longer be seen as a temporary solution. The rapid adaption of online learning has paved the way technologically for online content delivery, and this increase may allow more students in remote locations the opportunity to pursue a nursing education (Haslam, 2021).

- While many believe a curriculum transformation is needed after the COVID-19 pandemic to ensure that nurses of the future are well-prepared to administer care during a pandemic (Morin, 2020), the WHO State of the World's Nursing (2020) report states that undergraduate preparation should focus on primary care, "ensuring quality of care and patient safety, preventing and controlling infections, and combating antimicrobial resistance" (p. 12). Curricula need to be explicit about the nurse's role in "health promotion, health literacy and management of noncommunicable diseases" (p. 13). Preparing nurses for their critical role managing epidemics should be an integral part of the curriculum, irrespective of educational level (undergraduate or graduate). In addition, population health should be strengthened. The future healthcare workforce will deal with issues beyond pandemics and will need to be properly prepared to address the health issues of an aging population and those with mental health issues (Morin, 2020).

- This year, nursing regulatory bodies faced new challenges as they dealt with issues related to vaccine hesitancy/resistance from nurses and students and complaints of nurses providing misinformation to the public via social media. Nurses providing nonscientific information to the public is a threat to public safety and the public trust that has been placed in nurses. Nursing education programs need to continue to focus on and teach evidence-based practice.

- The latest statistics indicate there is a decrease in the number of LPNs/LVNs as well as practical/vocational nurse education programs. This decrease has the potential to severely impact long-term care and home health where LPNs/LVNs are in high demand and provide most of the care. It also indicates a need for support workers to assist in patient care and the development of clinical ladders that will offer a pipeline into the profession.

- The social determinants of health will continue to be a focus for educators, practitioners, and researchers in the coming years. Regulators can address these needs through the NLC and passing APRN Consensus Model legislation, thereby providing more access to care for the underserved and those in rural areas.

- Expect technology and robotics to continue to become routine aspects of healthcare delivery. Questions about accountability will arise and need to be addressed. As technology advances, so will telehealth services. Regulators need to stay ahead of the advances to ensure public safety.

- Regulators should expect a growing number of licensure compacts across disciplines. 


\section{References}

Accreditation Commission for Education in Nursing. (2017). Crosswalk of criteria for evaluation of nurse practitioner programs (2016) E ACEN standards E criteria (2017). http://www.acenursing.net/ resources/2017ACEN-2016NONPF.pdf

Alagha, M. A., Jaulin, F., Yeung, W., Celi, L. A., Cosgriff, C. V., \& Myers, L. C. (2021). Patient harm during COVID-19 pandemic: Using a human factors lens to promote patient and workforce safety. Journal of Patient Safety, 17(2), 87-89. https://doi.org/10.1097/ PTS.0000000000000798

Alegría, M., Frank, R. G., Hansen, H. B., Sharfstein, J. M., Shim, R. S., \& Tierney, M. (2021). Transforming mental health and addiction services. Health Affairs, 40(2). https://doi.org/10.1377/ hlthaff.2020.01472

Alexander, M., Martin, B., Kaminski-Ozturk, N., Zhong, E., \& Smiley, R. (2021). Envisioning the future of nursing regulation through research: A global agenda. Journal of Nursing Regulation, 12(3), 5-10. https://doi.org/10.1016/S2155-8256(21)00111-3

Algase, D., Stein, K., Arslanian-Engoren, C., Corte, C., Sommers, M. S., \& Carey, M. G. (2021). An eye toward the future: Pressing questions for our discipline in today's academic and research climate. Nursing Outlook, 69(1), 57-64. https://doi.org/10.1016/j. outlook.2020.08.010

American Academy of Physician Associates. (2021, May 24). AAPA house of delegates votes to change profession title to physician associate. https://www.aapa.org/news-central/2021/05/aapa-house-of-delegatesvotes-to-change-profession-title-to-physician-associate/

American Association of Colleges of Nursing. (2016). Crosswalk table comparing the Commission on Collegiate Nursing Education's (CCNE's) standards for accreditation of baccalaureate and graduate nursing programs (2018) and the National Task Force on Quality Nurse Practitioner Education (NTF) criteria for evaluation of nurse practitioner programs. https:// www.aacnnursing.org/Portals/42/CCNE/PDF/Crosswalk-2018Standards-2016-NTF-Criteria.pdf

American Association of Colleges of Nursing. (2021a). Student enrollment surged in U.S. schools of nursing in 2020 despite challenges presented by the pandemic. https://www.aacnnursing.org/NewsInformation/Press-Releases/View/ArticleId/24802/2020-survey-datastudent-enrollment.

American Association of Colleges of Nursing. (2021b). The essentials: Core competencies for professional nursing education. https://www.aacnnursing. org/Portals/42/AcademicNursing/pdf/Essentials-2021.pdf

American Association of Nurse Anesthesiology. (2021a, August 31). Certified registered nurse anesthetists fact sheet. https://www.aana.com/ membership/become-a-crna/crna-fact-sheet

American Association of Nurse Anesthesiology. (2021b, August 14). AANA announces major rebrand and moves forward as the American Association of Nurse Anesthesiology (News release). https://www.aana.com/ home/aana-updates/2021/08/14/aana-announces-major-rebrand-andmoves-forward-as-the-american-association-of-nurse-anesthesiology

American Association of Nurse Practitioners. (2021). Issues at-a-glance: Full practice authority. https://storage.aanp.org/www/documents/ practice/Full-Practice-Authority.pdf

American Medical Association. (2021a). Statement on AAPA change of 'physician assistant' title (Press release). https://www.ama-assn.org/presscenter/ama-statements/ statement-aapa-change-physician-assistant-title
American Medical Association. (2021b, November 12). Issue brief: Nation's drug-related overdose and death epidemic continues to worsen. AMA Advocacy Resource Center. https://www.ama-assn.org/ system/files/issue-brief-increases-in-opioid-related-overdose.pdf

American Nurses Association. (n.d.). Opioid epidemic: The evolving role of nursing. https://ana.aristotle.com/sitepages/Opioid.Epidemic.aspx

American Nurses Association. (2015). Code of ethics for nurses with interpretive statements. Nursebooks.org. https://www.nursingworld.org/ practice-policy/nursing-excellence/ethics/code-of-ethics-for-nurses/ coe-view-only/

American Nurses Association. (2021, September 1). Letter from ANA President to Department of Health and Human Services Secretary Becerra. https://www.nursingworld.org/ 4a49e2/globalassets/rssassets/analettertohhs_staffingconcerns_final-2021-09-01.pdf

American Society of Anesthesiologists. (2021, August 14). ASA position statement on AANA name change (Press release). https://www.asahq.org/ about-asa/newsroom/news-releases/2021/08/asa-condemns-aanasmisleading-name-change

Andrilla, C. H. A., Moore, T. E., Patterson, D. G., Larson, E. H. (2019). Geographic distribution of providers with a DEA waiver to prescribe buprenorphine for the treatment of opioid use disorder: A 5-year update. The Journal of Rural Health, 35(1), 108-112. https://doi. org/10.1111/jrh.12307

Appleby, J. (2021, August 26). Telehealth took off during the pandemic. Now, battles over state lines and licensing threaten patients' options. Time. https://time.com/6092635/telehealth-state-lines-licensing/

Arends, R., Gibson, N., Marckstadt, S., Birtson, V., Nissen, M. K., \& Voss, J. (2021, May 1). Enhancing the nurse practitioner curriculum to improve telehealth competency. Journal of the American Association of Nurse Practitioners, 33(5), 391-397. https://doi.org/10.1097/ jxx.0000000000000303

Ariz. S.B. 1824, 2021 Reg. Sess. (2021). https://apps.azleg.gov/BillStatus/ BillOverview/76145

Arnold, T. (2020, January 13). Virginia lawmaker introduces occupational license reciprocity bill. The Center Square. https://www. thecentersquare.com/virginia/virginia-lawmaker-introducesoccupational-license-reciprocity-bill/article_2ce3932e-3409-11eabf0e-ff84b1656554.html

Audiology \& Speech-Language Pathology Interstate Compact. (n.d.). Compact map. https://aslpcompact.com/compact-map/

Assistant Secretary for Preparedness and Response Technical Resources, Assistance Center, and Information Exchange. (2021, April 12). COVID-19 healthcare delivery impacts. https://files.asprtracie.hhs. gov/documents/covid-19-healthcare-delivery-impacts.pdf

Badowski, D., Rossler, K. L., \& Reiland, N. (2021). Exploring student perceptions of virtual simulation versus traditional clinical and manikin-based simulation. Journal of Professional Nursing, 37(4), 683-689. https://doi.org/10.1016/j.profnurs.2021.05.005

Baker, C., Cary, A. H., \& de Conceicao Bento, M. (2021). Global standards for professional nursing education: The time is now. Journal of Professional Nursing, 37(1), 86-92. https://doi.org/10.1016/j. profnurs.2020.10.001 
Baker, M., \& Heyward, G. (2021, September 16). Idaho allows overwhelmed hospitals across the state to ration care if necessary. The New York Times. https://www.nytimes.com/2021/09/16/us/idaho-covidhospitalizations.html

Balser, J., Ryu, J., Hood, M., Kaplan, G., Perlin, J., \& Siegel, B. (2021). Care systems COVID-19 impact assessment: Lessons learned and compelling needs. NAM Perspectives. National Academy of Medicine. https://doi.org/10.31478/202104d

Baumgartner, J. C. \& Radley, D. C. (2021, August 16). The drug overdose toll in 2020 and near-term actions for addressing it. The Commonwealth Fund. https://www.commonwealthfund.org/blog/2021/drugoverdose-toll-2020-and-near-term-actions-addressing-it

Bennett, M. P., Lovan, S., Smith, M., \& Ellis-Griffith, C. (2021). Nursing's leaky pipeline: Barriers to a diverse nursing workforce. Journal of Professional Nursing, 37(2), 441-450. https://doi.org/10.1016/j. profnurs.2020.05.002

Bestsennyy, O., Gilbert, G., Harris, A., \& Rost, J. (2021, July 9). Telehealth: A quarter-trillion-dollar post-COVID-19 reality? McKinsey $\mathcal{E}$ Company. https://www.mckinsey.com/industries/healthcare-systemsand-services/our-insights/telehealth-a-quarter-trillion-dollar-postcovid-19-reality\#

Billings, J., Ching, B. C. F., Gkofa, V., Greene, T., \& Bloomfield, M. (2021). Experiences of frontline healthcare workers and their views about support during COVID-19 and previous pandemics: A systematic review and qualitative meta-synthesis. BMC Health Services Research, 21. Article 923. https://doi.org/10.1186/s12913-02106917-z

Del. Admin. Code $24 \S 7.1$ (2021). https://regulations.delaware.gov/ AdminCode/title24/1900.shtml

Broome, M. E., Villarruel, A. M., \& Thompson, H. J. (2021). Innovations in Ph.D. education to prepare nurse scientists for the future. Journal of Professional Nursing, 37(1), 212-215. https://doi.org/10.1016/j. profnurs.2020.09.013

Brous, E. (2021). Crisis standards of care. American Journal of Nursing, 121(7), 51-54.

Burhans, L. D., Chastain, K., \& George, J. L. (2012). Just Culture and nursing regulation: Learning to improve patient safety. Journal of Nursing Regulation, 2(4), 43-49. https://doi.org/10.1016/S21558256(15)30254-4

Butcher, L. (2021, June 19). Is COVID-19 the tipping point for telemedicine? Smithsonian Magazine. https://www.smithsonianmag.com/ innovation/is-covid-19-tipping-point-for-telemedicine-180975131/

Calif. A.B. 1306, 2021-2022 Reg. Sess. (2021). https://leginfo.legislature. ca.gov/faces/billNavClient.xhtml?bill_id=202120220AB1306

Carpenter, T. (2020, February 7). Exemptions studied for criminal records in licensing. The Ottawa Herald. https://www.ottawaherald.com/ news/20200207/exemptions-studied-for-criminal-records-inlicensing

Cato, K. D., McGrow, K., \& Rosetti, S. C. (2020). Transforming clinical data into wisdom: Artificial intelligence implications for nurse leaders. Nursing Management, 51(11), 24-30. https://doi.org/10.1097/01. NUMA.0000719396.83518.d6

Center for Connected Health Policy. (2021, September 21). The role of funding in telehealth policy: Announcements, opportunities, and impacts. https://www.cchpca.org/resources/the-role-of-funding-intelehealth-policy-announcements-opportunities-and-impacts/
Centers for Disease Control and Prevention. (2020, December 17). Increase in fatal drug overdoses across the United States driven by synthetic opioids before and during the COVID-19 pandemic (Health Advisory). https://emergency.cdc.gov/han/2020/han00438. asp

Centers for Medicare and Medicaid Services. (2021, May 24). COVID-19 emergency declaration blanket waivers for health care providers. https:// www.cms.gov/files/document/summary-covid-19-emergencydeclaration-waivers.pdf

Chang, L.-Y., Yu, H.-H., \& Chao, Y.-F. C. (2019). The relationship between nursing workload, quality of care, and nursing payment in intensive care units. Journal of Nursing Research, 27(1), e8. https://oi. org/10.1097/jnr.0000000000000265

Chike-Harris, K. E., Garber, K., \& Derouin, A. (2021, July 8). Telehealth educational resources for graduate nurse faculty. Nurse Educator, 46(5), 295-299. https://doi.org/10.1097/NNE.0000000000001055

Combe, L. G. (2020). Reopening schools during COVID-19: School nurse ethical conflicts and moral dilemmas. NASN School Nurse, 35(6), 308-312. https://journals.sagepub.com/ doi/10.1177/1942602X20963522

Comprehensive Addiction and Recovery Act of 2016, S.B. 524, 114th Cong. (2016). https://www.congress.gov/bill/114th-congress/senatebill/524/text

Congresswoman Ann McLane Kuster. (2021, September 10). Kuster, Trone send letter to congressional leadership urging continued and increased funding to combat overdose crisis (Press release). https://kuster.house.gov/news/ documentsingle.aspx? DocumentID =3945

Cooper, J. (2021). An academic-practice partnership to Advance Million Hearts. Journal of Nursing Education, 60(2), 103-106. https://doi.org/ 10.3928/01484834-20210120-09

Coplan, B., Ritsema, T., \& Cawley, J. F. (2021). The PA title: Is a change the best way forward? Journal of the American Academy of Physician Assistants, 34(5), 16-17. https://doi.org/10.1097/01. JAA.0000742996.72926.32

Cos, T. A., Starbird, L. E., Lee, H., Chun, B., Gonnella, K., Bird, J., Livsey, K., Bastos, S., O’Brien, M., Clark, I., Jenkins, D., \& TavolaroRyley, L. (2021). Expanding access to nurse-managed medication for opioid use disorder. Nursing Outlook, 69(5), 848-855. https://doi.org/ 10.1016/j.outlook.2021.03.012

Counseling Compact. (n.d.). Map. https://counselingcompact.org/map/

Credentialing Resource Center. (2021, January 6). Nurse practitioners in Massachusetts granted full practice authority. healthleaders. https:// www.healthleadersmedia.com/nursing/nurse-practitionersmassachusetts-granted-full-practice-authority

Curl, E. D., Smith, S., Chisholm, L. A., McGee, L. A., \& Das, K. (2016). Effectiveness of integrated simulation and clinical experiences compared to traditional clinical experiences for nursing students. Nursing Education Perspectives, 37(2), 72-77. https://doi.org/10.5480/15-1647

Currie, J. M., Schnell, M. K., Schwandt, H., \& Zhang, J. (2021). Prescribing of opioid analgesics and buprenorphine for opioid use disorder during the COVID-19 pandemic. JAMA Network Open, 4(4), e216147-e216147. https://doi.org/10.1001/ jamanetworkopen.2021.6147

Cybersecurity and Infrastructure Security Agency \& United Kingdom's National Cyber Security Centre. (2020, April 8). Alert (AA20099A): COVID-19 exploited by malicious cyber actors. https:// us-cert.cisa.gov/ncas/alerts/aa20-099a 
Davis Jr, E. (2021, June 1). These states have banned vaccine passports. U.S. News $\mathcal{E}$ World Report. https://www.usnews.com/news/best-states/ articles/which-states-have-banned-vaccine-passports

DC Health. (2021). COVID-19 vaccination requirement. https://dchealth dc.gov/node/1556816

Drobac, K. Krista Drobac to Honorable Sherry Dorsey Walker. 2021. House Bill 21 \& House Bill 141. https://connectwithcare.org/ wp-content/uploads/2021/05/Alliance-for-Connected-Care-SupportLetter-DE-HB-21-and-HB-141.pdf

Drug Enforcement Administration. (n.d.). Mid-level practitioners authorization by state. https://www.deadiversion.usdoj.gov/drugreg/ practioners/index.html

Emergency Management Assistance Compact. (n.d.). What is EMAC? https://www.emacweb.org/index.php/learn-about-emac/what-is-emac

Emory, J., Kippenbrock, T., \& Buron, B. (2021). A national survey of the impact of COVID-19 on personal, academic, and work environments of nursing students. Nursing Outlook. Advance online publication. https://doi.org/10.1016/j.outlook.2021.06.014

Endicott, S. (2019, July 23). Time for full practice authority. University of Wisconsin-Madison School of Nursing. https://nursing.wisc.edu/ time-for-full-practice-authority/

Equal Access to Care Act, S. 3993, 116th Cong. (2020).

Evans, C. (2021, September 9). Letter to Senators Krawiec, Hise, Burgin, and Representatives White, Adcock, Cunningham, and Wheatley. https://www.ncmedsoc.org/wp-content/uploads/2021/09/BCBSNCSAVE-Act-Letter-final-002.pdf

Fang, D. \& Zhan, L. (2021) Completion and attrition of nursing PhD students of the 2001 to 2010 matriculating cohorts. Nursing Outlook, 69(3), 340-349. https://doi.org/10.1016/j.outlook.2020.12.014

Fang, D., Keyt, J. C., McFadden, T., \& Trautman, D. E. (2020). 20192020 Enrollment and graduations in baccalaureate and graduate programs in nursing. American Association of Colleges of Nursing.

Fang, D., Keyt, J. C., West, L. C., \& Trautman, D. E. (2021). 2020-2021 Enrollment and graduations in baccalaureate and graduate programs in nursing. American Association of Colleges of Nursing.

Farris, M. (2021, May 25). Bill would allow nurse practitioners to work without doctor oversight. $4 \mathrm{WWL}$. https://www.wwltv.com/article/ news/health/bill-would-allow-nurse-practitioners-to-work-withoutdoctor-oversight/289-e3d17d75-cab4-4ec2-b3f2-346d22028d12

Federation of State Medical Boards. (2021, July 29). FSMB: spreading covid-19 vaccine misinformation may put medical license at risk (News release). https://www.fsmb.org/advocacy/news-releases/fsmbspreading-covid-19-vaccine-misinformation-may-put-medicallicense-at-risk/

Feeg, V. D., Goberdhan, C. R., \& Mancino, D. J. (2021b). Trends in employment of new graduates when COVID-19 first impacted schools. Leader to Leader. https://www.ncsbn.org/15850.htm

Feeg, V., Mancino, D. J., Mooney, C., Catanese, S., \& Buonaguro, R. (2021a). The COVID-19 nursing student self-reported education and personal experiences during the early months of the pandemic. Deans Notes, 42(4), 1-7. https://www2.ajj.com/sites/default/files/ services/publishing/deansnotes/spring2021.pdf.

Feldscher, K. (2021, August 12). COVID's future: From pandemic to endemic? The Harvard Gazette. https://news.harvard.edu/gazette/ story/2021/08/what-will-it-be-like-when-covid-19-becomesendemicl
Foronda, C. L., Fernandez-Burgos, M., Nadeau, C., Kelley, C.N., \& Henry, M.N. (2020). Virtual simulation in nursing education: A systematic review spanning 1996 to 2018. Simulation in Healthcare, 15(1), $46-54$.

Fotsch, R. (2016). What's in a name? Legislative challenges with APRN title change. Journal of Nursing Regulation, 6(4), 73-74. https://doi. org/10.1016/S2155-8256(16)31006-7

Gebreheat, G., \& Teame, H. (2021). Ethical challenges of nurses in COVID-19 pandemic: Integrative review. Journal of Multidisciplinary Healthcare, 14, 1029-1035. https://doi.org/10.2147/JMDH.S308758

Gilliss, C. L., Poe, T., Hogan, T. H., Intinarelli, G., \& Harper, D. C. (2021). Academic/clinical nursing integration in academic health systems. Nursing Outlook, 69(2), 234-242.

Goni-Fuste, B., Wennberg, L., Martin-Delgado, L., Alfonso-Arias, C., Martin-Ferreres, M.L., \& Monforte-Royo, C. (2021). Experiences and needs of nursing students during pandemic outbreaks: A systematic overview of the literature. Journal of Professional Nursing, 37(1), 53-64. https://doi.org/10.1016/j.profnurs.2020.12.004.

Goodnough, A. (2021, April 14). Overdose deaths have surged during the pandemic, C.D.C. data shows. The New York Times. https://www. nytimes.com/2021/04/14/health/overdose-deaths-fentanyl-opiodscoronaviurs-pandemic.html

Governor's Press Office. (2021, January 1). Governor Baker signs health care legislation increasing access to quality, affordable care, promoting telehealth and protecting access to COVID-19 testing, treatment (Press release). https://www.mass.gov/news/governor-baker-signs-health-carelegislation-increasing-access-to-quality-affordable-care

Graber, M. L., \& Schrandt, S. (2021). Improving telediagnosis: A call to action. Final project findings. Society to Improve Diagnosis in Medicine. https://www.improvediagnosis.org/wp-content/uploads/2021/08/ Final-Project-Findings-TeleDx.pdf

Graham, C. (2021, March 30). Ready for duty: health care robots get good prognosis for next pandemic. The Hub. https://hub.jhu. edu/2021/03/30/robots-in-health-care-settings-challengesadvantages/

Haerling (Adamson), K., \& Prion, S. (2021). Questions regarding substitution of simulation for clinical. Clinical Simulation in Nursing, 50, 79-80. https://doi.org/10.1016/j.ecns.2020.06.014.

Haslam, M. B. (2021). What might COVID-19 have taught us about the delivery of Nurse Education, in a post-COVID-19 world?. Nurse Education Today, 97, 104707.

Hayden, J. K., Smiley, R. A., Alexander, M., Kardong-Edgren, S., \& Jeffries, P. R. (2014). The NCSBN national simulation study: A longitudinal, randomized controlled study replacing clinical hours with simulation in prelicensure nursing education. Journal of Nursing Regulation, 5(2 Suppl.), S1-S64.

Health Resources and Services Administration. (2010). The registered nurse population: Findings from the 2008 National Sample Survey of Registered Nurses. https://campaignforaction.org/wp-content/ uploads/2016/06/RN_Population.pdf

Henderson, J. (2021, August 16). Rebrand of nurse anesthetists met with criticism from physician group. https://www.medpagetoday.com/ special-reports/exclusives/94062

Hentze, I., \& Herman, Z. (2021, March 19). State efforts to improve occupational licensing mobility. National Conference of State Legislatures. https://www.ncsl.org/research/labor-and-employment/state-effortsto-improve-occupational-licensing-mobility.aspx 
Hill, S., \& Albert, N. M. (2021). Understanding the experiences of African American nursing students. Journal of Nursing Education, 60(3), 150-154. https://doi.org/10.3928/01484834-20210222-05

Hinton, M. J. (2021, March 5). Congratulations Utah NPs! HB 287 just passed the final vote! Utah Nurse Practitioners. https://utahnp. enpnetwork.com/nurse-practitioner-news/212899-congratulationsutah-nps-hb-287-just-passed-the-final-vote-

Honig, J., Stone, P. W., Vose, C., Prado-Inzerillo, M., \& Frazier, L. (2021). A clinical and academic partnership: An exemplar from the COVID eipicenter. Journal of Professional Nursing, 37(2), 241-243. https://doi. org/10.1016/j.profnurs.2020.12.008

Hooker, M., DeLaurentis, A., Klein, S., \& Kurtyka, J. (2021). Fraud emerges as telehealth surges. The White Collar Crime Committee Newsletter. https://www.americanbar.org/content/dam/aba/publications/ criminaljustice/2021/telehealth_fraud.pdf

Hughes, S. (2021, September 27). AHA urges CMS to ensure its mandatory vaccine rule is feasible, fair. https://www.aha.org/2021-09-27aha-urges-cms-ensure-its-mandatory-vaccination-rule-feasible-fair

Iheduru-Anderson, K. C. (2021). The White/Black hierarchy institutionalizes white supremacy in nursing and nursing leadership in the United States. Journal of Professional Nursing, 37(2), 411-421. https:// doi.org/10.1016/j.profnurs.2020.05.005

Institute of Medicine. (2011). Future of nursing: Leading change, advancing bealth. The National Academies Press. https://www.nap.edu/ catalog/12956/the-future-ofnursing-leading-change-advancinghealth

International Council of Nurses. (2021). The global nursing shortage and nurse retention (Policy brief). https://www.icn.ch/sites/default/files/ inline-files/ICN\%20Policy\%20Brief_Nurse\%20Shortage $\% 20$ and\%20Retention_0.pdf

Interstate Commission for EMS Personnel Practice. (n.d.). States \& commissioners. https://www.emscompact.gov/the-commission/ commissioners

Interstate Medical Licensure Compact. (n.d.). Participating states. https:// www.imlcc.org/participating-states/

Jago, R., van der Gaag, A., Stathis, K., Petej, I., Lertvittayakumjorn, P., Krishnamurthy, Y., Gao, Y., Caceres Silva, J., Webster, M., Gallagher, A., Austin, Z. (2021). Use of artificial intelligence in regulatory decision-making. Journal of Nursing Regulation, 12(3), 11-19. https://doi.org/10.1016/S2155-8256(21)00112-5

Jo, S., Kurt, S., Bennett, J. A., Mayer, K., Pituch, K. A., Simpson, V., Skibiski, J., Takagi, E., Karaaslan, M. M., Ozluk, B., \& Reifsnider, E. (2021). Nurses' resilience in the face of coronavirus (COVID-19): An international view. Nursing E Health Sciences, 23(3), 646-657.

Johns Hopkins University. (2020, August 12). JHU robotic system remotely controls ventilators in COVID-19 patient rooms. https:// releases.jhu.edu/2020/08/12/jhu-robotic-system-remotely-controlsventilators-in-covid-19-patient-rooms/

Kansas State Board of Nursing. (2021, May 14). Monthly update. https:// ksbn.kansas.gov/wp-content/uploads/2021/05/KSBN-MonthlyUpdate-5-14-2021.pdf

Kittredge, B. (2021, March 4). Full practice authority for nurse practitioners died. The need remains. Empower Mississippi. https://empowerms. org/full-practice-authority-for-nurse-practitioners-died-the-needremains/
Kornfield, M., \& Timsit, A. (2021, October 16). Vaccine mandates stoked fears of labor shortages. But hospitals say they're working. The Washington Post. https://www.washingtonpost.com/health/2021/10/16/ hospital-covid-vaccine-mandate/

Krass, M., Henderson, P., Mello, M. M., Studdert, D. M., \& Ho, D. E. (2021). How US law will evaluate artificial intelligence for covid-19. BMJ, 372, n234. https://doi.org/10.1136/bmj.n234

Ky. Gen. Assemb. H. J. Res. 1, 2021 Spec. Sess. (2021). https://apps. legislature.ky.gov/recorddocuments/bill/21SS/hjr1/bill.pdf

La. Proclamation No. 168 JBE 2021. (2021, August 31). https://gov. louisiana.gov/assets/Proclamations/2021/168JBE2021StateofEmerge ncyCOVIDSigned.pdf

Leighton, K., Kardong-Edgren, S., McNelis, A. M., Foisy-Doll, C., \& Sullo, E. (2021). Traditional clinical outcomes in prelicensure nursing education: An empty systematic review. Journal of Nursing Education, 60(3), 136-142. https://doi. org/10.3928/01484834-20210222-03

Lewis, L., Biederman, D., Hatch, D., Li, A., Turner, K., \& Molloy, M. A. (2021). Outcomes of a holistic admissions process in an accelerated baccalaureate nursing program. Journal of Professional Nursing, 37(4), 714-720. https://doi.org/10.1016/j.profnurs.2021.05.006

Lomis, K., Jeffries, P., Palatta, A., Sage, M., Sheikh, J., Sheperis, C., \& Whelan, A. (2021, September 8). Artificial intelligence for health professions educators. NAM Perspectives. Discussion Paper, National Academy of Medicine. https://doi.org/10.31478/202109a

Lund, S., Madgavkar, A., Manyika, J., Smit, S., Eilingrud, K., \& Robinson, O. (2021, February 18). The future of work after COVID-19. McKinsey Global Institute. https://www.mckinsey.com/featuredinsights/future-of-work/the-future-of-work-after-covid-19

Margus, C., Sarin, R. R., Molloy, M., \& Ciottone, G. R. (2020). Crisis standards of care implementation at the state level in the United States. Prehospital and Disaster Medicine, 35(6), 599-603. https://doi. org/10.1017/S1049023X20001089

Martin, B., \& Alexander, M. (2019). The economic burden and practice restrictions associated with collaborative practice agreements: A national survey of advanced practice registered nurses. Journal of Nursing Regulation, 9(4), 22-40. https://doi.org/10.1016/S21558256(19)30012-2

Martin, B., \& Reneau, K. (2021). Evaluating the adverse event decision pathway: A survey of Canadian nursing leaders. Journal of Nursing Regulation, 12(1), 71-77. https://doi.org/10.1016/S21558256(21)00020-X

Martin, B., Reneau, K., \& Jarosz, L. (2018). Patient safety culture and barriers to adverse event reporting: A national survey of nurse executives. Journal of Nursing Regulation, 9(2), 9-17. https://doi. org/10.1016/S2155-8256(18)30113-3

Mass. S.B. 2472, 192nd Gen. Court (2021a). https://malegislature.gov/ Bills/192/S2472

Mass. S.B. 2475, 192nd Gen. Court (2021b). https://malegislature.gov/ Bills/192/S2475

Masters, K. (2020, April 13). Nurse practitioners say supervision requirements are a hindrance amid COVID-19 pandemic. Virginia Mercury. https://www.virginiamercury.com/2020/04/13/nurse-practitionerssay-supervising-requirements-are-becoming-a-problem-amid-covid19-pandemic/ 
McFadden, T., Keyt, J., \& Fang, D. (2021). Special survey on vacant faculty positions for academic year 2021-2022. https://www.aacnnursing.org/ Portals/42/News/Surveys-Data/2021-Faculty-Vacancy-Report.pdf

Melnyk, B. M., Tan, A., Hsieh, A. P., Gawlik, K., Arslanian-Engoren, C., Braun, L. T., Dunbar, S., Dunbar-Jacob, J., Lewis, L. M., Millan, A., Orsolini, L., Robbins, L. B., Russell, C. L., Tucker, S., \& Wilbur, J. (2021). Critical care nurses' physical and mental health, worksite wellness support, and medical errors. American Journal of Critical Care, 30(3), 176-184. https://doi.org/10.4037/ajcc2021301

Michel, A., Ryan, N., Mattheus, D., Knopf, A., Abuelezam, N. N., Stamp, K., Branson, S., Hekel, B., \& Fontenot, H.B. (2021). Undergraduate nursing students' perceptions on nursing education during the 2020 COVID-19 pandemic: A national sample. Nursing Outlook, 69(5), 903-912. https://doi.org/10.1016/j.outlook.2021.05.004

Mich. H.B. 4376 (2021). http://legislature.mi.gov/doc. aspx?2021-HB-4376

Mich. H.B. 4377 (2021). http://legislature.mi.gov/doc. aspx?2021-HB-4377

Mich. S.B. 157 (2021). http://legislature.mi.gov/doc.aspx?2021-SB-0157

Mich. S.B. 312 (2021). http://legislature.mi.gov/doc.aspx?2021-SB-0312

Michigan.gov. (2021, June 9). Governor Whitmer signs bipartisan bills helping veterans and their families continue their careers in Michigan, accelerating Michigan's economic recovery (Press release). https://www.michigan.gov/ whitmer/0,9309,7-387-90499-561538--,00.html

Mixer, S. J., Beebe, L. H., Elliott, L. M., Turley, D., Craig, J., Chelko, M., \& McCoig, C. (2021). Transforming RN roles in using and academic-practice partnership to improve healthcare access for underserved populations. Journal of Professional Nursing, 37(2), 459-466. http://doi.org/10.1016/j.profnurs.2020.06.006

Molina, M. F., Cash, R. E., Carreras-Tartak, J., Ciccolo, G., Petersen, J., Mecklai, K., Rodriguez, G., Castilla-Ojo, N., Boms, O., Velasquez, D., Macias-Konstantopoulos, W., Camargo, C. A., \& Samuels-Kalow, M. (2021). Applying crisis standards of care to critically ill patients during the COVID-19 pandemic: Does race/ethnicity affect triage scoring? Journal of the American College of Emergency Physicians Open, 2(4), 1-12. https://doi.org/10.1002/emp2.12502

Morgantini, L. A., Naha, U., Wang, H., Francavilla, S., Acar, Ö., Flores, J. M., Crivellaro, S., Moreira, D., Abern, M., Eklund, M., Vigneswaran, H. T., \& Weine, S. M. (2020). Factors contributing to healthcare professional burnout during the COVID-19 pandemic: A rapid turnaround global survey. PLOS ONE, 15(9). Article e0238217. https:// doi.org/10.1371/journal.pone.0238217

Morin, K. H. (2020). Nursing education after COVID-19: Same or different?. Journal of clinical nursing.

Morley, G., Grady, C., McCarthy, J., \& Ulrich, C. M. (2020). Covid-19: Ethical challenges for nurses. The Hastings Center Report, 50(3), 35-39. https://doi.org/10.1002/hast.1110

Morris, N. S., Wassef, M. E., Sullivan-Bolyai, S., Bova, C., \& Kane, A. T. (2021). Making explicit the development of PhD-prepared nurses to steward the discipline. Nursing Outlook, 69(1), 50-56. https://doi. org/10.1016/j.outlook.2020.08.002

Morrison, V., Hauch, R. R., Perez, E., Bates, M., Sepe, P., \& Dans, M. (2021). Diversity, equity, and inclusion in nursing: The Pathway to Excellence framework alignment. Nursing Administration Quarterly, 45(4), 311-323. https://doi.org/10.1097/NAQ.0000000000000494
Mullangi, S., Agrawal, M., \& Schulman, K. (2021). The COVID-19 pandemic-An opportune time to update medical licensing. JAMA Internal Medicine, 181(3), 307-308. https://doi.org/10.1001/ jamainternmed.2020.8710

Munn, L. T., Liu, T.-L., Swick, M., Rose, R., Broyhill, B., New, L., \& Gibbs, M. (2021). Well-being and resilience among health care workers during the COVID-19 pandemic: A cross-sectional study. American Journal of Nursing, 121(8), 24-34.

Muoio, D. (2021, November 23). How many employees have hospitals lost to vaccine mandates? Here are the numbers so far. Fierce Helathcare. https://www.fiercehealthcare.com/hospitals/how-manyemployees-have-hospitals-lost-to-vaccine-mandates-numbers-so-far

Murphy, C. (2020, August 4). Murphy, Blunt introduce legislation to allow bealth care professionals to render services anywhere throughout covid-19 pandemic (Press release). https://www.murphy.senate.gov/newsroom/ press-releases/murphy-blunt-introduce-legislation-to-allow-healthcare-professionals-to-render-services-anywhere-throughout-covid-19pandemic-

Loveless, T. (2021, March 18). Why common core failed. Brown Center Chalkboard. https://www.brookings.edu/blog/brown-centerchalkboard/2021/03/18/why-common-core-failed/

N.Y. Exec. Order No. 210. (2021, June 24). https://www.governor.ny.gov/ sites/default/files/2021-06/EO_210.pdf

National Academies of Sciences, Engineering, and Medicine. (2021). Lessons learned in health professions education during the COVID-19 pandemic, part 1: Proceedings of a workshop. The National Academies Press. https://doi.org/10.17226/26210

National Academies of Sciences, Engineering, and Medicine. (2021). The future of nursing 2020-2030: Charting a path to achieve health equity. The National Academies Press. https://doi. org/10.17226/25982

National Center for Health Statistics. (2021, September 5). Vital statistics rapid release: provisional drug overdose death counts. https://www. cdc.gov/nchs/nvss/vsrr/drug-overdose-data.htm

National Center for Health Workforce Analysis. (2021). Projections of supply and demand for women's health service providers: 2018-2030. U.S. Department of Health and Human Services. https://bhw.hrsa.gov/ sites/default/files/bureau-health-workforce/data-research/projectionssupply-demand-2018-2030.pdf

National Council of State Boards of Nursing. (n.d.). APRN Compact supporters across the U.S. https://aprncompact.com/index.htm

National Council of State Boards of Nursing. (2019). Report of findings from the 2018 LPN/VN nursing knowledge survey. NCSBN Research Brief, 76. https://www.ncsbn.org/LPN_Practice_Analysis_FINAL. pdf

National Council of State Boards of Nursing. (2020). U.S. nursing leadership supports practicelacademic partnerships to assist the nursing workforce during the COVID-19 crisis (Policy brief). https://www.ncsbn.org/ PolicyBrief_US_Nursing_Leadership_COVID19_updated.pdf

National Council of State Boards of Nursing. (2021a). National Nursing Database. https://www.ncsbn.org/national-nursing-database.htm

National Council of State Boards of Nursing. (2021b). NCLEX pass rates (2018, 2019, 2020, 2021) [Data set]. https://www.ncsbn.org/1237. htm 
National Council of State Boards of Nursing. (2021c, September 27). Clinical experiences for unvaccinated nursing students (Policy Brief). https://www.ncsbn.org/PolicyBriefUnvaccinatedNursingStudents. pdf

National Council of State Boards of Nursing. (2021d). Nurse licensure and NCLEX exam statistics (2003-2020) [Data set]. https://www. ncsbn.org/1236.htm

National Council of State Boards of Nursing. (2021e, November 16.) Dissemination of non-scientific and misleading COVID-19 information by nurses (Policy statement). https://www.ncsbn.org/PolicyBriefDiss eminationofCOVID19Info.pdf

National Council of State Boards of Nursing. (2021f, October 13). State response to COVID-19. https://www.ncsbn.org/State_COVID-19_ Response.pdf

National Council of State Boards of Nursing. (2021h). APRN Consensus Model by state. https://www.ncsbn.org/APRN_Consensus_Grid_ August2021-8.18.21.pdf

National Council of State Boards of Nursing. (2021i). NursingAmerica. https://nursingamerica.org/

National Council of State Boards of Nursing. (In Press). Report of findings from the $2021 \mathrm{LPN} / \mathrm{VN}$ nursing knowledge survey. NCSBN Research Brief.

National Military Family Association. (n.d.). Relicensing is a barrier for working military spouses. https://www.militaryfamily.org/licensingcertification/

National Organization of Nurse Practitioner Faculties. (2016). Criteria for Evaluation of Nurse Practitioner Education Programs, 5th edition: A Report on the National Task Force on Quality Nurse Practitioner Education. https://cdn.ymaws.com/www.nonpf.org/resource/resmgr/Docs/ EvalCriteria2016Final.pdf

National Organization of Nurse Practitioner Faculties. (In press). Criteria for Evaluation of Nurse Practitioner Education Programs, 6th edition. https://cdn.ymaws.com/www.nonpf.org/resource/resmgr/Docs/ EvalCriteria2016Final.pdf

National Student Nurses' Association. (2021, August 16). Survey of vaccination status July 1-August 15th for nursing students, faculty and new graduates reveals unexpected results (Press release). https://www.nsna.org/ uploads/2/2/4/5/22459246/national_student_nurses_press_ release_-_report_of_july_2021_survey_of_vaccination_rates_-_final. pdf

N.C. S.B. 249, 2021 Reg. Sess. (2021). https://www.ncleg.gov/ Sessions/2021/Bills/Senate/PDF/S249v0.pdf

N.D. H.B. 1044, 2021 Reg. Sess. (2021). https://www.legis.nd.gov/ assembly/67-2021/documents/21-8003-02000.pdf

N.H. H.B. 220, 2021 Reg. Sess. (2021). https://legiscan.com/NH/bill/ HB220/2021

Neb. L.B. 390, 2021 Reg. Sess. (2021). https://nebraskalegislature.gov/ bills/view_bill.php? DocumentID=43999

New Hampshire Board of Nursing. (2018). Position statement regarding the use of Nurse Anesthesiologist as a communication tool and optional descriptor for certified registered nurse anesthetists. https:// static1.squarespace.com/ static/5bf069ef3e2d09d0f4e0a54f/t/5f6f8a708d2cb23bb10f 50a0/1601145457231/ $\mathrm{NH}+\mathrm{BON}+\mathrm{NURSE}+\mathrm{ANESTHESIOLOGIST}$.pdf
New Hampshire Supreme Court. (2021, March 9). In re petition of New Hampshire Association of Nurse Anesthetists (Case no. 2019-0716). https://www.courts.state.nh.us/supreme/finalorders/2021/20190716. pdf

Nguyen, J., Liu, A., McKenney, M., Liu, H., Ang, D., \& Elkbuli, A. (2021). Impacts and challenges of the COVID-19 pandemic on emergency medicine physicians in the United States. The American Journal of Emergency Medicine, 48, 38-47. https://doi.org/10.1016/j. ajem.2021.03.088

Nundy, S. (2021, May 12). A surprising pandemic side effect: it has improved health care. The Washington Post. https://www. washingtonpost.com/outlook/health-care-covid-diabeteshome/2021/05/12/ae298558-b26e-11eb-ab43-bebddc5a0f65_story. html

O'Kane, M., Agrawal, D., Binder, L., Dzau, V., Gandhi, T. K., Harrington, R., Mate, L., McGann, P., Meyers, D., Rosen, P., Schreiber, M., \& Schummers, D. (2021). An equity agenda for the field of health care quality improvement. NAM Perspectives. National Academy of Medicine. https://doi.org/10.31478/202109b

O'Reilly-Jacob, M., \& Perloff, J. (2021). The effect of supervision waivers on practice: A survey of Massachusetts nurse practitioners during the COVID-19 pandemic. Medical Care, 59(4), 283-287. https:// journals.lww.com/lww-medicalcare/fulltext/2021/04000/the_effect_ of_supervision_waivers_on_practice_a.2.aspx

Occupational Therapy Licensure Compact. (n.d.). Occupational Therapy Licensure Compact: Compact map. https://otcompact.org/compactmap/

Office for Civil Rights. (2021, January 20). Notification of enforcement discretion for telehealth remote communications during the COVID19 nationwide public health emergency. HHS.gov. https://www.hhs. gov/hipaa/for-professionals/special-topics/emergency-preparedness/ notification-enforcement-discretion-telehealth/index.html

Olson, L. L., \& Stokes, F. (2016). The ANA Code of Ethics for nurses with interpretive statements: Resource for nursing regulation. Journal of Nursing Regulation, 7(2), 9-20. https://doi.org/10.1016/S21558256(16)31073-0

Oregon Board of Nursing. (2021, October 13). Board meeting minutes. https://www.oregon.gov/osbn/Documents/Minutes_2021_October. pdf

Patel, K. R. (2021, March 17). "Tele-triage": The COVID-19 crisis's transformation of emergency care and potential post-pandemic opportunities. Proskauer. https://www.healthcarelawbrief. com/2021/03/tele-triage-the-covid-19-crisiss-transformation-ofemergency-care-and-potential-post-pandemic-opportunities/

Peterson, M. N., \& Slabinski, M. (2020, February 7). The burden of occupational licensing on everyday Americans. American Legislative Exchange Council. https://www.alec.org/article/the-burden-ofoccupational-licensing-on-everyday-americans/

Pfenning, S. (2021). North Dakota Board of Nursing testimony. https:/ www.legis.nd.gov/assembly/67-2021/testimony/SHUMSER-104420210216-6637-F-PFENNING_STACEY.pdf

Physical Therapy Compact. (n.d.). Compact map. http://ptcompact.org/ ptc-states

Poghosyan, L. (2021, March 9). We trusted nurse practitioners to handle a pandemic. Why not regular care? Niskanen Center. https://www. niskanencenter.org/we-trusted-nurse-practitioners-to-handle-apandemic-why-not-regular-care/ 
Psychology Interjurisdictional Compact. (n.d.). PSYPACT Map. https:// psypact.org/page/psypactmap

Puzantian, H., \& Darwish, H. (2021). Redesigning a PhD measurement course for a new era in nursing science. Journal of Professional Nursing, 37(2), 387-390. https://doi.org/10.1016/j.profnurs.2020.04.019

Quinn, W. (2021, August 5). Delaware becomes 24th state to recognize full practice authority for APRNs. Campaign for Action. https:// campaignforaction.org/delaware-recognizes-aprn-full-practiceauthority/

Reed, A. (2021a, November 1). Health-care worker vaccine mandate rule OK'd for publication. Bloomberg Law. https://news.bloomberglaw. $\mathrm{com} /$ health-law-and-business/health-care-worker-vaccine-mandaterule-okd-for-publication-4

Reed, A. (2021b, August 24). Covid vaccine mandates at hospitals to soar on Pfizer approval. Bloomberg Law. https://news.bloomberglaw.com/ health-law-and-business/covid-vaccine-mandates-at-hospitals-tosoar-on-pfizer-approval

Registered Nursing, 51 D.C.R. $8613 \S 17-5416$ (2004). https://dcregs. dc.gov/Common/DCMR/SectionList.aspx?SectionNumber=17-5416

Relias Media. (2021, April 1). CMS report confirms need for CRNAs. Same-Day Surgery. https://www.reliasmedia.com/articles/147677cms-report-confirms-need-for-crnas

Robertson, B., McDermott, C., Star, J., \& Clevenger, C. K. (2021). The academic-practice partnership: Educating future nurses. Nursing Administration Quarterly, 45(4), E1-E11. https://doi.org/10.1097/ NAQ.0000000000000487

Russell, K. (2016). Due process and right-touch regulation strengthen regulatory decision making. Journal of Nursing Regulation, 7(2), 39-42. https://doi.org/10.1016/S2155-8256(16)31077-8

Rutledge, C. M., O’Rourke, J., Mason, A. M., Chike-Harris, K., Behnke, L., Melhado, L., Downes, L., \& Gustin, T. (2021, January 19). Telehealth competencies for nursing education and practice: The four P's of telehealth. Nurse Educator, 46(5), 300-305. https://doi. org/10.1097/NNE.0000000000000988

Sansom, C. M. (2017). Creating a complaint resolution analysis for professional accountability and public protection. Journal of Nursing Regulation, 8(1), 38-45. https://doi.org/10.1016/S2155-8256(17)30073-X

Scott, J. (2021, July 30). How telemedicine requirements and policies will change post-pandemic. HealthTech Magazine. https:// healthtechmagazine.net/article/2021/07/how-telemedicinerequirements-and-policies-will-change-post-pandemic-perfon

Severance-Medaris, C. (2021, July 12). The other epidemic: COVID-19 and opioid overdose. https://www.ncsl.org/research/health/the-otherepidemic-covid-19-and-opioid-overdose-magazine2021.aspx

Sherman, L. (2021, April 4). 100 NC lawmakers signed onto a health care bill. Then donors started calling. News Observer. https://www. newsobserver.com/news/politics-government/article250287935.html

Shrank, W. H., DeParle, N.-A, Gottlieb, S., Jain, S. H., Orszag, P., Powers, B. W., \& Wilensky, G. R. (2021). Health costs and financing: Challenges and strategies for a new administration. Health Affairs, 40(20), 235-242. https://doi.org/10.1377/hlthaff.2020.01560
Sitammagari, K., Murphy, S., Kowalkowski, M., Chou, S.-H., Sullivan, M., Taylor, S., Kearns, J., Batchelor, T., Rivet, C., Hole, C., Hinson, T., McCreary, P., Brown, R., Dunn, T., Neuwirth, Z., \& McWilliams, A. (2021). Insights from rapid deployment of a "virtual hospital" as standard care during the COVID-19 pandemic. Annals of Internal Medicine, 174(2), 192-199. https://www.acpjournals.org/doi/ pdf/10.7326/M20-4076

Smiley, R. A., Lauer, P., Bienemy, C., Berg, J. G., Shireman, E., Reneau, K. A., \& Alexander, M. (2018). The 2017 national nursing workforce survey. Journal of Nursing Regulation, 9(3), S1-S88.

Smiley, R. A., Ruttinger, C., Oliveira, C. M., Hudson, L. R., Allgeyer, R., Reneau, K. A., Silvestre, J. H., \& Alexander, M. (2021). The 2020 National Nursing Workforce Survey. Journal of Nursing Regulation, 12(1), S1-S96. https://doi.org/10.1016/S2155-8256(21)00027-2

Smith, S. M., Buckner, M., Jessee, M. A., Robbins, V., Horst, T., \& Ivory, C. H. (2021). Impact of COVID-19 on new graduate nurses' transition to practice: Loss or gain? Nurse Educator, 46(4), 209-214. https:// doi.org/10.1097/NNE.0000000000001042

Spector, N., Buck, M., \& Phipps, S. (2021). A novel framework for practice-academic partnerships during the pandemic — and into the future. American Journal of Nursing, 121(12), 53-58.

Spector, N., Silvestre, J., Alexander, M., Martin, B. Hooper, J. I., Squires, A., \& Oiemeni, M. (2020). NCSBN regulatory guidelines and evidence-based quality indicators for nursing education programs. Journal of Nursing Regulation, 11(2 Suppl.), S1-S64. https://doi. org/10.1016/S2155-8256(20)30075-2

Spetz, J., Chapman, S., Tierney, M., Phoenix, B., \& Hailer, L. (2021). Barriers and facilitators of advanced practice registered nurse participation in medication treatment for opioid use disorder: A mixed methods study. Journal of Nursing Regulation, 12(2), 5-22.

State of Oregon Newsroom. (2021, August 19). Governor Kate Brown announces two new vaccination measures to address hospital crisis, keep students safe (Media Release). https://www.oregon.gov/newsroom/pages/ NewsDetail.aspx? newsid $=64283$

Stocking, J. C., Sandrock, C., Fitall, E., Hall, K. K., \& Gale, B. (2021). AHRQ PSNet Annual Perspective: Impact of the COVID-19 pandemic on patient safety. https://psnet.ahrq.gov/perspective/ahrq-psnet-annualperspective-impact-covid-19-pandemic-patient-safety

Stringer, K. L., Langdon, K. J., McKenzie, M., Brockmann, B., \& Marotta, P. (2021). Leveraging COVID-19 to sustain regulatory flexibility in the treatment of opioid use disorder. Journal of Substance Abuse Treatment, 123. Article 108263. http://doi.org/10.1016/j. jsat.2020.108263

Su, H., Di Lallo, A., Murphy, R. R., Taylor, R. H., Garibaldi, B. T., \& Krieger, A. (2021). Physical human-robot interaction for clinical care in infectious environments. Nature Machine Intelligence, 3(3), 184-186. https://www.nature.com/articles/s42256-021-00324-z

Substance Abuse and Mental Health Services Administration. (2020, April 21). FAQs: Provision of methadone and buprenorphine for the treatment of opioid use disorder in the COVID-19 emergency. https://www.samhsa.gov/sites/default/files/faqs-for-oud-prescribingand-dispensing.pdf

Substance Abuse and Mental Health Services Administration. (2021a, May 14). Buprenorphine. https://www.samhsa.gov/medicationassisted-treatment/medications-counseling-related-conditions/ buprenorphine 
Substance Abuse and Mental Health Services Administration. (2021b, November 18). Medication assisted treatment (MAT): Statues, regulations and guidelines. https://www.samhsa.gov/medication-assistedtreatment/statutes-regulations-guidelines

Substance Use-Disorder Prevention that Promotes Opioid Recovery and Treatment for Patients and Communities Act (SUPPORT), H.R. 6, 115th Cong. (2018). https://www.congress.gov/bill/115th-congress/ house-bill/6.

Sullivan, N., Swoboda, S. M., Breymier, T., Lucas, L., Sarasnick, J., Rutherford-Hemming, T., ... \& Kardong-Edgren, S. S. (2019). Emerging evidence toward a 2: 1 clinical to simulation ratio: a study comparing the traditional clinical and simulation settings. Clinical Simulation in Nursing, 30, 34-41.

Sümen, A., \& Adibelli, D. (2021). Nursing students' readiness and coping strategies for the Covid-19 pandemic in Turkey. Journal of Professional Nursing, 37(3), 553-561. https://doi.org/10.1016/j. profnurs.2021.03.005.

Svorny, S., \& Cannon, M. F. (2020, August 4). Health care workforce reform: COVID-19 spotlights need for changes to clinician licensing. CATO Institute. https://www.cato.org/policy-analysis/health-careworkforce-reform-covid-19-spotlights-need-changes-clinicianlicensing

Taylor, M. A., Kepner, S., Gardner, L. A., \& Jones, R. (2020). Patient safety concerns in COVID-19-related events: A study of 343 event reports from 71 hospitals in Pennsylvania. Patient Safety, 2(2), 16-27. https://doi.org/10.33940/data/2020.6.3

Tejos, R., Navia, A., Cuadra, A., Fernandez-Diaz, O. F., \& Berner, J. E. (2020). Avoiding a second wave of medical errors: The importance of human factors in the context of a pandemic. Aesthetic Plastic Surgery, 44(5), 1926-1928. https://doi.org/10.1007/s00266-020-01868-y

Temporary Reciprocity to Ensure Access to Treatment Act, H.R. 8283 , 116th Cong. (2020)

Temporary Reciprocity to Ensure Access to Treatment Act, S.4421, 116th Cong. (2020).

Tenn. Gen. Assemb., H.B. 1353 (2021). https://wapp.capitol.tn.gov/apps/ BillInfo/Default.aspx?BillNumber $=$ HB1353

Tycko \& Zavareei Whistleblower Practice Group. (2021, April 27). The United States Department of Justice scores another victory exposing telemedicine fraud in an ongoing mission to protect the integrity of healthcare programs and save taxpayers billions. National Law Review, XI(117). https://www.natlawreview.com/article/united-statesdepartment-justice-scores-another-victory-exposing-telemedicinefraud

U.S. Bureau of Labor Statistics. (2021a, March 31). Occupational employment and wage statistics. http://www.bls.gov/oes/oes_emp.htm

U.S. Bureau of Labor Statistics. (2021b, September 15). Occupational outlook handbook. https://www.bls.gov/ooh/

U.S. Bureau of Labor Statistics. (2021c). Nurse anesthetists, nurse midwives, and nurse practitioners. Occupational Outlook Handbook. https:// www.bls.gov/ooh/healthcare/nurse-anesthetists-nurse-midwives-andnurse-practitioners.htm

U.S. Bureau of Labor Statistics. (2021d). Occupational employment and wages, May 2020: 29-1171 Nurse practitioners. https://www.bls. gov/oes/current/oes291171.htm
U.S. Bureau of Labor Statistics. (2021e). Occupational employment and wages, May 2020: 29-1161 Nurse midwives. https://www.bls.gov/ oes/current/oes291161.htm

U.S. Bureau of Labor Statistics. (2021f). Occupational employment and wages, May 2020: 29-1151 Nurse anesthetists. https://www.bls.gov/ oes/current/oes291151.htm

U.S. Census Bureau. (2020). 2019 American community survey singleyear estimates. https://www.census.gov/newsroom/press-kits/2020/ acs-1year.html

U.S. Census Bureau. (2021). 2020 population and housing data. https:// www.census.gov/library/visualizations/interactive/2020-populationand-housing-state-data.html

U.S. Department of Defense. (2021, March 15). DOD receives approval for grants to develop interstate compacts for licensure portability (News release). https://www.defense.gov/Newsroom/Releases/Release/ Article/2537098/dod-receives-approval-for-grants-to-developinterstate-compacts-for-licensure-p/

U.S. Department of Health and Human Services Press Office. (2021a, August 18). Biden-Harris administration invests over $\$ 19$ million to expand telehealth nationwide and improve health in rural, other underserved communities (Press release). https://www.hhs.gov/about/ news/2021/08/18/biden-harris-administration-invests-over-19million-expand-telehealth-nationwide-improve-health-rural.html

U.S. Department of Health and Human Services Press Office. (2021b, April 27). HHS releases new buprenorphine practice guidelines, expanding access to treatment for opioid use disorder. (Press release). https://www.hhs.gov/about/news/2021/04/27/hhs-releases-newbuprenorphine-practice-guidelines-expanding-access-to-treatmentfor-opioid-use-disorder.html

U.S. Department of Health and Human Services Office of Inspector General. (2021a). Hospitals reported that the COVID-19 pandemic has significantly strained health care delivery. Results of a National Pulse Survey, February 22-26, 2021. https://oig.hhs.gov/oei/reports/OEI-09-2100140.pdf

U.S. Department of Health and Human Services Office of Inspector General. (2021b). States reported multiple challenges with using telehealth to provide behavioral health services to Medicaid enrollees (Data brief, OEI02-19-00400). https://oig.hhs.gov/oei/reports/OEI-02-19-00400.pdf

U.S. Department of Justice Office of Public Affairs. (2021, September 17). National health care fraud enforcement action results in charges involving over $\$ 1.4$ billion in alleged losses (Press release). https://www.justice. gov/opa/pr/national-health-care-fraud-enforcement-action-resultscharges-involving-over-14-billion

U.S. Food and Drug Administration. (2021, August 23). FDA approves first COVID-19 vaccine (News release). https://www.fda.gov/newsevents/press-announcements/fda-approves-first-covid-19-vaccine

Virginia Council of Nurse Practitioners. (2021, May 26). NP Licensure Changes Beginning July 1. https://www.vcnp.net/np-licensurechanges-beginning-july-1/

Vt. S. 117. (2021). https://legislature.vermont.gov/bill/status/2022/S.117

W. Va. H.B. 2024, Reg. Sess. 2021 (2021). https://www.wvlegislature. gov/Bill_Status/bills_text.cfm?billdoc=HB2024\%20SUB $\% 20$ ENR. htm\&yr $=2021 \&$ sesstype $=$ RS\&i $=2024$

Wei, E. K., Long, T., \& Katz, M. H. (2021). Nine lessons learned from the COVID-19 pandemic for improving hospital care and health care delivery. JAMA Internal Medicine, 181(9), 1161-1163. https://doi. org/10.1001/jamainternmed.2021.4237 
Wisc. A.B. 148. Reg. Sess. 2012-2022 (2021). https://docs.legis.

wisconsin.gov/2021/proposals/reg/asm/bill/ab148

World Health Organization. (2020). State of the World's Nursing Report2020.

World Health Organization. (2021a). Global strategic directions for nursing and midwifery 2021-2025.

World Health Organization. (2021b). Ethics and governance of artificial intelligence for bealth.

Zebley, K. (2021, January 13). Support/Comment Letters: HB 1044: A bill for an act to amend and reenact section 43-12.4-01 of the North Dakota Century Code, relating to the advanced practice registered nurse license compact (Letter to Rep. Dobervich). https://www.americantelemed.org/ wp-content/uploads/2021/01/ATA-ND-HB-1044-1-15-21.pdf

Zerwic, J. J., Montgomery, L. A., Dawson, C., Dolter, K. J., \& Stineman, A. (2021). Planning and implementing a practice/academic partnership during COVID-19. Journal of Professional Nursing, 37(1), 24-28. https://doi.org/10.1016/j.profnurs.2020.11.007 


\section{APPENDIX A}

\section{Policy and Position Statements}

A review was conducted of position statements, advisory opinions, practice statements, clinical practice advisories, declaratory rulings, and interpretive guidelines developed by U.S. Nursing Regulatory Bodies (NRBs) from September 2020 through September 2021.

The purpose of these guidance documents is to provide direction to nurses practicing in the United States. They reflect the decisions made by NRBs regarding specific nursing practice concerns. NRBs can review the existing guidance documents with the intent of anticipating any emerging issues and trends that may affect their NRB in the upcoming year.

Seven states (Arizona, Kentucky, Nevada, North Dakota, South Carolina, Washington, and Wyoming) revised or adopted new statements on the role and scope of practice of advanced practice registered nurses (APRNs). These include statements and modifications on the prescriptive authority of APRNs, clarifying what APRNs can and cannot prescribe and to whom. Specifically, several statements were released that APRNs cannot prescribe medications to family or friends. Scope of practice updates include the role of the APRN in performing specific procedures such as intubation and fluoroscopy.

Four states (Arizona, Texas, Washington, and Wyoming) adopted or revised rulings related to patient death-specifically, the role of the RN, LPN/LVN, and APRN in the event of patient death and the different roles/expectations for the nurse types in the determination and pronouncement of death.

Four states (Nebraska, New York, Oregon, and Texas) adopted new or revised existing statements regarding patient abandonment, several of which were made in the wake of emergency measures that states have taken over the past year during the pandemic. These statements clarify the role and duty of nurses regarding caring for their patients.

Four states (New York, Oregon, Washington, and Wyoming) revised or adopted new practice opinions concerning telehealth and/or electronic prescribing, focusing on the scope of practice for RNs, LPNs/LVNs, and APRNs when conducting telehealth.

Additionally, four states (Florida, Kentucky, Washington, and Wyoming) revised or adopted practice opinions regarding dermatological practices. These mostly focused on the scope of practice for RNs, LPNs/LVNs, or APRNs regarding cosmetic/aesthetic dermatological procedures.

The following is a list of the position/practice statements, advisory opinions, practice statements, clinical practice advisories, declaratory rulings, and interpretive guidelines issued or revised by U.S. NRBs during September 2020 through September 2021:

\section{Alaska}

- Adopted the following advisory opinion: Low-Dose Ketamine Infusions in Non-Acute Care Settings
Arizona

- Adopted the following advisory opinion: Practice DecisionTree for the Certified Nursing Assistant and the Licensed Nursing Assistant

- Revised the following advisory opinions: Acupuncture Procedures Performed by Advanced Practice Registered Nurses, Certified Nurse Midwives Ordering Regional Analgesia in Labor Management, Determination of Death: Role of RN/LPN, External Jugular Cannulation for Peripheral IV (EJ PIV) and/or Peripherally Inserted Central Catheter (EJ PICC), Epidural Analgesia by Certified Registered Nurse Anesthetist, Laparoscopic Adjustable Gastric Band (LAGB) Fill, Intrauterine/Intracervical Insemination, Intranasal Administration of Midazolam (Versed) forTreatment of Signs and Symptoms of Acute Seizure Outside the Clinical Setting, Lumbar Puncture, Punch and Shave Biopsies Performed by Registered Nurses, Registered Nurse First Assistant - RNFA, Testing Guidelines for PreLicensure Nursing Programs in Arizona

Arkansas

- Adopted the following position statement: Role of the Licensed Nurse in the Practice of Aesthetics

Connecticut

- Adopted the following declaratory ruling: Scope of Practice for School Nurses to Adjust Insulin Doses for School Children With Parental Input

\section{Florida}

- Released the following declaratory statements: Placement of Dermal and Epidermal Stitches Following Skin Cancer Removal, Intravenous Administration of Ketamine to Patients in the PACU, Intravenous Administration of Ketamine to Patients in the ICU, Administration of Low Dose Ketamine for the Purpose of Pain Control in the Acute Care Hospital Setting, Administration of Low Dose Ketamine for the Purpose of Pain Control in the Acute Care Hospital Setting

Idaho

- Adopted the following guidance and position statements: Ethics in Nursing, Prescribing of Controlled Substances in Idaho

\section{Kentucky}

- Revised the following advisory opinions: Implementation of Patient Care Orders, Administration of "PRN" Medication and Placebos; Placement of Central and Arterial Lines and Arterial Blood Sampling by Nurses; The Role of Nurses in Procedural Sedation, Analgesia, Airway Management, and Chest Tube Removal; Role of the Advanced Practice Registered Nurse in the Prescribing of Medications to Self and/or Family; Cosmetic and Dermatological Procedures by Nurses

\section{Massachusetts}

- Released the following position statements: Massachusetts Nurses Association Position Statement on Anti-Rac- 
ism, Massachusetts Nurses Association Position Statement on Vaccine to Combat COVID-19 \& Nurses Rights to Informed Consent Voluntary Nature of Acceptance of Vaccine, Massachusetts Nurses Association Position Statement on Safe Patient Handling \& Mobility

\section{Minnesota}

- Adopted the following guidelines: NCSBN Nursing Guidelines for Medical Marijuana and Implications for Nurses Practicing in Minnesota Providing Care for Clients Using Medical Cannabis

Missouri

- Revised the following position statement: Utilization of Unlicensed Health Care Personnel

Nebraska

- Adopted the following advisory opinions: Sedation and Analgesia

- Revised or reaffirmed the following advisory opinions: Patient Abandonment, Nursing Accountability to Perform Cardiopulmonary Resuscitation, Safe Practice: Fitness to Practice, Safe Practice: Nursing Roles and Assignments, Sub-anesthetic Ketamine

Nevada

- Adopted the following practice decisions: Role of the RN and LPN with GastrostomyTubes (G-tubes), Role of the $\mathrm{RN}$ in Sexual Assault Examination, Role of the RN and LPN in ComplementaryTherapies/Modalities, APRN Scope in Intubation

- Revised the following practice decisions: Role of the RN in Intubation

New York

- Revised the following practice information: Abandonment of Patients Who Need Care, Ethical Practice, AntibodyTherapy (Intravenous or Subcutaneous Infusions) Non-Patient Specific Orders and Protocols, Advanced Home Health Aides, Prescription Privileges and Electronic Prescribing, Practice Requirements for Nurse Practitioners

\section{North Carolina}

- Revised the following joint position statement: North Carolina Board of Nursing and the North Carolina State OpioidTreatment Authority

\section{North Dakota}

- Approved the following practice guidance statement: Practice Guidance - RN and LPN Practice: Components of Nursing Comparison Chart

- Endorsed the following interpretative statement: NDBON Endorses NDMIRT Position Statement for APRN's Performing/Supervising Fluoroscopy

\section{Ohio}

- Revised the following interpretive guidelines: Guidelines for Conservative Sharp Wound Debridement

\section{Oklahoma}

- Revised the following position statements and guidelines: Exclusionary Formulary for Advanced Practice Registered Nurses with Prescriptive Authority, CRNA Inclusionary Formulary, Limited Obstetric Ultrasound and Limited Ultrasound in a Reproductive Medicine Setting Examinations Performed by Registered Nurse Guidelines

Oregon

- Approved the following interpretative statement: Use of Telehealth Technologies in the Practice of Nursing

- Amended the following interpretive statement: Patient Abandonment

Pennsylvania

- Approved the following guidelines: Guidelines for Safe Administration of Low-Dose Ketamine, Treatment of Acute and Chronic Pain in Patients With Sickle Cell Disease

South Carolina

- Approved the following position statement: Use of Expedited PartnerTherapy (EPT)

- Revised the following advisory opinions: Scope of Responsibility of the LPN in the Administration of Peripheral and Central IntravenousTherapies and Procedures, Role and Scope of Responsibilities for the RN to Administer Fentanyl Intravenously for Pain Management, The Role and Scope of Responsibility of the RN and LPN to Perform Basic (Level I), Intermediate (Level II) and Advanced (Level III) Foot and Nail Care, Scope of Practice of a Licensed APRN, RN, or LPN to Perform Micropigmentation, Also Known as Microblading, APRN with Prescriptive Authority Prescribing Medications for Members of His or Her Immediate Family

\section{South Dakota}

- Approved the following position statement: Vaccination by Student Nurses

Texas

- Revised the following position statements:The Role of the LVN in Pronouncement of Death, Board Rules Associated with Alleged Patient Abandonment, The Role of LVNs \& RNs in Management and/or Administration of Medications via Epidural or Intrathecal Catheter Routes, Role of the Nurse in Moderate Sedation, Registered Nurses in the Management of an Unwitnessed Arrest in a Resident in a Long Term Care Facility, Professional Boundaries Including Use of Social Media by Nurses

Utah

- Released the following standing order: Dispensing Naloxone for Opioid Overdose Prevention

Virginia

- Adopted the following guidance document: Practice of ConversionTherapy 
- Reaffirmed the following guidance document: Attachment of Scalp Leads for Internal Fetal Monitoring

\section{Washington}

- Adopted the following advisory opinion: Cosmetic/Aesthetic Dermatologic Procedures

- Revised the following advisory opinions: Administration of Cannabis/Marijuana Products in School Settings (K-12 Grades, Public and Private Schools); Death with Dignity (Aid-in-Dying); Infusion Therapy Management; Determining, Pronouncing and Certifying Death; Nursing Telehealth Practice: Registered Nurse, Licensed Practical Nurse, Nursing Technician, and Nursing Assistant; Perioperative Registered Nurse First Assistant (RNFA); Telehealth Advanced Practice Nursing Care Services

\section{Wyoming}

- Approved the following advisory opinions: APRN Scope of Practice Guidelines; Determination, Pronouncement, and Certification of Death; COVID-19 Vaccine Administration Temporary Permit; Verification of Active Nursing Practice; School and Alternative Setting Nursing Practice

- Revised the following advisory opinions: Placement of Central and Arterial Lines; Amniotomy; Aesthetic, Cosmetic \& Dermatologic Procedures; Practice During COVID-19 Declared State of Emergency; Emergency Direct Care Worker; Nursing and Electronic Delivery of Care 